\title{
Efectos del gasto público en riego en los hogares de la sierra del Perú*
}

\author{
Álvaro Hopkins Barriga*
}

\begin{abstract}
RESUMEN
La presente investigación evalúa el impacto del gasto público en riego en los hogares de la Sierra del Perú que practican la agricultura de manera independiente y que cuentan con tierras de cultivo. Para dicho fin, se calculó el presupuesto ejecutado en riego por el gobierno nacional, regional y local entre los años 2008 y 2010, lo cual implicó el cruce de la base de datos del Sistema Integrado de Administración Financiera(SIAF) y el Banco de Proyectos del Sistema Nacional de Inversión Pública (SNIP) para una adecuada identificación de dicho gasto. Se aplicó la metodología de Diferencias en Diferencias con control en covariables. Para esto se construyó un pool de hogares a partir de la Encuesta Nacional de Hogares (Enaho) del Instituto Nacional de Estadística (INEI) tomando como línea de base los cortes de los años 2007 y 2008 y como seguimiento los años 2012 y 2013. La muestra se segmentó en dos grupos según la incidencia de la pobreza monetaria del distrito, de acuerdo al Mapa de Pobreza del año 2007: hogares en distritos pobres y hogares en distritos no pobres. Dicha segmentación permite aislar el efecto endógeno al tratamiento de utilizar la línea de pobreza calculada para cada hogar en la Enaho. Los impactos estimados muestran un efecto positivo en los hogares no pobres evaluados, a través de un incremento del ingreso no salarial agropecuario (producción independiente) y del ingreso salarial no agropecuario (actividades dependientes no agropecuarias). En los hogares pobres el efecto en el ingreso neto principal más secundario y en el ingreso neto agropecuario es estadísticamente igual a cero.
\end{abstract}

Palabras clave: evaluación de impacto, infraestructura, riego, gasto público, Perú, desarrollo rural.

Clasificación JEL: D12, D13, H31, H41, H72, O12, O18, O54, Q12

\footnotetext{
* La presente publicación es un extracto de Hopkins, Álvaro (2016). Efectos del gasto público en riego en los hogares de la sierra del Perú (Tesis de Maestría en Economía). Pontificia Universidad Católica del Perú, LimaPerú. El autor agradece a Juan Manuel García, Manuel Glave y Viviana Cruzado por sus recomendaciones y guía para la elaboración de esta investigación. Cualquier error u omisión son responsabilidad del autor.

** Ministerio de Economía y Finanzas del Perú. alvarohopkins@gmail.com
} 


\title{
Effects of Public Spending on Irrigation on Households in the Peruvian Highlands
}

\begin{abstract}
This study assesses the impact that public spending on irrigation has on households in the Peruvian highlands that hold cultivable land and practice agriculture on an independent basis. To this end, we calculated the budget executed for irrigation by central, regional, and local government between 2008 and 2010, which entailed crosschecking the Integrated Financial Administration (System de Administración Financiera, SIAF) database and the National Public Investment Project Bank (Banco de Proyectos del Sistema Nacional de Inversión Pública, SNIP) to adequately identify this expenditure. We applied the differences-in-differences method with control covariates, for which we constructed a pool of households taken from the National Household Survey (Encuesta Nacional de Hogares, Enaho) conducted by the National Institute of Statistics (Instituto Nacional de Estadística, INEI), using the cut-off years of 2007 and 2017 as the baseline and 2012 and 2013 for follow-up. We segmented the sample into two groups based on the incidence of monetary policy by district, per the 2007 Poverty Map: households in poor districts, and households in nonpoor districts. This segmentation allowed us to isolate the endogenous effect of the treatment of using the poverty line calculated for each household in the Enaho. The impacts estimated evince a positive effect on the non-poor households assessed, in the form of an increase in agricultural nonwage income (independent production) and in non-agricultural wage income (non-agricultural dependent activities). In the poor households, the effect on primary and secondary net income and on net agricultural income is statistically equal to zero.
\end{abstract}

Keywords: Impact assessment, Infrastructure, Irrigation, Public spending, Peru, Rural development. JEL Codes: D12, D13, H31, H41, H72, O12, O18, O54, Q12

\section{INTRODUCCIÓN}

Históricamente, la inversión en infraestructura de riego ha sido la principal estrategia para incrementar la productividad agrícola y reducir la pobreza. En el discurso de 28 de julio del año 2012 el presidente Ollanta Humala declara que el gobierno concentrará esfuerzos para mejorar la productividad y competitividad del agro con una orientación hacia la inclusión, haciendo énfasis tanto en la provisión de infraestructura agraria como en la construcción de reservorios y canales de irrigación. En el discurso del año 2013 se reafirma esta postura, declarando ese año como «Año de la Inversión para el Desarrollo Rural y la Seguridad Alimentaria». En ese año resalta la creación del Fondo Mi Riego con S/.1000 millones destinados a financiar obras de riego en zonas alto andinas a más de 1500 metros sobre el nivel del mar (msnm). Para el año 2015 se destinó S/.650 millones adicionales al Fondo y se incluyó proyectos en zonas sobre los $1000 \mathrm{msnm}$.

Sin embargo, a pesar de su importancia, el gasto en infraestructura de riego no es suficiente, ya que los hogares de bajos ingresos no tienen los recursos para acceder al uso de esta infraestructura o, si encuentran los recursos para hacerlo, estos no son suficientes para costear el uso eficiente de la infraestructura, el pago de fertilizantes, semillas, 
o de medios de transporte que les permita comercializar sus productos. La ejecución de proyectos complementarios es necesaria para generar sinergias y potenciar los beneficios a la población (Escobal, 2005 y Escobal y Torero, 2000).

En tal sentido, el objetivo de esta investigación es evaluar los efectos del gasto público en riego, ejecutado por todos los niveles de gobierno entre los años 2008 y 2011, en hogares rurales de producción agrícola independiente en la sierra del Perú. Esto ofrecerá una perspectiva preliminar de lo que se puede esperar de iniciativas como la del Fondo Mi Riego y formular recomendaciones de política para incrementar el impacto positivo en la población ${ }^{1}$.

\section{OBJETIVOS Y JUSTIFICACIÓN}

Uno de los principales fines de las políticas de desarrollo es la reducción de las tasas de pobreza. En el Perú, como en muchos otros países, hay una elevada concentración de la tasa de pobreza monetaria en la zona rural del país, donde el ingreso agrícola es uno de los principales componentes del ingreso en los hogares pobres, a través de la producción en la propia parcela o por la venta de mano de obra (BID y CIES, 2011). Por este motivo, los recursos públicos y de donaciones que buscan combatir la pobreza en áreas rurales se han destinado a la inversión en infraestructura - por ejemplo: caminos, energía eléctrica, agua y saneamiento- o proyectos complementarios a la agricultura -como programas de asistencia técnica, infraestructura de riego y acceso a mercados. Esta investigación estudia el efecto en la reducción de la pobreza en hogares de producción agrícola independiente de la sierra, a través de una de las alternativas de inversión pública más utilizadas como apoyo a la agricultura²: el riego.

La inversión pública en infraestructura de riego es de tal importancia que desde 2003 existe una Política y Estrategia Nacional de Riego en el Perú. Asimismo, el Sistema Nacional de Inversión Pública (SNIP) elaboró en 2011 una guía metodológica para el diseño de estudios de perfil y pre-factibilidad de inversiones de riego menor ${ }^{3}$. Del mismo modo, el Ministerio de Agricultura y Riego (Minagri) presentó en abril de 2012 el Plan Estratégico Sectorial Multianual 2012-2016, en donde se resalta la importancia de una política de desarrollo de la infraestructura de riego a nivel nacional, desde grandes

\footnotetext{
1 Esta investigación parte de un estudio previo: Hopkins, A. y Figallo, M. (2014). La sierra tiene sed: efecto de las inversiones públicas en riego sobre los hogares de agricultura familiar de la sierra. SEPIA XV, 567-597. Este estudio frente al del 2014: (i) incluye el gasto público en riego del gobierno nacional y regional, (ii) mejora la precisión en la estrategia de identificación de los hogares de tratamiento y no tratamiento, mediante el uso complementario del Banco de Proyectos del Sistema Nacional de Inversión Pública, (iii) realiza un ejercicio de Diferencia en Diferencias (DD) con covariables pero sin emparejamiento, para una muestra tipo pool de datos 2007-2008 (Línea de Base) y 2012-2013 (Seguimiento), y la (iv) segmenta la muestra según incidencia de la pobreza del distrito en vez de la condición de la pobreza del hogar, la cual sería endógena a la intervención. 2 De acuerdo a los datos del año 2012 de la Consulta Amigable del SIAF, el Grupo funcional 0050: Infraestructura de riego representa el $45 \%$ de la Función de gasto 10. Agropecuaria.

3 Para agricultores que trabajen menos de 5 ha y que juntos sumen un máximo de 500 ha.
} 
proyectos de irrigación ejecutados por el gobierno nacional y/o regional como Olmos, Majes II y Chavimochic, hasta el apoyo a los gobiernos locales en el impulso de proyectos de construcción, mejoramiento y/o mantenimiento de la infraestructura de riego.

Recientemente, dicho planteamiento se ha concretizado destinando, para el año 2013, 40\% del presupuesto del sector — hasta un máximo de S/. 1000 millones_- para el Fondo Mi Riego (Minagri web). Este Fondo financia proyectos de riego, como la construcción de reservorios y canales de regadío en zonas alto andinas sobre los $1500 \mathrm{msnm}$, cuyos expedientes técnicos son presentados por los Gobiernos Regionales y Locales. Estos proyectos son evaluados por la Dirección General de Infraestructura Agraria y Riego del Minagri y aprobados por el Comité Técnico del Fondo, priorizando aquellos que beneficien la mayor cantidad de personas y hectáreas. Para el año 2015, se agregó S/.650 millones al Fondo y se amplió a zonas sobre los $1000 \mathrm{msnm}$.

Para comprender el contexto en el que este tipo de intervenciones son diseñadas y sus posibles efectos, se analiza las principales diferencias entre productores con riego, sea de gravedad o tecnificado, y productores de secano ${ }^{4}$.

\subsection{HECHOS ESTILIZADOS: DIFERENCIAS ENTRE PRODUCTORES CON RIEGO Y BAJO SECANO}

En esta sección se caracteriza a los productores agropecuarios independientes de la sierra rural con dotación de tierra, utilizando como fuente de información los módulos agrícolas y el módulo Sumaria de la Enaho del año 2013 realizada por el INEI. En la Tabla 1 se tabula la distribución sin ponderar de los hogares de secano y con riego según rango de dotación de tierras. En esta muestra, el 12,65\% de hogares realiza agricultura con riego, el $90 \%$ de hogares tiene una dotación de tierra menor a 5 hectáreas (en adelante ha) y la mayor concentración de hogares está en el rango de menos de 1 ha (50\%), seguido del rango entre 1 y 3 ha $(31,8 \%)$. Esta concentración debe ser considerada en el análisis econométrico debido a que podría sesgar los resultados por presencia de posibles outliers que sesgarían los coeficientes estimados, su varianza y, por ende, su nivel de significancia.

Asimismo, es necesario conocer cuánto riego utilizan los productores con acceso a este. Con los datos de la Enaho se puede construir el porcentaje de tierras bajo riego e incluso distinguirlo según el tipo de riego. No obstante, la pregunta de la Enaho sobre tipo de riego confunde la tecnología utilizada para irrigar (gravedad o tecnificado) y la fuente del agua para riego (pozo). Por este motivo, en la categoría «riego de pozo» podría agruparse productores que extraen agua de pozo y que utilizan riego tecnificado o riego por gravedad. En el Gráfico 1 se presenta la distribución del porcentaje de ha bajo riego de la muestra de hogares con riego analizada. Claramente, hay un sesgo hacia valores cercanos a 100\% de superficie bajo riego. No obstante, 14,4\% de los hogares con

\footnotetext{
4 Se recomienda al lector revisar Hopkins (2016) para un análisis sobre la tendencia macroeconómica de mediano plazo de la agricultura en el Perú y sobre la superficie potencial a ser irrigada utilizando datos de la Oficina Nacional de Evaluación de Recursos Naturales (Onern).
} 
acceso a riego tienen menos del $20 \%$ de sus tierras irrigadas. En la Tabla 2 se muestra que, en promedio, los productores irrigan más del $60 \%$ de sus tierras, principalmente mediante riego por gravedad $(51,5 \%)$ y en menor proporción por riego tecnificado $(5,9 \%)$. Al analizar según rango de dotación de tierras se encuentra que los hogares con menos de 10 ha irrigan cerca del $70 \%$ de sus tierras. Para aquellos con más de 10 ha el rango es fluctuante: $60,9 \%$ para el rango de 10 a 20 ha, $47 \%$ para los que tienen de 20 a 50 ha; $100 \%$ para el rango de 50 a 100 ha y 79,6\% para los que cuentan con más de $100 \mathrm{ha}$. El riego por pozo tiene una mayor presencia en los productores con más de 5 ha.

Tabla 1. Distribución de productores agropecuarios según rango de dotación de tierra y agricultura de riego o secano, 2013

\begin{tabular}{lcccccc}
\hline \multirow{2}{*}{$\begin{array}{c}\text { Rango } \\
\text { de tierras }\end{array}$} & \multicolumn{3}{c}{ Número de hogares } & \multicolumn{4}{c}{ Porcentaje de hogares según rango de tierras } \\
\cline { 2 - 7 } & Secano & Riego & Total & Secano & Riego & Total \\
\hline$<1$ ha & 2985 & 470 & 3455 & 50,3 & 47,5 & 49,9 \\
$1-<3$ ha & 1870 & 331 & 2201 & 31,5 & 33,4 & 31,8 \\
$3-<5$ ha & 495 & 95 & 590 & 8,3 & 9,6 & 8,5 \\
$5-<10$ ha & 320 & 54 & 374 & 5,4 & 5,5 & 5,4 \\
$10-<20$ & 145 & 26 & 171 & 2,4 & 2,6 & 2,5 \\
$20-<50$ & 78 & 7 & 85 & 1,3 & 0,7 & 1,2 \\
$50-<100$ & 25 & 3 & 28 & 0,4 & 0,3 & 0,4 \\
$100-$ más & 22 & 4 & 26 & 0,4 & 0,4 & 0,4 \\
\hline Total & 5940 & 990 & 6930 & 100,0 & 100,0 & 100,0 \\
\hline
\end{tabular}

Fuente: Enaho 2013.

Gráfico 1. Distribución del porcentaje de ha bajo riego, 2013

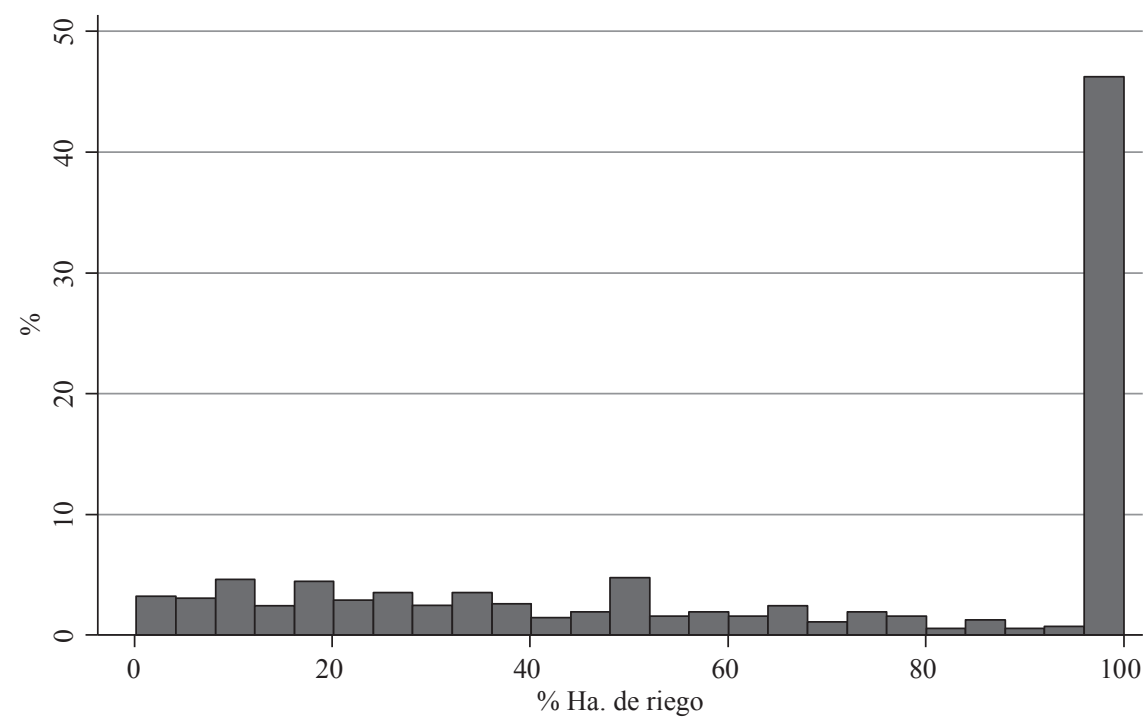

Fuente: Enaho 2013. 
Tabla 2. Porcentaje de ha con riego según tipo de riego, 2013

\begin{tabular}{lccccc}
\hline \multicolumn{1}{c}{ Tipo de riego } & Media & Mediana & Desviación estándar & Mínimo & Máximo \\
\hline Total & 65,7 & 76,5 & 36,5 & 0,2 & 100,0 \\
Riego por gravedad & 51,5 & 50,0 & 43,7 & 0,0 & 100,0 \\
Riego tecnificado & 5,9 & 0,0 & 20,3 & 0,0 & 100,0 \\
Riego por pozo & 8,3 & 0,0 & 22,5 & 0,0 & 100,0 \\
\hline
\end{tabular}

Fuente: Enaho 2013.

Tabla 3. Promedio del porcentaje de tierras con riego según tipo de riego y rango de dotación de tierras, 2013

\begin{tabular}{lccccc}
\hline Rango de tierras & Riego & $\begin{array}{c}\text { Riego } \\
\text { por gravedad }\end{array}$ & $\begin{array}{c}\text { Riego } \\
\text { tecnificado }\end{array}$ & $\begin{array}{c}\text { Riego } \\
\text { por pozo }\end{array}$ & $\begin{array}{c}\text { Número } \\
\text { de hogares }\end{array}$ \\
\hline$<1$ ha & 63,3 & 50,8 & 7,5 & 5,0 & 271 \\
$1-<3$ ha & 69,1 & 58,5 & 4,2 & 6,4 & 238 \\
$3-<5$ ha & 63,8 & 49,8 & 4,9 & 9,1 & 73 \\
$5-<10$ ha & 69,6 & 44,4 & 5,2 & 20,0 & 41 \\
$10-<20$ & 57,6 & 16,5 & 9,4 & 31,7 & 16 \\
$20-<50$ & 41,0 & 7,5 & 0,0 & 33,6 & 6 \\
$50-<100$ & 100,0 & 0,0 & 50,0 & 50,0 & 2 \\
$100-m a ́ s$ & 79,6 & 24,9 & 0,0 & 54,7 & 4 \\
\hline
\end{tabular}

Fuente: Enaho 2013.

En la Tabla 4 se presenta la diferencia en medias de la población según cuatro grupos de variables: pobreza monetaria, características del hogar, ingresos y actividad agrícola. Los hogares con riego son menos pobres extremos al 99\% de confianza y, al 95\% de confianza, menos pobres no extremos. Sobre las características del hogar, se observa que el jefe de hogar tiene en promedio un año más de educación, lo cual se ve reflejado en el mayor ratio de jefes de hogar con secundaria completa o más niveles de educación. Se encuentra que los hogares con secano tienen un mayor número de miembros del hogar.

Los hogares con riego tienen, en general, un menor acceso a servicios públicos como agua y servicios higiénicos de red pública dentro de la vivienda, así como alumbrado eléctrico. No obstante, el nivel de ingreso neto principal y secundario es significativamente mayor en los hogares con riego que con secano. Esto se debe a que los hogares con riego tienen un mayor ingreso neto no salarial agropecuario (producción independiente) y salarial no agropecuario.

Con respecto a la actividad agrícola, no hay diferencias en la dotación de tierras. Sin embargo, se encuentra diferencias en medias estadísticamente significativas al 99\% en el valor bruto de producción (VBP) agrícola, en el VBP cuyo principal destino es la venta y en el porcentaje vendido, así como en el gasto agrícola total y en cada uno de sus componentes. 
Tabla 4. Diferencia entre hogares de la sierra con producción agrícola independiente con más de $0 \%$ de ha de riego $v s$. hogares con $100 \%$ de ha de secano, 2013

\begin{tabular}{|c|c|c|c|c|c|c|}
\hline \multirow{2}{*}{$\begin{array}{l}\text { Grupo de } \\
\text { variables }\end{array}$} & \multirow{2}{*}{ Variables } & \multicolumn{2}{|c|}{ Riego } & \multicolumn{2}{|c|}{ Secano } & \multirow{2}{*}{$\begin{array}{c}\text { Diferencia en me dias } \\
\text { Riego-Secano }\end{array}$} \\
\hline & & $\mathbf{N}$ & Media & $\mathbf{N}$ & Media & \\
\hline \multirow{3}{*}{ Pobreza } & $\begin{array}{l}\text { Ratio de hogares pobres } \\
\text { extremos }\end{array}$ & 651 & 0.126 & 4,495 & 0.174 & $-0.048 * * *$ \\
\hline & \begin{tabular}{|l|} 
Ratio de hogares pobres no \\
extremos
\end{tabular} & 651 & 0.293 & 4,495 & 0.341 & $-0.048 * *$ \\
\hline & Ratio de hogares no pobres & 651 & 0.581 & 4,495 & 0.485 & $0.095^{* * *}$ \\
\hline \multirow{6}{*}{$\begin{array}{l}\text { Caracte rís ticas } \\
\text { del hogar }\end{array}$} & Años de educación del JH & 651 & 5.447 & 4,495 & 4.65 & $0.797 * * *$ \\
\hline & $\begin{array}{l}\text { Ratio de JH con } \\
\text { secundaria completa o más }\end{array}$ & 651 & 0.147 & 4,495 & 0.108 & $0.040 * * *$ \\
\hline & $\begin{array}{l}\text { Número de miembros del } \\
\text { hogar }\end{array}$ & 651 & 2.625 & 4,495 & 2.712 & -0.0870 \\
\hline & \begin{tabular}{|l} 
Ratio de hogares con \\
acceso a agua de red \\
pública dentro de la \\
vivienda \\
\end{tabular} & 651 & 0.449 & 4,495 & 0.588 & $-0.140 * * *$ \\
\hline & $\begin{array}{l}\text { Ratio de hogares con } \\
\text { acceso a SSHH de red } \\
\text { pública dentro de la } \\
\text { vivienda }\end{array}$ & 651 & 0.0510 & 4,495 & 0.08 & $-0.029 * * *$ \\
\hline & $\begin{array}{l}\text { Ratio de hogares con } \\
\text { alumbrado por electricidad }\end{array}$ & 651 & 0.740 & 4,495 & 0.711 & 0.0290 \\
\hline \multirow{5}{*}{ Ingresos } & \begin{tabular}{|l|} 
Ingreso neto \\
principal+secundario
\end{tabular} & 651 & 8,175 & 4,495 & 6,222 & $1,953.207 * * *$ \\
\hline & \begin{tabular}{|l|} 
Ingreso Neto No Salarial \\
Agropecuario (S/.) \\
\end{tabular} & 651 & 5,364 & 4,495 & 3,861 & $1,503.655^{* * *}$ \\
\hline & \begin{tabular}{|l|} 
Ingreso Neto No Salarial \\
No Agropecuario (S/) \\
\end{tabular} & 651 & 536.0 & 4,495 & 493.3 & 42.71 \\
\hline & \begin{tabular}{|l} 
Ingreso Neto Salarial \\
Agropecuario (S/.) \\
\end{tabular} & 651 & 483.2 & 4,495 & 566.8 & -83.57 \\
\hline & \begin{tabular}{|l} 
Ingreso Neto Salarial No \\
Agropecuario (S/.)
\end{tabular} & 651 & 1,669 & 4,495 & 1,154 & $514.877^{* * *}$ \\
\hline \multirow{10}{*}{ Actividad agrícola } & Tierra (На.) & 651 & 3.458 & 4,495 & 3.337 & 0.121 \\
\hline & \begin{tabular}{|l|} 
VBP Agrícola (S/.) \\
\end{tabular} & 651 & 5,392 & 4,495 & 2,698 & $2,694.390 * * *$ \\
\hline & $\begin{array}{l}\text { VBP Agrícola- } \\
\text { Autoconsumo (S/.) }\end{array}$ & 651 & 732.6 & 4,495 & 679.4 & $53.212 *$ \\
\hline & \begin{tabular}{|l} 
VBP Agrícola-Venta (S/.) \\
\end{tabular} & 651 & 2143 & 4,495 & 1023 & $1,119.788 * * *$ \\
\hline & $\%$ VBP Ventas & $\underline{648}$ & 25.32 & $\underline{4,490}$ & 20.25 & $5.069^{* * *}$ \\
\hline & \begin{tabular}{|l|l} 
Gasto agrícola total (S/.) \\
\end{tabular} & 651 & 1,713 & 4,495 & 998.1 & $714.483^{* * *}$ \\
\hline & $\begin{array}{l}\text { Gasto agrícola en agua de } \\
\text { riego }(\mathrm{S} / \mathrm{)})\end{array}$ & 651 & 31.11 & 4,495 & 3.612 & $27.501 * * *$ \\
\hline & $\begin{array}{l}\text { Gasto agrícola en semillas } \\
\text { (S/.) }\end{array}$ & 651 & 362.0 & 4,495 & 257.1 & $104.871 * * *$ \\
\hline & \begin{tabular}{|l} 
Gasto agrícola en jornales \\
$(\mathrm{S} / \mathrm{)})$
\end{tabular} & 651 & 309.2 & 4,495 & 132.7 & $176.494 * * *$ \\
\hline & $\begin{array}{l}\text { Gasto en abono y pesticidas } \\
\text { (S/.) }\end{array}$ & 651 & 467.8 & 4,495 & 241.4 & $226.415^{* * *}$ \\
\hline
\end{tabular}

Nivel de significancia estadística ${ }^{* * *} \mathrm{p}<0.01,{ }^{* *} \mathrm{p}<0.05,{ }^{*} \mathrm{p}<0.1$.

Nota: Se encontró tres hogares con riego y cinco de secano con VBP igual a cero.

Fuente: Enaho 2013. 


\subsection{OBJETIVOS Y PREGUNTAS DE INVESTIGACIÓN}

Con el objetivo de profundizar en los factores que pueden estar afectando esta dinámica de crecimiento y salida de la pobreza, se analiza el impacto del gasto público en riego ejecutado por todos los niveles de gobierno en la sierra del Perú. La literatura revisada muestra una relación positiva en el Perú entre acceso a riego y variables como el ingreso de hogar. Sin embargo, estudios recientes han encontrado un efecto diferenciado entre hogares pobres y no pobres según la definición de pobreza monetaria del INEI, lo cual motiva a segmentar el grupo de estudio. Se debe tener en consideración que usar la línea de pobreza del hogar implica un posible problema de endogeneidad al depender esta de los ingresos, la cual es una variable de resultado con una relación directa con el gasto en riego. En este sentido, se presenta una alternativa metodológica que está exenta de este problema.

Esta investigación presenta un reto debido a que la información del Sistema Integrado de Administración Financiera (SIAF) del Ministerio de Economía y Finanzas requiere de una revisión minuciosa para identificar el gasto público en riego. Se encontró errores de registro por parte de los operadores y por falencias en el SIAF, al no tener filtros para este registro. Se ha encontrado gasto en riego registrado fuera de la Función de gasto Agricultura, así como proyectos de otros sectores en esta Función de gasto.

De manera concreta, las principales preguntas que esta investigación busca responder son:

a) ¿Cuál es el impacto del gasto en riego en los ingresos y en la composición de los mismos en hogares de producción agrícola independiente de la sierra rural del Perú?

b) ¿Qué diferencia se encuentra entre hogares de producción agrícola independiente pobres y no pobres?

\section{INVERSIÓN EN INFRAESTRUCTURA DE RIEGO Y DESARROLLO RURAL}

Con el fin de definir el estado de la cuestión entre el gasto en riego y su efecto en los hogares, se hace una revisión de estudios que evalúan la importancia de la infraestructura pública para el desarrollo rural. Luego, se analiza el canal de impacto de la infraestructura en la agricultura para, finalmente, concentrarnos en los efectos de la inversión en infraestructura de riego en los hogares de producción agropecuaria.

\subsection{El Rol DE LA INFraestruCtura}

La inversión en infraestructura pública y su rol clave en el desarrollo económico ha sido ampliamente discutida en la literatura económica. Hay un consenso sobre el rol potenciador de la infraestructura pública como instrumento de desarrollo y de reducción de la pobreza. La idea central es que la infraestructura pública genera un shock en la población 
que accede y se beneficia directamente de ella, y en algunos casos puede existir población beneficiada indirectamente. Este shock puede trasladar a la población de un equilibrio bajo, pero estable, a uno de mayor bienestar. Para comprender este rol potenciador de la infraestructura pública se parte por definirla y plantear las principales teorías del desarrollo económico.

Un aspecto clave que sostiene Rosenstein-Rodan (1957) es que existe un mínimo de recursos necesarios, más no suficientes, para que un programa de desarrollo de un país tenga éxito y que la inversión conjunta de múltiples inversiones pequeñas será mayor que la inversión individual y aislada de cada una. Es decir, una gran inversión en infraestructura generaría un big push en una gama de actividades económicas, para lo que es necesario una adecuada planificación y conocimiento de las potencialidades del país, región o ciudad.

En la literatura local, diversos autores han analizado las particularidades de la economía peruana, en especial del ámbito rural. Con el objetivo de evaluar la viabilidad de la pequeña agricultura en el Perú, Figueroa (1997) analiza tres mercados, el de crédito, asistencia técnica y el laboral. El autor encuentra que en el mercado de crédito y asistencia técnica, el escaso desarrollo de los mercados está causado por una baja demanda y oferta, mientras que en el mercado laboral depende de una baja demanda. Esto genera un equilibrio estable y bajo que redunda en un círculo vicioso de «no hay mercados porque hay pobreza rural y hay pobreza rural porque no hay mercados» (p. 95). Para salir de este punto de equilibrio vinculado a una trampa de pobreza se requiere de variables exógenas, tales como la tecnología, las instituciones y los bienes públicos en el campo, las cuales tendrían un efecto en los «costos de transacción y de adopción de innovaciones tecnológicas» (p. 95).

Estos bienes públicos cumplen el rol de un piso que permite que la población pueda maximizar sus estrategias de vida con el objetivo de incrementar su bienestar. El trabajo de Escobal (2008) encuentra que la diversificación de actividades, entre agropecuarias y no agropecuarias, es una estrategia de los hogares para mejorar sus ingresos. No obstante, pareciera que existe una relación de $\mathrm{U}$ entre la diversificación de fuentes de generación de ingresos y el nivel de total de ingresos del hogar. Esto implica que hay un punto de inflexión a partir del cual la diversificación produce una mejora de los ingresos. Antes de este punto, la diversificación crea barreras para el incremento de la productividad por especialización y, por ende, menor generación de ingresos. El autor recomienda «ampliar las oportunidades en el área rural mediante programas públicos de provisión de infraestructura y que generen una plataforma de servicios que rentabiliza los activos que están en poder de los pobres» (Escobal, 2008, p. 108).

Esta recomendación también se sustenta en los resultados de Escobal, Saavedra y Torero (1998) donde se encuentra que los activos públicos potencian la rentabilidad de los activos privados, lo cual facilita la reducción de la pobreza. Una serie de variables que está fuertemente vinculada con que un hogar sea pobre o no, incluye: capital humano 
(tamaño de la familia, nivel educativo, experiencia); capital físico (stock de tierra, ganado y equipo); capital financiero (acceso a créditos y valor de bienes durables) y capital público (acceso a servicios públicos como agua, desagüe y electricidad, distancia al centro de salud o escuela, importancia del trueque). El acceso a bienes públicos reduce la probabilidad de ser pobre, debido a que estos bienes permiten que el hogar genere un flujo de ingresos suficiente. Además, el estudio encuentra complementariedades entre activos públicos y la rentabilidad de activos privados, facilitando la reducción de la pobreza.

Del mismo modo, Escobal y Torero (2000) estudian cómo las externalidades negativas de la geografía peruana pueden generar trampas de pobreza a hogares con escasos activos privados que carecen de acceso a infraestructura pública. Lo que se encuentra es que, controlando solo por variables geográficas, hay diferencias provinciales en el gasto de los hogares. Al incluir variables de infraestructura (como el número de necesidades básicas insatisfechas, centros médicos y escuelas por habitante), el efecto de la geografía no es estadísticamente significativo. Se concluye que «una adecuada dotación de activos públicos y privados permite superar los efectos potencialmente negativos de una geografía adversa» (Escobal y Torero, 2000, p. 37). Sin embargo, la geografía sí influye negativamente en el nivel de dotación de infraestructura pública, lo cual tiene un efecto negativo en el nivel de gasto de los hogares.

El trabajo de Zegarra y Minaya (2007) realiza un análisis temporal de las series de gasto público rural en Perú y varios países de América Latina, utilizando una base de datos elaborada por la FAO para el periodo 1985-2001, con el objetivo de identificar la contribución del gasto público al crecimiento productivo agrícola y a la reducción de la pobreza. Se encuentra que el gasto total rural tiene efecto positivo en la producción agrícola por poblador rural.

Finalmente, Escobal y Ponce (2002), realizan una evaluación cuasi-experimental del Programa de Caminos Rurales, utilizando una base de datos medida después de la intervención, es decir, un análisis sin línea de base de corte transversal, y como método de análisis el emparejamiento por medio del Propensity Score Matching (PSM). El estudio encuentra un incremento del ingreso per cápita del hogar, en especial del ingreso salarial no agropecuario, aunque sin cambios significativos en el gasto per cápita del hogar, lo cual se debe al aumento en el ahorro a través de la compra de stock de ganado.

De acuerdo a la evidencia presentada, hay impactos positivos en los hogares por la inversión en infraestructura pública. Sin embargo, la inversión pública en riego tiene la particularidad de afectar la productividad de factores específicos de la actividad agrícola, desde los fundamentales, como la tierra, hasta encontrar altos niveles de complementariedad con determinadas variedades de cultivo y tipo de fertilizantes. Este tipo de inversión debe ser adoptado por los usuarios sujetos a su contexto local. Los niveles más avanzados de innovación no son asequibles inmediatamente, por lo que requieren de un proceso de asimilación de la nueva técnica mediante prueba y error hasta que es adoptada en el proceso productivo (Hayami y Ruttan, 1971, p. 175). 


\subsection{El CAMbio TÉCNiCO EN LA AGRICULTURA}

Las innovaciones o mejoras en el acceso al agua tienden a tener un efecto que potencia la productividad marginal de otros factores (Zegarra, 2002). Entonces, este acceso al agua actúa como una mejora en el factor tecnológico $A$ de una función de producción tradicional Cobb-Douglas:

$$
Y=F(A, L, K)
$$

Donde un aumento de $A$ permitiría producir lo mismo que antes, pero ahorrando el uso de los factores de producción. Partiendo de Solow (1957), un cambio técnico es cualquier modificación en la función de producción. De acuerdo a lo planteado por Gonzales de Olarte y Kervyn (1987) el cambio técnico es «un cambio en una de las características de una técnica, es decir un elemento de un vector técnico o de una matriz tecnológica» diferente al progreso técnico, definido como alcanzar «un nivel de producción más alto utilizando cantidades no mayores de todos los insumos» (p. 81). Entonces, podemos entender como cambio técnico cualquier modificación en la variable $A$ de la función de producción planteada anteriormente.

Sin embargo, ¿cómo afecta al cambio técnico el hecho de que las economías campesinas en la sierra del Perú no necesariamente sean maximizadoras de ganancias? (Figueroa, 1997 y Gonzales de Olarte y Kervyn, 1987). Gonzales de Olarte y Kervyn (1987) plantean que la elección de las técnicas dependerá del objetivo de la producción. Una misma técnica no necesariamente permitirá mejorar «la ganancia monetaria, el ingreso por hectárea o la seguridad alimentaria (p. 88). En una economía de mercado, el agricultor comerciante está incentivado/obligado a adoptar rápidamente la mayor escala técnica, minimizar el costo medio unitario y así evitar ser sacado del mercado. Sin embargo, cuando un alto componente de la producción agropecuaria es destinado al autoconsumo, este sirve como «un colchón protector contra las fuerzas del mercado» (p. 87).

De acuerdo con Figueroa (1997) se puede establecer que estas ineficiencias se generan por ineficacia en las instituciones, que conlleva al poco desarrollo de los intercambios de mercado, lo cual incrementa los costos de transacción entendidos como costos de información, búsqueda, negociación, selección, monitoreo, coordinación y cumplimiento de los contratos, excluyendo los costos de transporte. Debido a que los agricultores no pueden cambiar estas ineficiencias, cumplen el rol de restricciones de contexto. Entonces, uno puede plantear que los agricultores son «eficientes» debido a que maximizan sus beneficios sujetos a restricciones del hogar, como la dotación de activos (tiempo, tierra, entre otros), así como restricciones institucionales o de costos de transacción. Esto genera un equilibrio estable y bajo, que requiere del impacto de variables exógenas para llegar a una situación de mayor bienestar.

¿Cómo lograr este cambio mediante variables exógenas? De acuerdo al modelo de innovación inducida, desarrollado por Hayami y Ruttan (1971), los niveles de productividad 
de los agricultores en los países más avanzados, que pueden considerarse en la frontera de productividad, no son inmediatamente asequibles por los países con productividad baja. Se requiere de inversión en investigación agraria para adaptar dichos cambios al contexto local, y desarrollar tecnologías apropiadas a los entornos naturales e institucionales de cada país, así como destinar recursos para generar la infraestructura física, como el riego, e institucional necesarias a fin de alcanzar un nivel adecuado de producción potencial que permita el progreso tecnológico. Los esfuerzos destinados a la innovación buscan sustituir/ahorrar los factores con mayor precio relativo (más caros). Por ejemplo, con el objetivo de suplir la tierra (bien escaso) se utiliza fertilizantes que incrementan el rendimiento por hectárea, lo cual implica la adopción de cultivos sensibles a los fertilizantes (Hayami y Ruttan, 1970). Asimismo, se requiere de la complementariedad de un mejor control del agua, que se logra mediante sistemas de riego y drenaje.

De esta forma, la inversión en infraestructura de riego sería una condición necesaria, más no suficiente, para el cambio técnico y el incremento de la productividad de la agricultura. La adopción de nueva tecnología, como semillas mejoradas y fertilizantes, requiere la complementariedad de dicha infraestructura para su éxito.

\subsection{LiteratURA TEÓRICA SOBRE EL EFECTO DEL RIEGO}

La inversión en riego es un instrumento orientado a reducir la pobreza de los hogares que tienen un elevado componente agrícola en su estructura de ingresos. Sin embargo, como sostienen Lipton, Litchfield y Faurès (2003), su impacto será diferenciado por la gran heterogeneidad que existe dentro de la pobreza. Asimismo, tal como señalan Schoengold y Zilberman (2007), puede implicar costos como los ambientales debido a la destrucción de hábitats y bloqueo de corredores migratorios de especies, salinidad de fuentes de agua dulce, anegamiento y salinidad de la tierra, reducción de sedimento y nutrientes en el agua y su contaminación.

La literatura establece dos tipos de canales de transmisión (Hussain y Hanjra, 2004 y Lipton et al., 2003): directos e indirectos. Además, el nivel del impacto puede categorizarse como micro, meso y macro. Esquemáticamente, se da la siguiente estructura de impactos:

Tabla 5. Canales de transmisión de la infraestructura en riego

\begin{tabular}{lll}
\hline Nivel/Canal & \multicolumn{1}{c}{ Directo } & \multicolumn{1}{c}{ Indirecto } \\
\hline Micro & $\begin{array}{l}\text { Rendimiento y retornos, cambios en la estructura de } \\
\text { cultivos, demanda de mano de obra y en el precio de } \\
\text { los cultivos. }\end{array}$ & $\begin{array}{l}\text { Adopción de otras tecnologías: } \\
\text { fertilizantes, pesticidas, etc. }\end{array}$ \\
\hline Meso & $\begin{array}{l}\text { Migración incentivada por más oportunidades laborales, cambios en la gestión del recurso } \\
\text { hídrico y usos no agrícolas del agua. }\end{array}$ \\
\hline Macro & Mejora en la tasa de crecimiento nacional del PBI agrícola y no agrícola. \\
\hline
\end{tabular}

Fuente: Hussain y Hanjra (2004) y Lipton et al. (2003). 
Esta investigación se concentra en los impactos directos e indirectos a nivel micro en los hogares de producción agrícola. Según Lipton et al. (2003), el efecto directo del riego en el ingreso agrícola se transmite por tres canales:

1) Reduce la probabilidad de pérdida de cultivos por una oferta de agua errática, insuficiente y/o poco confiable.

2) La certidumbre de acceso al agua ayuda a aumentar la variedad de tipos de cultivos que pueden ser producidos en la parcela.

3) Una mayor dotación de agua aumenta el área de producción agrícola.

Para Schoengold y Zilberman (2007), una oferta de agua más estable y segura permite reducir el grado de incertidumbre para la elección del tipo de cultivo y riego. Cultivos de alto rendimiento tienen un alto costo y requieren de una cantidad de agua fija. Tal es el caso de los frutales o vińedos.

Una menor pérdida de la producción puede generar efectos en el precio de los insumos y en los productos finales. Si no hay efectos precio entonces los impactos estarán concentrados en aquellos agricultores con parcelas propias. En cambio, si el aumento del ingreso agrícola incentiva una mayor demanda de mano de obra, presionaría el aumento en el jornal, con lo cual la inversión en riego tendría un efecto positivo en los ingresos de aquellos hogares que manejan parcelas de otras personas. Este mayor incremento de la demanda de mano de obra puede deberse a una mayor necesidad de trabajadores para la siembra y cosecha de nueva tierra para la agricultura, terrenos con más de 1 campaña, o para la industria que se vincula a la producción agrícola. Así hay un incremento en los ingresos de actividades agrícolas como no agrícolas (Schoengold y Zilberman, 2007).

Además, si se produce un impacto negativo en el precio de los productos agrícolas por una mayor oferta, el efecto neto dependerá de si son cultivos de alto rendimiento o no. Si son cultivos de alto rendimiento, la inversión en riego tendrá un mayor efecto rendimiento que compensará la caída en el precio por una mayor oferta. En cambio, si son cultivos de bajo rendimiento, la caída en el precio probablemente anule la mejora en los rendimientos.

Es decir:

$$
\text { Cultivos de alto rendimiento }(C A R) \rightarrow|\nabla P|<\left|\Delta \frac{Y}{H a}\right|
$$

Si los cultivos no son de alto rendimiento, el factor de la derecha será menor o igual que el factor de la izquierda, provocando un efecto negativo o nulo de la inversión en riego en los ingresos agrícolas.

Otros efectos de corto-mediano plazo serían aquellos mencionados por Ray, Rao y Subbarao (1988), Ruttan y Hayami (1989) y Schoengold y Zilberman (2007). La inversión en riego favorece la adopción de nueva tecnología agrícola, como el uso de fertilizantes, pesticidas y semillas mejoradas, es decir el esquema de la Revolución Verde. 


\subsection{EVIDENCIA DEL EFECTO EN RIEGO EN LA AGRICULTURA}

Hussain y Hanjra (2004) presentan una revisión de la literatura sobre riego y su impacto en la agricultura para varios países, mayoritariamente países asiáticos. Se encuentra que el acceso a riego (por gravedad o tecnificado) permite aumentar hasta una campaña más al año obteniendo un uso más intensivo de la tierra. Del mismo modo, aumenta el rendimiento por hectárea de cultivos como el arroz y el maíz. Con respecto a la absorción de empleo, las zonas con riego demandan más mano de obra, con mayores salarios, que las áreas sin acceso a riego. A partir de esta revisión de literatura, los autores hallan una presencia mayoritaria de menores tasas de pobreza en zonas con acceso a riego.

Duflo y Pande (2007) desarrollan una evaluación del impacto de grandes proyectos de irrigación mediante represas en India. El estudio encuentra que las represas benefician a la población downstream debido a una mayor cantidad de hectáreas irrigadas y de energía eléctrica. Sin embargo, la población upstream solo se beneficia de la construcción de la obra y/o del desarrollo de actividades económicas que se producen en torno al reservorio.

Gebregziabher y Namara (2008) evalúan el impacto de la inversión en riego en pequeños proyectos como instrumentos para reducir la pobreza en un área crítica como Tigray, en Etiopía. Se encuentra que la inversión en proyectos de riego, de forma estadísticamente significativa, provoca un mayor gasto en mano de obra agrícola y un mayor ingreso en el hogar. Asimismo, estos proyectos tienen un impacto superior en aquellos hogares con riego que en los que carecen de él, y el ingreso no agrícola se correlaciona negativamente con la presencia de riego.

El trabajo de Hopkins y Barrantes (1987) estudia la diversidad de la economía campesina en la sierra del Perú para identificar las principales variables que permitan construir una tipología de la agricultura. Comprende solo la sierra, para minimizar la potencial heterogeneidad que implicaría incluir la costa y la selva en el análisis. Específicamente, el estudio abarca los departamentos de Apurímac, Arequipa y Cusco. Los autores encuentran que el riego tiene un impacto en la estructura de cultivo, en el tipo de arado utilizado y en la fragmentación de la unidad agropecuaria. El riego permite la producción de una mayor variedad de cultivos, llevándolo a la parcelación de los predios y aumentando el número de unidades agropecuarias. Asimismo, el mayor acceso a riego está vinculado a un menor uso del arado de energía humana. El estudio concluye que programas de riego o de asistencia técnica podrían ser más eficientes en la incidencia de la estructura de cultivos que los mecanismos de articulación al mercado.

Baca (1998) desarrolla una investigación sobre los efectos del Plan MERISS Inka ejecutado en la sierra del Perú. Este proyecto fue iniciado en 1975 con el apoyo de la cooperación de la República Federal de Alemania. El estudio analiza el efecto de tres proyectos ejecutados entre 1980 y 1994 en el valle Vilcanota. Se encuentra que se generó un mayor volumen de agua y frecuencia, vinculado a una mejor regulación del servicio. 
Así, hay más agricultores que tienen la cantidad de agua necesaria que les permite garantizar sus cosechas. Se tiene agua suficiente en los meses de mayor demanda del recurso hídrico, lo cual les ha permitido adelantar el uso de riego e incluso lograr segundas cosechas. Esto se asocia a un aumento de la diversidad de cultivos, como hortalizas, forrajes, habas, alverja verde y zapallo. Se encuentra que los cambios en la cartera productiva están relacionados a la demanda del mercado donde comercializan sus productos. Es así como la oferta agrícola se adapta a la demanda del mercado. Aquellos hogares con acceso a riego aumentaron el uso de semillas mejoradas y de tecnología complementaria.

Finalmente, un estudio más reciente es el de Del Carpio, Loayza y Datar (2011) sobre los impactos del Programa Subsectorial de Irrigación (PSI) ejecutado en la costa del Perú entre los años 2000 y 2005. Los autores utilizan como metodología econométrica las Diferencias en Diferencias. La identificación del impacto y del contrafactual se da a partir de una discontinuidad espacial alrededor de los proyectos ejecutados, que permite seleccionar los hogares en centros poblados que tenían una mayor probabilidad de acceso al servicio según su cercanía. La base de datos que utilizan es la Encuesta Nacional de Hogares (Enaho) de los años 1998-2007. El modelo teórico que plantean identifica dos efectos diferenciados: 1) aumento en la productividad de los agricultores pobres y 2) incremento en la productividad de las grandes chacras de productores no pobres. Para diferenciar a hogares pobres de no pobres aplican la condición de pobreza del módulo Sumaria de la Enaho. Encuentran que la producción agrícola decae en los hogares pobres, pero aumenta sus ingresos. Mientras que en los hogares no pobres, la producción agrícola aumenta al igual que el ingreso del hogar. Esto se explica a partir de los cambios en la composición del ingreso. El porcentaje del ingreso independiente de los hogares pobres cae (vinculado al ingreso agropecuario en su propia parcela) mientras que el peso relativo del ingreso dependiente aumenta (vinculado también a actividades no agropecuarias). En el caso de los hogares no pobres, el porcentaje del ingreso por activos (rentas) es el componente del ingreso que más aumenta.

\section{MODELO E HIPÓTESIS DEL ESTUDIO}

\subsection{OPTIMIZACIÓN DE INGRESOS EN HOGARES DE PRODUCCIÓN AGROPECUARIA}

Los hogares rurales tienden a diversificar sus ingresos no solo a través del cultivo de varios productos, sino buscando diferentes fuentes de ingreso (Figueroa, 1989; Gonzales de Olarte y Kervyn, 1987 y Hopkins y Barrantes, 1987). Escobal (2008) define cuatro estrategias de ingresos:

- No salarial agropecuario

- No salarial no agropecuario

- Salarial agropecuario

- Salarial no agropecuario 
Esta misma lógica de diversificación de ingresos es aplicada por los hogares inscritos en la definición de hogares de producción agropecuaria, nuestra unidad de análisis. Simplificando, podemos decir que existen dos componentes que conforman sus ingresos $(\mathrm{Y})$, un componente agrícola $(\mathrm{A})$ y pecuario $(\mathrm{P})$ donde se incluye los productos y los derivados de estos productos y cuya producción depende necesariamente del acceso del agua para riego, entre otros factores, y otro componente, el laboral (L) que no depende del acceso de agua para riego (a). Se asume que el acceso al agua para riego depende positivamente del gasto público $\mathrm{G}$ en riego.

Asimismo, cabe señalar que el proceso maximizador de estos ingresos está sujeto a una serie de restricciones. En particular, señalamos dos. La primera, es el tiempo que se dedica a cada una de las actividades mencionadas $\left(t_{A}, t_{P}\right.$ y $\left.t_{L}\right)$, cuya suma no puede superar el tiempo que se está operativo para trabajar (T). La segunda restricción establecida guarda relación con la importancia de los cultivos de subsistencia o autoconsumo (Figueroa, 1989 y 1997; Gonzales de Olarte y Kervyn, 1987), por lo cual la producción agropecuaria y sus derivados deben ser tales que cubran las necesidades que aseguren el nivel de subsistencia $\left(\mathrm{A}_{0}\right.$ y $\left.\mathrm{P}_{0}\right)$. El problema a solucionar es el siguiente:

$$
\operatorname{Max}_{\left\{t_{A}, t_{P}, t_{L\}}\right.} Y=f(A, P, L)
$$

\begin{tabular}{|c|c|c|}
\hline \multirow[t]{5}{*}{ Sujeto a: } & Tecnología & Dotaciones \\
\hline & $A=A\left(a, t_{A}\right)$ & $t_{A}+t_{P}+t_{L} \leq T$ \\
\hline & $P=P\left(a, t_{P}\right)$ & $A_{0} \leq A$ \\
\hline & $L=L\left(w, t_{L}\right)$ & $P_{0} \leq P$ \\
\hline & $a=a(G)$ & \\
\hline
\end{tabular}

Debido a las desigualdades en las restricciones del modelo, la solución se obtiene por las condiciones de Karush-Kuhn-Tucker (KKT).

Lagrangiano: $L=f(A, L)+\lambda\left(T-t_{A}-t_{L}\right)+\gamma_{A}\left(A-A_{0}\right)+\gamma_{P}\left(P-P_{0}\right)$

\section{Condiciones de Primer Orden (CPO):}

$$
\begin{gathered}
\frac{\partial L}{\partial t_{A}}: \frac{\partial F}{\partial A} \frac{\partial A}{\partial t_{A}}-\lambda+\gamma_{A} \frac{\partial A}{\partial t_{A}} \leq 0 ; A \geq 0 \\
\frac{\partial L}{\partial t_{P}}: \frac{\partial F}{\partial P} \frac{\partial P}{\partial t_{P}}-\lambda+\gamma_{P} \frac{\partial P}{\partial t_{P}} \leq 0 ; P \geq 0 \\
\frac{\partial L}{\partial t_{L}}: \frac{\partial F}{\partial L} \frac{\partial L}{\partial t_{L}}-\lambda \leq 0 ; L \geq 0
\end{gathered}
$$




$$
\begin{gathered}
\frac{\partial L}{\partial \lambda}: T-t_{A}-t_{P}-t_{L} \geq 0 ; \lambda \geq 0 \\
\frac{\partial L}{\partial \gamma_{A}}: A-A_{0} \geq 0, \gamma_{A} \geq 0 \rightarrow \frac{\partial L}{\partial \gamma_{A}} \gamma_{A}=0 \\
\frac{\partial L}{\partial \gamma_{P}}: P-P_{0} \geq 0, \gamma_{P} \geq 0 \rightarrow \frac{\partial L}{\partial \gamma_{P}} \gamma_{P}=0
\end{gathered}
$$

Los escenarios según las condiciones de KKT y sus implicancias se resumen en la Tabla 6.

Tabla 6. Condiciones de KKT, multiplicadores de Lagrange y sus implicancias

\begin{tabular}{llllll}
\hline \multicolumn{3}{l}{ Multiplicadores de Lagrange } & \multicolumn{3}{c}{ Implicancias } \\
\hline$\lambda=0$ & $\gamma_{1}=0$ & $\gamma_{2}=0$ & $T-t_{A}-t_{P}-t_{L}>0$ & $\mathrm{~A}>A_{0}$ & $\mathrm{P}>P_{0}$ \\
$\lambda=0$ & $\gamma_{1}>0$ & $\gamma_{2}=0$ & $T-t_{A}-t_{P}-t_{L}>0$ & $\mathrm{~A}=A_{0}$ & $\mathrm{P}>P_{0}$ \\
$\lambda=0$ & $\gamma_{1}=0$ & $\gamma_{2}>0$ & $T-t_{A}-t_{P}-t_{L}>0$ & $\mathrm{~A}>A_{0}$ & $\mathrm{P}=P_{0}$ \\
$\lambda=0$ & $\gamma_{1}>0$ & $\gamma_{2}>0$ & $T-t_{A}-t_{P}-t_{L}>0$ & $\mathrm{~A}=A_{0}$ & $\mathrm{P}=P_{0}$ \\
$\lambda>0$ & $\gamma_{1}=0$ & $\gamma_{2}=0$ & $T-t_{A}-t_{P}-t_{L}=0$ & $\mathrm{~A}>A_{0}$ & $\mathrm{P}>P_{0}$ \\
$\lambda>0$ & $\gamma_{1}>0$ & $\gamma_{2}=0$ & $T-t_{A}-t_{P}-t_{L}=0$ & $\mathrm{~A}=A_{0}$ & $\mathrm{P}>P_{0}$ \\
$\lambda>0$ & $\gamma_{1}=0$ & $\gamma_{2}>0$ & $T-t_{A}-t_{P}-t_{L}=0$ & $\mathrm{~A}>A_{0}$ & $\mathrm{P}=P_{0}$ \\
$\lambda>0$ & $\gamma_{1}>0$ & $\gamma_{2}>0$ & $T-t_{A}-t_{P}-t_{L}=0$ & $\mathrm{~A}=A_{0}$ & $\mathrm{P}=P_{0}$ \\
\hline
\end{tabular}

Sin embargo, solo los casos en los que $\lambda>0$, son importantes para nuestro estudio, ya que, si no, estaríamos estudiando aquellos hogares que no están sujetos a una restricción de tiempo para la producción o, en otras palabras, que tienen una dotación de tiempo suficientemente laxa como para maximizar sus beneficios sin tener la necesidad de trabajar todo lo que podrían hacerlo. El valor de $\gamma_{1}$ es el precio sombra del autoconsumo de la producción agrícola del hogar, y el de $\gamma_{2}$ el de la producción pecuaria.

Escenarios:

1) Escenario sin restricciones de autoconsumo $\lambda>0, \gamma_{1}=0, \gamma_{2}=0$ :

No hay restricción en el nivel de autoconsumo de ningún tipo de producto. Esto significa que el valor sombra para el hogar, de satisfacer un nivel mínimo de producción para el autoconsumo, es nulo. Entonces, la asignación de tiempo y el nivel de producción óptimo dependerán de la igualdad de la productividad marginal, condicional a satisfacer la restricción de tiempo $T-t_{A}-t_{P}-t_{L}=0$ :

$$
\frac{\partial F}{\partial A} \frac{\partial A}{\partial t_{A}}=\frac{\partial F}{\partial P} \frac{\partial P}{\partial t_{P}}=\frac{\partial F}{\partial L} \frac{\partial L}{\partial t_{L}}
$$


2) Escenario con autoconsumo agrícola mínimo $\lambda>0, \gamma_{1}>0, \gamma_{2}=0$ :

Solo hay restricción en el autoconsumo de productos agrícolas, no de productos pecuarios. Es decir, el hogar debe generar un mínimo de producción agrícola para satisfacer la necesidad de autoconsumo de estos bienes, mientras que la producción pecuari y el ingreso laboral no agropecuario se maximizan según sus productividades marginales.

$$
\begin{gathered}
\frac{\partial L}{\partial \gamma_{A}}: \gamma_{A}>0 \rightarrow \frac{\partial L}{\partial \gamma_{A}} \gamma_{A}=0 \leftrightarrow A-A_{0}=0 \rightarrow A^{*}=A_{0} \\
\frac{\partial F}{\partial P} \frac{\partial P}{\partial t_{P}}=\frac{\partial F}{\partial L} \frac{\partial L}{\partial t_{L}}
\end{gathered}
$$

Condicional a: $t_{A^{*}}=T-t_{P}-t_{L}$

3) Escenario con autoconsumo pecuario mínimo $\lambda>0, \gamma_{1}=0, \gamma_{2}>0$ :

Simétrico al caso anterior, solo hay restricción en el consumo de productos pecuarios, no en el de los agrícolas. Entonces, el hogar producirá un mínimo de producción pecuaria $P_{0}$ para satisfacer la necesidad de consumo del hogar, $y$ maximizará el uso del tiempo en la producción agrícola o de ingresos laborales no agropecuarios, según la productividad marginal de cada actividad:

$$
\begin{aligned}
\frac{\partial L}{\partial \gamma_{P}}: \gamma_{P}>0 \rightarrow \frac{\partial L}{\partial \gamma_{P}} \gamma_{P}=0 \leftrightarrow P-P_{0}=0 \rightarrow P^{*}=P_{0} \\
\frac{\partial F}{\partial A} \frac{\partial A}{\partial t_{A}}=\frac{\partial F}{\partial L} \frac{\partial L}{\partial t_{L}}
\end{aligned}
$$

Condicional a: $t_{P^{*}}=T-t_{A}-t_{L}$

4) Escenario con doble restricción en el autoconsumo $\lambda>0, \gamma_{1}>0, \gamma_{2}>0$ :

En este escenario el hogar producirá un mínimo de producción agrícola y pecuaria. Una vez satisfecho este mínimo de producción, destinará el tiempo restante en la generación de ingresos laborales no agropecuarios.

$$
\begin{gathered}
\frac{\partial L}{\partial \gamma_{A}}: \gamma_{A}>0 \rightarrow \frac{\partial L}{\partial \gamma_{A}} \gamma_{A}=0 \leftrightarrow A-A_{0}=0 \rightarrow A^{*}=A_{0} \\
\frac{\partial L}{\partial \gamma_{P}}: \gamma_{P}>0 \rightarrow \frac{\partial L}{\partial \gamma_{P}} \gamma_{P}=0 \leftrightarrow P-P_{0}=0 \rightarrow P^{*}=P_{0} \\
t_{L^{*}}=T-t_{A^{*}}-t_{P^{*}} \rightarrow L^{*}=L\left(w, t_{L^{*}}\right)
\end{gathered}
$$


El primer caso posible (1) es que la productividad de $A$ sea suficiente como para producir un excedente además de $A_{0}$ y $P_{0}$, donde el retorno por una unidad de tiempo adicional es igual tanto en $A, P$ y $L$. En este caso, el mayor acceso a riego generaría posibles mayores retornos en la producción de $A$ y $P$, lo que implicaría una reasignación del uso del tiempo, privilegiando los bienes $A$ y/o $P$. Incluso, podría verse una reasignación diferenciada entre $A$ y $P$.

Un segundo grupo de escenarios corresponde a 2,3 y 4 , donde la productividad de los bienes $A$ y/o P puede que sea lo suficientemente baja para que el hogar decida asignar un mayor tiempo a su producción con el objetivo de poder conseguir llegar a la producción de subsistencia $A_{0}$ y/o $P_{0}$. En dichos escenarios, un aumento de la productividad en la producción de $A$ y/o $P$, guiado por un mayor acceso al agua, generaría una necesidad menor de asignación de tiempo para poder producir $A_{0}$ y/o $P_{0}$. Por lo tanto, un aumento del acceso al agua de riego generaría un mayor uso del tiempo en las actividades relacionadas al mercado laboral (escenario 4), o una reasignación entre $A$ y $P$ (escenarios 2 y 3 ).

\subsection{Estática COMPARATIVA}

El impacto del aumento en gasto en riego sobre el acceso al agua no se conoce, por lo que se debe asumir que $\frac{\partial a}{\partial G}$ es mayor a cero. Entonces, de acuerdo al modelo, se esperaría encontrar un aumento en las horas de trabajo dedicadas a las actividades que utilizan el insumo de agua de riego «a», y, por lo tanto, un aumento en los niveles de ingreso de estas actividades. Las diferencias entre el cambio en los ingresos se deberán a dos factores: la valorización de la producción de autoconsumo que tiene el hogar y la productividad marginal de cada actividad.

Así, se tiene

1) Escenario sin restricciones de autoconsumo $\left(\lambda>0, \gamma_{1}=0, \gamma_{2}=0\right)$ :

Si hay más gasto en riego, esto aumenta el acceso al agua de riego y tiene un impacto positivo en las productividades marginales de $t_{A} \mathrm{y} t_{p}$. Se tendrá mayor impacto dependiendo de las productividades marginales de cada actividad. Los efectos pueden observarse en el nivel de ingreso agrícola y pecuario.

$$
\begin{aligned}
\Delta t_{A}>\Delta t_{P} \leftrightarrow \frac{\partial P M g_{A}}{\partial a} \frac{\partial a}{\partial G}>\frac{\partial P M g_{P}}{\partial a} \frac{\partial a}{\partial G} \rightarrow \Delta A>\Delta P \rightarrow \Delta Y \\
\Delta t_{A}<\Delta t_{P} \leftrightarrow \frac{\partial P M g_{A}}{\partial a} \frac{\partial a}{\partial G}<\frac{\partial P M g_{P}}{\partial a} \frac{\partial a}{\partial G} \rightarrow \Delta A<\Delta P \rightarrow \Delta Y
\end{aligned}
$$


2) Escenario con autoconsumo agrícola mínimo $\left(\lambda>0, \gamma_{1}>0, \gamma_{2}=0\right)$ :

Debido a que el gar solo quiere satisfacer el nivel mínimo de autoconsumo agrícola, asignará su mano de obra a actividades más productivas, las cuales igualarán su productividad marginal.

$$
\begin{gathered}
\Delta A=0 \rightarrow \Delta t_{A}\left\langle 0 y \Delta t_{P}\right\rangle 0 y \Delta t_{L}>0 \\
\Delta t_{P}>\Delta t_{L} \leftrightarrow \frac{\partial P M g_{P}}{\partial a} \frac{\partial a}{\partial G}>\frac{\partial P M g_{L}}{\partial t_{A}} \frac{\partial t_{A}}{\partial a} \frac{\partial a}{\partial G} \rightarrow \Delta P>\Delta L \rightarrow \Delta Y \\
\Delta t_{P}<\Delta t_{L} \leftrightarrow \frac{\partial P M g_{P}}{\partial a} \frac{\partial a}{\partial G}<\frac{\partial P M g_{L}}{\partial t_{A}} \frac{\partial t_{A}}{\partial a} \frac{\partial a}{\partial G} \rightarrow \Delta P<\Delta L \rightarrow \Delta Y
\end{gathered}
$$

3) Escenario con autoconsumo pecuario mínimo $\left(\lambda>0, \gamma_{1}=0, \gamma_{2}>0\right)$ :

Este caso es simétrico al 2.

$$
\begin{gathered}
\Delta P=0 \rightarrow \Delta t_{P}\left\langle 0 y \Delta t_{A}\right\rangle 0 y \Delta t_{L}>0 \\
\Delta t_{A}>\Delta t_{L} \leftrightarrow \frac{\partial P M g_{A}}{\partial a} \frac{\partial a}{\partial G}>\frac{\partial P M g_{L}}{\partial t_{A}} \frac{\partial t_{A}}{\partial a} \frac{\partial a}{\partial G} \rightarrow \Delta A>\Delta L \rightarrow \Delta Y \\
\Delta t_{A}<\Delta t_{L} \leftrightarrow \frac{\partial P M g_{A}}{\partial a} \frac{\partial a}{\partial G}<\frac{\partial P M g_{L}}{\partial t_{A}} \frac{\partial t_{A}}{\partial a} \frac{\partial a}{\partial G} \rightarrow \Delta A<\Delta L \rightarrow \Delta Y
\end{gathered}
$$

4) Escenario con doble restricción en el autoconsumo $\left(\lambda>0, \gamma_{1}>0, \gamma_{2}>0\right)$ :

En este escenario número 4, el mayor acceso al agua de riego permite dedicar menos tiempo a las actividades agropecuarias y más a actividades de mayor productividad para el hogar, como el trabajo dependiente.

$$
\Delta P=0 \rightarrow \Delta t_{P}<0 \text { y } \Delta A=0 \rightarrow \Delta t_{A}\langle 0 \rightarrow \Delta L\rangle 0 \rightarrow \Delta Y
$$

\subsection{HIPÓTESIS}

Las soluciones 1 y 4 son bastante opuestas. A manera de hipótesis, el modelo estaría indicando dos resultados clave:

- En primer lugar, que un aumento en el acceso a riego conlleva un aumento de los ingresos de los productores agropecuarios.

- En segundo lugar, que la causa de estos mayores ingresos estaría explicada, principalmente, por una recomposición de sus ingresos dependiendo de qué tan importante sea la restricción de autoconsumo para estos productores agropecuarios. 
Estas hipótesis se derivan también de la revisión de literatura teórica y empírica. A fin de probar la segunda hipótesis, se asume que los hogares pobres valorizarán más la producción de autoconsumo y se encontrarán cerca de los escenarios 2, 3 o, en extremo, del escenario 4, de mayor restricción del autoconsumo. Es decir, se esperaría que los hogares pobres reciban un impacto menor en el ingreso agropecuario y mayor en el ingreso no agropecuario. Por otro lado, aquellos hogares sobre la línea de pobreza es posible que no valoricen tanto el autoconsumo y que el riego tenga efectos positivos en las actividades agropecuarias, superiores a los hogares pobres.

\section{METODOLOGÍA}

\subsection{Estrategia DE IDENTIFICACIÓN DEL TRATAMIENTO}

Para identificar la variable de tratamiento se utiliza la base de datos del Sistema Integrado de Administración Financiera (SIAF) la cual tiene información del gasto en proyectos y actividades a nivel distrital, ejecutado por los tres niveles de gobierno; nacional, regional y local, para el periodo 2008-2010. Los datos se tienen disponibles para todos los niveles de gobierno. Se acotó el análisis hasta el año 2010 debido a que en 2011 hubo cambio de autoridades locales en enero y elecciones generales entre abril y junio y cambio de gobierno en julio, lo cual podría introducir «ruido» en la variable de gasto ${ }^{5}$. Asimismo, debido a que se encontraron errores de registro en la base del SIAF, se utilizó el Banco de Proyectos del SNIP para realizar la identificación de proyectos de riego. Una evidencia de estos errores de registro es la falta de concordancia entre la cadena funcional programática ${ }^{6}$ colocada en el SNIP y la que se registra en el SIAF. Este error genera dos problemas. Primero, se registra proyectos de inversión pública (PIP) de riego en cadenas que no son de riego, y en las cadenas para PIP de riego se registra otro tipo de proyectos.

El primer paso consiste en identificar todos los PIP de riego en la base del SNIP, siguiendo la cadena de gasto correspondiente. Ambas bases pueden empatarse utilizando el código SIAF asignado por la Dirección General de Presupuesto Público (DGPP). Luego, se analiza las líneas de gasto del SIAF que no empataron con la del SNIP, y se filtran utilizando un algoritmo de palabras clave para encontrar aquellos proyectos, o gasto corriente en riego, que no entran al banco de proyectos, pero son incorporados al sistema de gasto mediante una cadena de gasto genérico (ver la Tabla 19 de la sección Anexo).

La identificación del tratamiento se define a partir del gasto relativo en riego. Se utiliza el gasto total ejecutado del periodo 2008-2010 para capturar el efecto acumulativo de la inversión en infraestructura de riego y se define dos medidas de gasto relativo

\footnotetext{
5 En los primeros años de cada gobierno (nacional, regional y local), hay una tendencia a un menor gasto público lo cual puede implicar el inicio de nuevas obras cuyos impactos serían observados varios ańos después. 6 Hasta el año 2009 la estructura funcional programática se basaba en los tres siguientes registros: función, programa y subprograma. A partir del año 2010 cambia por: función, división funcional y grupo funcional.
} 
en riego: con respecto a la población total y PEA agrícola. Luego, se realiza un análisis de percentiles para los dos indicadores. Los distritos considerados como grupos de tratamiento serán aquellos que se mantengan en el percentil superior de estos dos indicadores, y los de no tratamiento o control serán aquellos que estén en el percentil inferior (véase el Gráfico 2). Para esto definimos dos percentiles superiores: 50 y 20 por ciento superior. Por simplicidad, los definimos como T50 y T20. En este sentido, el impacto sería un efecto piso. Como se puede observar en el Gráfico 2, hay un área de observaciones excluidas representada por el área negra.

\section{Gráfico 2. Metodología de identificación de tratados} y no tratados

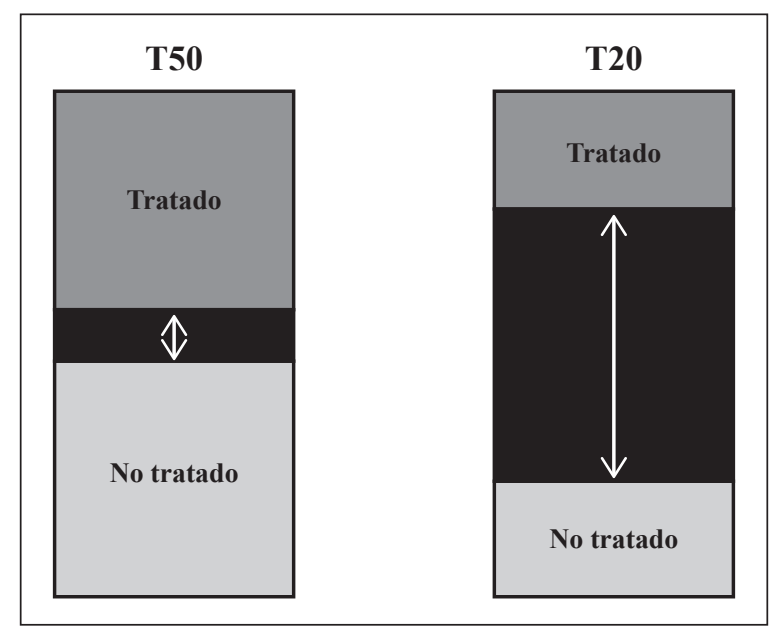

No obstante, la división de la muestra no necesariamente será simétrica como el ejemplo del el Gráfico 2, dado que cada observación debe pertenecer, para los dos indicadores de gasto relativo, a un distrito cuyo percentil es 50 o 20, superior para tratados, o inferior para controles.

Para dividir la muestra entre hogares pobres y no pobres, Del Carpio et al. (2011) y Hopkins y Figallo (2014) utilizan la línea de pobreza monetaria del hogar que está registrada en el módulo de Sumaria de la Enaho. Sin embargo, la pobreza monetaria del hogar depende de las variables de resultado vinculadas al ingreso. Es decir, la segmentación de la muestra sería endógena a la intervención. Los hogares que cambian su estado de pobreza debido a la intervención, pasarán de un segmento de la muestra a otro, pero sin que se pueda observar, debido a que la muestra no es un panel de hogares seguidos en el tiempo. A fin de evitar esta segmentación endógena, se utiliza el porcentaje de pobres del distrito según el Mapa de Pobreza 2007. Se aplica un método similar al que se usó para definir a los grupos de tratamiento y control. Como distritos pobres se considera a aquellos que están en el percentil 35 superior (distritos con el mayor porcentaje 
de pobres) y como distritos no pobres los que están en el percentil 35 inferior (distritos con el menor porcentaje de pobres).

\subsection{ANÁlisis Del gasto Público EN RIEgo}

Siguiendo a Del Carpio et al. (2011), se ha optado por el uso de la Enaho medida por el INEI. Desde el año 20047 , la Enaho consiste en un método de medición continua, con representatividad anual a nivel nacional, para los 24 departamentos, por dominios geográficos (costa, sierra, selva), tanto urbano como rural, y a nivel de área metropolitana de Lima y Callao ${ }^{8}$. Una ventaja del método continuo de la Enaho es que permite juntar dos o más años y trabajarla como una muestra bianual. Entonces, dados los años de gasto considerados, 2008-2010, se puede asumir como una línea de base (LdB) la muestra de hogares bianual 2007-2008, y como muestra de seguimiento la muestra 2012-2013, para el grupo de distritos comunes. Con el fin de reducir la varianza de los resultados y asegurar un mínimo de hogares por distrito, se filtró aquellos con menos de diez hogares encuestados. Este criterio se tomó para cada una de las muestras bianuales. El siguiente paso es vincular la Enaho con el SIAF para identificar los hogares en distritos de tratamiento y de no tratamiento o control.

Para definir los distritos de tratamiento y control, se parte analizando el marco de evaluación del gasto público en riego. Según los datos del SIAF, el gasto total en riego para el periodo 2008-2010 es de S/. 3262 millones, donde el 26\% corresponde al gobierno nacional, el $38 \%$ al gobierno regional y el $35 \%$ al gobierno local (ver la Tabla 7 ). El gasto del gobierno regional y local muestra una tendencia creciente entre 2008 y 2010, mientras que en el año 2010 cae probablemente por el cambio de autoridades del gobierno regional y local'.

Siguiendo un procedimiento exhaustivo ${ }^{10}$ de revisión y empate de las bases de datos, se definió como marco el gasto en riego no multidistrital 2008-2010. El gasto multidistrital está relacionado a proyectos de riego mayor, enfocado a potenciar un tipo de agricultura de mayor escala, por lo que se excluye del análisis.

\footnotetext{
Se considera la Enaho con la metodología actualizada, la cual modifica los factores de expansión sobre la base del Censo de Población y Vivienda 2007, mejora la medición del gasto corriente y cambia la construcción de las líneas de pobreza. La representatividad y los módulos evaluados no cambian significativamente entre ańos.

8 INEI (2013). Ficha Técnica de la Encuesta Nacional de Hogares.

9 El porcentaje de ejecución tiende a caer en promedio luego de los procesos electorales y el cambio de autoridades, tanto locales, regionales como del gobierno nacional.

${ }^{10}$ Se recomienda revisar Hopkins (2016) para una explicación en detalle del procesamiento de las bases de datos.
} 
Tabla 7. Distribución del gasto en riego anual, según nivel de gobierno (2008-2011)

\begin{tabular}{|c|c|c|c|c|c|c|}
\hline \multirow{3}{*}{$\begin{array}{l}\text { Nivel de } \\
\text { gobierno }\end{array}$} & \multicolumn{6}{|c|}{ Millones de nuevos soles a precios corrientes } \\
\hline & \multicolumn{4}{|c|}{ Año } & \multirow{2}{*}{$\begin{array}{c}\text { Total } \\
(2008-2010)\end{array}$} & \multirow{2}{*}{$\begin{array}{c}\text { Total } \\
(2008-2011)\end{array}$} \\
\hline & 2008 & 2009 & 2010 & 2011 & & \\
\hline Nacional & 161 & 457 & 245 & 139 & 864 & 1003 \\
\hline Regional & 357 & 412 & 485 & 439 & 1253 & 1692 \\
\hline Local & 264 & 384 & 496 & 389 & 1145 & 1534 \\
\hline Total & 783 & 1253 & 1226 & 967 & 3262 & 4229 \\
\hline \multirow{3}{*}{$\begin{array}{l}\text { Nivel de } \\
\text { gobierno }\end{array}$} & \multicolumn{6}{|c|}{ Porcentaje anual según nivel de gobierno } \\
\hline & \multicolumn{4}{|c|}{ Año } & \multirow{2}{*}{$\begin{array}{c}\text { Total }(2008- \\
2010)\end{array}$} & \multirow{2}{*}{$\begin{array}{c}\text { Total (2008 } \\
2011)\end{array}$} \\
\hline & 2008 & 2009 & 2010 & 2011 & & \\
\hline Nacional & 21 & 36 & 20 & 14 & 26 & 24 \\
\hline Regional & 46 & 33 & 40 & 45 & 38 & 40 \\
\hline Local & 34 & 31 & 40 & 40 & 35 & 36 \\
\hline Total & 100 & 100 & 100 & 100 & 100 & 100 \\
\hline
\end{tabular}

Fuente: SIAF y Banco de Proyectos del SNIP. Elaboración propia.

Tabla 8. Distribución anual del gasto en riego no multidistrital, según región natural (2008-2010)

\begin{tabular}{|c|c|c|c|c|}
\hline \multirow{3}{*}{$\begin{array}{l}\text { Región } \\
\text { natural }\end{array}$} & \multicolumn{4}{|c|}{ Millones de nuevos soles a precios corrientes } \\
\hline & \multicolumn{3}{|c|}{ Ańo } & \multirow{2}{*}{ Total } \\
\hline & 2008 & 2009 & 2010 & \\
\hline Costa & 132 & 286 & 244 & 662 \\
\hline Sierra & 370 & 692 & 589 & 1,651 \\
\hline Selva & 29 & 46 & 32 & 106 \\
\hline Total & 531 & 1023 & 865 & 2419 \\
\hline \multirow{3}{*}{$\begin{array}{l}\text { Región } \\
\text { natural }\end{array}$} & \multicolumn{4}{|c|}{ Porcentaje anual según región natural } \\
\hline & \multicolumn{3}{|c|}{ Año } & \multirow{2}{*}{ Total } \\
\hline & 2008 & 2009 & 2010 & \\
\hline Costa & 25 & 28 & 28 & 27 \\
\hline Sierra & 70 & 68 & 68 & 68 \\
\hline Selva & 5 & 4 & 4 & 4 \\
\hline Total & 100 & 100 & 100 & 100 \\
\hline
\end{tabular}

Fuente: SIAF y Banco de Proyectos del SNIP. Elaboración propia. 
A partir del marco de evaluación del gasto en riego no multidistrital en la sierra, empatamos utilizando el código de ubicación geográfica (ubigeo) a nivel distrital con las bases bianuales de la Enaho (2007-2008 y 2012-2013). La muestra de hogares se encuentra distribuida en un conjunto de distritos equivalente al 65\% del marco de evaluación. Si se restringe únicamente a aquellos distritos con más de diez hogares por distrito en cada muestra bianual, el marco muestral cae a 55\% del marco de evaluación (ver la Tabla 8).

Tabla 9. Monto evaluado con respecto al marco de evaluación, según nivel de gobierno

\begin{tabular}{lcccccc}
\hline \multirow{2}{*}{$\begin{array}{c}\text { Nivel de } \\
\text { gobierno }\end{array}$} & Marco de evaluación & Muestra Enaho & \multicolumn{3}{c}{$\begin{array}{c}\text { Muestra Enaho } \\
\text { (más de diez hogares } \\
\text { por distrito por } \\
\text { muestra bianual) }\end{array}$} \\
\cline { 2 - 7 } & $\begin{array}{c}\text { Millones de } \\
\text { nuevos soles }\end{array}$ & $\%$ & $\begin{array}{c}\text { Millones de } \\
\text { nuevos soles }\end{array}$ & $\%$ & $\begin{array}{c}\text { Millones de } \\
\text { nuevos soles }\end{array}$ & $\%$ \\
\hline Nacional & 309 & 19 & 179 & 17 & 139 & 15 \\
Regional & 491 & 30 & 302 & 28 & 248 & 27 \\
Local & 851 & 52 & 601 & 56 & 522 & 57 \\
Total & 1651 & 100 & 1082 & 100 & 909 & 100 \\
\hline
\end{tabular}

Fuente: SIAF y Banco de Proyectos del SNIP. Elaboración propia.

Sobre la base de este marco muestral, realizamos la identificación de los distritos de tratamiento y no tratamiento, siguiendo la metodología descrita en la subsección 4.1. Para cada tipo de identificación de tratados y no tratados, se presenta en la Tabla 10 el gasto distrital promedio y total del periodo 2008-2010. El gasto promedio total en riego 2008-2010 de los distritos de control T50 es aproximadamente S/. 385 mil y los controles T20 poco más de S/. 147 mil, mientras que el gasto promedio en los tratados es de S/. 3,8 millones y S/. 6,7 millones respectivamente. Al tomar el gasto relativo según el número de la población total, la población rural y la PEA agrícola, las diferencias entre controles y tratados se acentúan.

Tabla 10. Monto promedio según identificación del tratamiento y grupo de evaluación

\begin{tabular}{lcccc}
\hline \multirow{1}{*}{\multicolumn{1}{c}{ Grupo }} & \multicolumn{4}{c}{ Identificación del tratamiento } \\
\cline { 2 - 5 } & \multicolumn{3}{c}{ T50 } & \multicolumn{2}{c}{ T20 } \\
\cline { 2 - 5 } & Control & Tratado & Control & Tratado \\
\hline Total 2008-2010 & 385362 & 3883520 & 147480 & 6747386 \\
Por poblador & 34 & 645 & 11 & 1412 \\
Por poblador rural & 69 & 1617 & 16 & 3599 \\
Por trabajador agrícola & 216 & 4650 & 61 & 10137 \\
\hline
\end{tabular}

Fuente: SIAF y Banco de Proyectos del SNIP. Elaboración propia. 


\subsection{Metodología eCONOMÉTrica}

Las evaluaciones de impacto se aplican con el objetivo de encontrar relaciones de causa efecto para determinar si se está logrando o no los resultados esperados. Es decir, es un problema de inferencia causal (Khandker, Koolwal y Samad, 2010). Una adecuada evaluación debe aislar las diferencias en resultados con y sin el programa evaluado para así poder establecer una relación de causa-efecto del tratamiento sobre las variables de resultado. Para ello se recurre al escenario contrafactual: ¿qué hubiera pasado con ese mismo individuo/hogar si el programa nunca se hubiera realizado? Debido a que no es posible observar a un mismo sujeto de análisis en dos situaciones distintas en un mismo momento, es necesario pensar en otras opciones (Khandker et al., 2010). Dada las características de la intervención y la disponibilidad de información para evaluar sus efectos en la población objetivo, se ha identificado la posibilidad de aplicar el método econométrico de diferencias en diferencias con un pool de datos.

Siguiendo el estudio de Del Carpio et al. (2011), es posible construir una pseudo línea de base a partir de los datos previos a los años evaluados. Es decir, es posible establecer como línea de base una muestra de hogares entre los años 2007 y 2008, aprovechando el método de muestreo continuo de la Enaho. Del mismo modo, se puede tomar los años de seguimiento 2012 y 2013. En este sentido, tendríamos en los años de línea de base $(T=0)$ observaciones en distritos de tratamiento $(D=1)$ y en distritos de control $(D=$ 0 ), y de manera similar para la muestra de seguimiento $(T=1)$. El estimador de impacto sería el coeficiente de la multiplicación de $\mathrm{TxD}$, el cual sería igual a 1 únicamente para los datos de seguimiento en los distritos de tratamiento. Siguiendo a Blundell y CostaDias, 2000, el estimador de DD $\left(\hat{\alpha}^{D D}\right)$ se deriva de la siguiente expresión (1):

$$
\hat{\alpha}^{D D}=\left(\bar{Y}_{t 0}^{T}-\bar{Y}_{t 1}^{T}\right)-\left(\bar{Y}_{t 0}^{C}-\bar{Y}_{t 1}^{C}\right)
$$

Donde $\bar{Y}^{T}$ y $\bar{Y}^{C}$ es la media de la variable de resultado para los tratados y controles, respectivamente, en la medición de línea de base $t 0$ y en la de seguimiento $t$. Para estimar estos valores se toma la esperanza matemática de cada variable condicional a la variable de tratamiento y del momento de línea de base o de seguimiento de la muestra:

$$
\begin{aligned}
\hat{\alpha}^{D D} & =\{E(Y \mid D=1, T=1)-E(Y \mid D=1, T=0)\} \\
& -\{E(Y \mid D=0, T=1)-E(Y \mid D=0, T=0)\}
\end{aligned}
$$

Para estimar $\hat{\alpha}^{D D}$, definamos la siguiente ecuación (3), donde $Y_{i}$ es la variable de resultado y $e$ el término de error:

$$
Y_{i}=a_{0}+a_{1} T_{i}+a_{2} D_{i}+a_{3} T x D_{i}+e
$$

La ecuación (3) estaría compuesta por las siguientes medias condicionales:

$$
E(Y \mid D=1, T=1)=a_{0}+a_{1}+a_{2}+a_{3}
$$




$$
\begin{gathered}
E(Y \mid D=1, T=0)=a_{0}+a_{2} \\
E(Y \mid D=0, T=1)=a_{0}+a_{1} \\
(Y \mid D=0, T=0)=a_{0}
\end{gathered}
$$

Reemplazando en la ecuación (3), obtenemos el estimador $\hat{\alpha}^{D D}(4)$ :

$$
\begin{gathered}
\hat{\alpha}^{D D}=\left\{\left(a_{0}+a_{1}+a_{2}+a_{3}\right)-\left(a_{0}+a_{2}\right)\right\}-\left\{\left(a_{0}+a_{1}\right)-\left(a_{0}\right)\right\} \\
\hat{\alpha}^{D D}=a_{3}
\end{gathered}
$$

Este método permite el control de la variable de resultado por variables observables y variables no observables invariantes en el tiempo, como variables institucionales que no solo determinan el gasto en el componente de riego, sino otras actividades que los municipios hacen en función de mejorar la vida de la población de su localidad. Así tenemos dos grupos de variables $X$, un conjunto de variables $X_{i}^{d}$ de características del distrito y variables $X_{i}^{h}$ del hogar.

El vector de características distritales $X_{i}^{d}$ consiste en variables de línea de base o prelínea de base (2007 o antes) las cuales fueron obtenidas a partir de información del Censo de Población y Vivienda de 2007 o que se calculen a partir de esta, tales como: población, acceso a servicios básicos, como agua y desagüe conectado a una red pública, y alumbrado eléctrico, porcentaje de población rural, dominio geográfico en el que se encuentra, entre otras. Del Censo Agropecuario (Cenagro) del año 1994 se estimó variables estructurales a nivel distrital como las hectáreas agrícolas totales y bajo riego del año 1994. Las características del hogar y del jefe de hogar $\left(X_{i}^{h}\right)$ son construidas con el conjunto de información de la Enaho del año 2007, 2008, 2012 y 2013.

Estas covariables se interpretan en función a su efecto en la variable de resultado (ingreso del hogar, por ejemplo). Entonces, en la ecuación (3) incluimos los vectores de variables $X_{i}^{d}$ y $X_{i}^{h}$, con lo que obtenemos la ecuación (5).

$$
Y_{i}=a_{0}+a_{1} T_{i}+a_{2} D_{i}+a_{3} T x D_{i}+b_{1} X_{i}^{h}+b_{2} X_{i}^{d}+e_{i}
$$

Un supuesto clave del modelo es el de tendencias paralelas, el cual implica que las observaciones de tratamiento hubieran seguido la misma tendencia que las observaciones de control en un escenario sin intervención. Finalmente, la base de datos construida con la Enaho 2007-2008 y 2012-2013 consiste en hogares distintos, pero que conforman el mismo grupo de distritos de ambos cortes bianuales. Es decir, existe una muestra de hogares 2007-2008 y 2012-2013 en los mismos distritos evaluados. En forma esquemática la base de datos estaría construida tal como se presenta en la Tabla 2. 
Ilustración 2. Diseño de la base de datos

\begin{tabular}{ccccc}
\hline & & Tratamiento & Periodo & Tratamiento X periodo \\
\cline { 3 - 5 } ID Hogar & Ańo & $\begin{array}{c}\text { Tratado=1, } \\
\text { Control=0 }\end{array}$ & $\begin{array}{c}\text { Seguimiento=1, } \\
\text { Línea de Base=0 }\end{array}$ & Impacto \\
\hline 1 & 2007 & 0 & 0 & 0 \\
2 & 2007 & 0 & 0 & 0 \\
3 & 2007 & 1 & 0 & 0 \\
4 & 2007 & 1 & 0 & 0 \\
5 & 2008 & 0 & 0 & 0 \\
6 & 2008 & 0 & 0 & 0 \\
7 & 2008 & 1 & 0 & 0 \\
8 & 2008 & 1 & 0 & 0 \\
9 & 2012 & 0 & 1 & 0 \\
10 & 2012 & 0 & 1 & 1 \\
11 & 2012 & 1 & 1 & 1 \\
12 & 2012 & 1 & 1 & 0 \\
13 & 2013 & 0 & 1 & 0 \\
14 & 2013 & 0 & 1 & 1 \\
15 & 2013 & 1 & 1 & 1 \\
16 & 2013 & 1 & 1 & \\
\hline
\end{tabular}

En la Tabla 12 se presenta la distribución de los hogares que están localizados en los distritos del marco de evaluación. Esta muestra se concentra en distritos que equivalen al 55\% del marco de evaluación. Esta proporción es importante, considerando el hecho de que este gasto público en riego no se diseñó para ser evaluado. Las cortes del año 2012 y 2013 presentan un mayor número de hogares debido al incremento de la muestra de la Enaho.

Tabla 12. Distribución de los hogares según año de la encuesta y muestra de línea de base y seguimiento

\begin{tabular}{|c|c|c|c|}
\hline Muestra & Año & Número de hogares & Porcentaje (\%) \\
\hline \multirow{2}{*}{ Línea de base } & 2007 & 3267 & 23,08 \\
\hline & 2008 & 3226 & 22,79 \\
\hline \multirow{2}{*}{ Seguimiento } & 2012 & 3516 & 24,84 \\
\hline & 2013 & 4147 & 29,29 \\
\hline \multicolumn{2}{|c|}{ Total } & 14156 & 100,00 \\
\hline
\end{tabular}

Sin embargo, esta muestra es heterogénea en distintos niveles, pero principalmente en la dotación de tierra de cada hogar. En la Tabla 13 se muestra la distribución de hogares según rango de dotación de tierras. Cerca del $80 \%$ de los hogares está concentrado en el rango de menos de 3 ha de tierra, y poco más de $14 \%$ entre 3 y 10 ha. El resto de hogares se distribuye en el rango de 10 a más de 100 ha. Ante esto es necesario revisar 
la presencia de posibles outliers, o valores extremos, que podrían afectar los resultados. En principio, se estaría considerando hogares con grandes unidades agropecuarias que responden a una lógica distinta a hogares de un proceso productivo de menor escala. Asimismo, estos valores podrían ocultar errores de registro en la toma de datos de la Enaho. Para identificar posibles outliers utilizamos el método de Billor, Hadi y Velleman (2000), denominado BACON (Blocked adaptive computationally efficient outlier nominators).

Tabla 13. Distribución de los hogares según rango de dotación de tierra

\begin{tabular}{ccc}
\hline Rango de dotación de tierra & Número de hogares & Porcentaje (\%) \\
\hline$<1$ ha & 6898 & 48,73 \\
$1-<3$ ha & 4571 & 32,29 \\
$3-<5$ ha & 1205 & 8,51 \\
$5-<10$ ha & 840 & 5,93 \\
$10-<20$ & 366 & 2,59 \\
$20-<50$ & 176 & 1,24 \\
$50-<100$ & 64 & 0,45 \\
$100-$ más & 36 & 0,25 \\
\hline Total & 14156 & 100,0 \\
\hline
\end{tabular}

Como variable para identificar a los outliers se utiliza la dotación de tierras del hogar. El método de BACON detecta como outliers 1539 observaciones (ver la Tabla 14), con valores de 4,7 ha hasta 630 ha. La dispersión de estos hogares considerados outliers es de una desviación estándar de 36 ha, mientras que la muestra total es de 13 ha y la muestra sin outliers de 1 ha (ver la Tabla 15).

Tabla 14. Distribución de outliers y no outliers por el método de Billor, Hadi y Velleman (2000), según rango de dotación de tierra

\begin{tabular}{ccccc}
\hline $\begin{array}{c}\text { Rango de dotación } \\
\text { de tierra }\end{array}$ & No & Sí & Total & $\begin{array}{c}\text { Porcentaje de outliers } \\
(\%)\end{array}$ \\
\cline { 2 - 3 } & 6898 & 0 & 6898 & 0 \\
$1-1$ ha & 4571 & 0 & 4571 & 0 \\
$3-<$ ha & 1148 & 57 & 1205 & 5 \\
$5-<10$ ha & 0 & 840 & 840 & 100 \\
$10-<20$ & 0 & 366 & 366 & 100 \\
$20-<50$ & 0 & 176 & 176 & 100 \\
$50-<100$ & 0 & 64 & 64 & 100 \\
$100-$ más & 0 & 36 & 36 & 100 \\
\hline Total & 12,617 & 1,539 & 14,156 & 11 \\
\hline
\end{tabular}


Tabla 15. Estadística descriptiva de la dotación de tierras de outliers y no outliers por el método de Billor, Hadi y Velleman (2000)

\begin{tabular}{cccccc}
\hline Outliers & $\begin{array}{c}\text { Número } \\
\text { de hogares }\end{array}$ & Media & $\begin{array}{c}\text { Desviación } \\
\text { estándar }\end{array}$ & Mínimo & Máximo \\
\hline No & 12,617 & 1.142 & 1.019 & 0.001 & 4.625 \\
Sí & 1,539 & 17.455 & 36.218 & 4.664 & 630.050 \\
\hline Total & 14156 & 2.916 & 13.009 & 0.001 & 630.050 \\
\hline
\end{tabular}

Sobre la base de la identificación de outliers por el método de Billor et al. (2000), acotamos la muestra a hogares con menos de 4625 ha. En el Gráfico 3 se presenta las distribuciones de la dotación de tierras de los hogares sin outliers en distritos pobres y no pobres, y en el Gráfico 4 según identificación de tratamiento, la cual se comporta de manera similar en ambos casos. Al segmentar la muestra por grupos de evaluación (controles y tratados), según tipo de muestra (muestra total, en distritos pobres y no pobres) y tipo de identificación del tratamiento (T50 y T20), se observa una muestra balanceada y amplia (ver el Gráfico 5 y la Tabla 16).

Gráfico 2. Distribución de la dotación de tierras sin outliers por el método de Billor, Hadi y Velleman (2000), según condición de pobreza del distrito

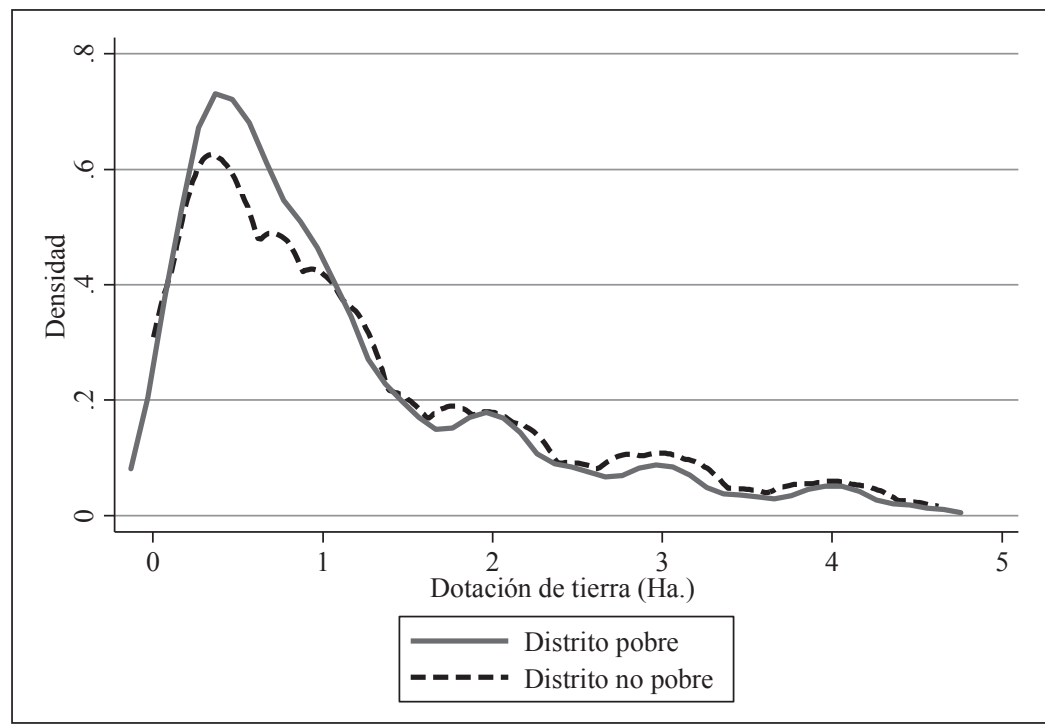

Fuente: Enaho 2007, 2008, 2012 y 2013. 
Gráfico 4. Distribución de la dotación de tierras sin outliers por el método de Billor, Hadi y Velleman (2000), según identificación del tratamiento

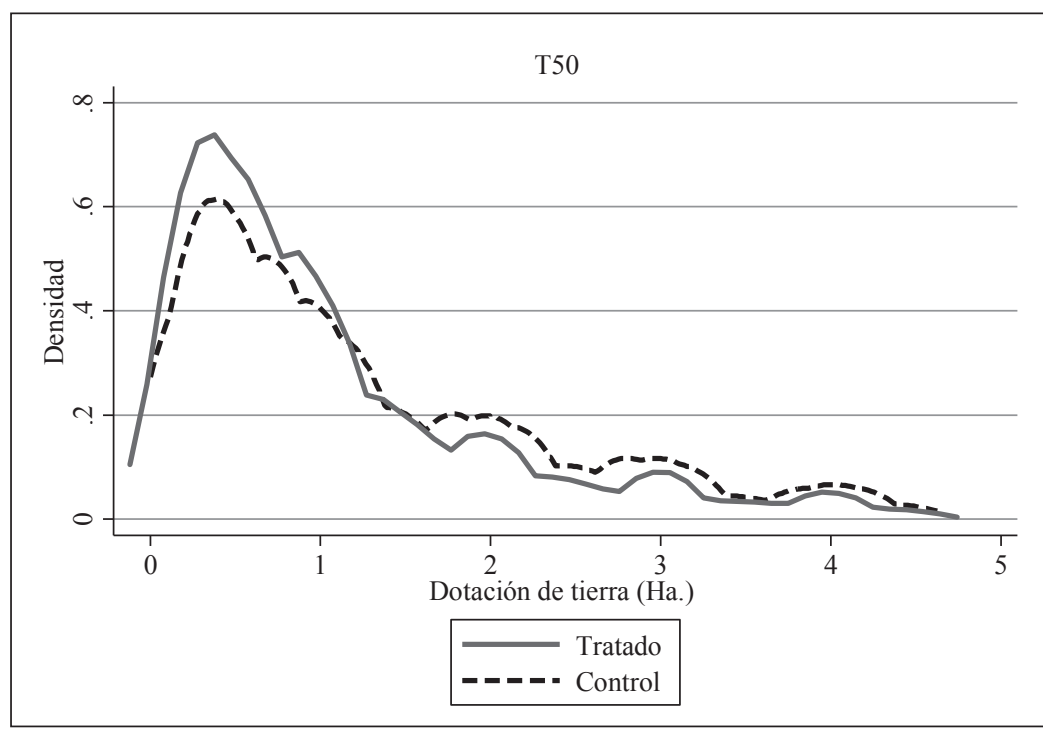

Fuente: Enaho 2007, 2008, 2012 y 2013.

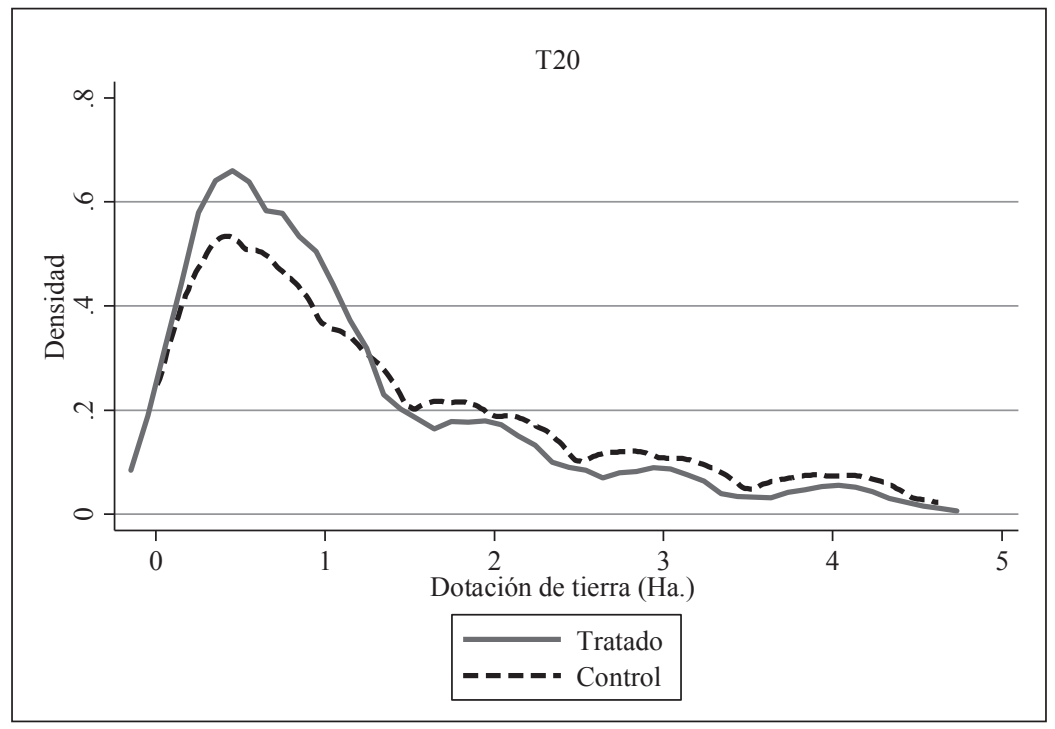

Fuente: Enaho 2007, 2008, 2012 y 2013. 
Gráfico 5. Distribución de la muestra de hogares: total, distritos pobres y no pobres

(a) Muestra total

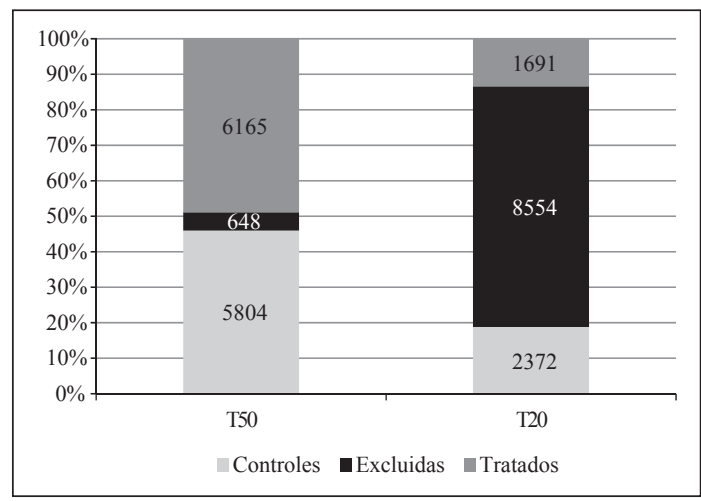

(b) Distritos pobres

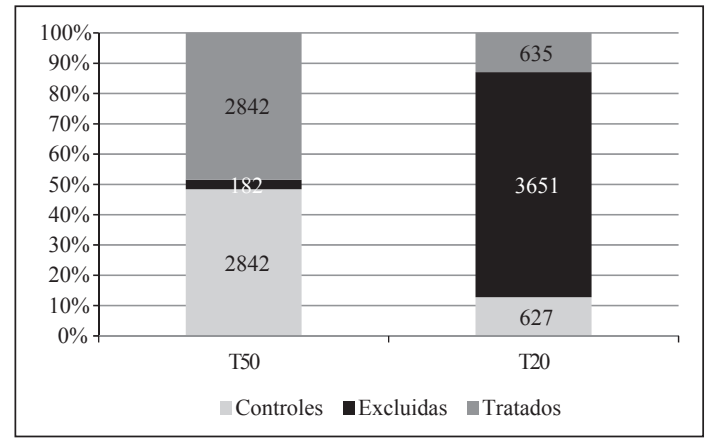

(c) Distritos no pobres

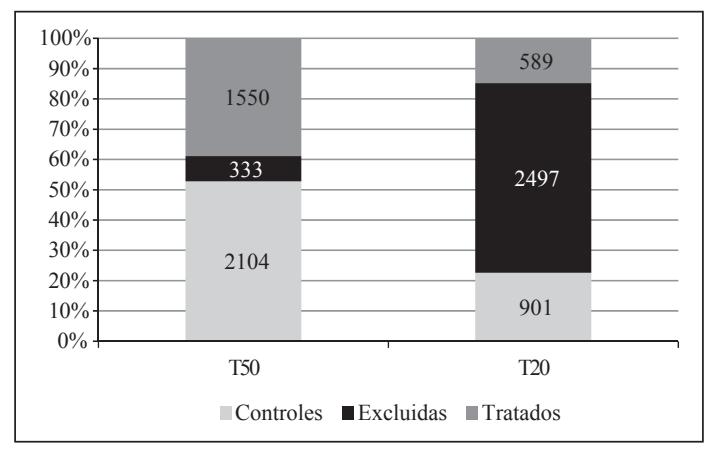

Tabla 16. Distribución de la muestra de hogares según grupo de evaluación, identificación del tratamiento y condición de pobreza

\begin{tabular}{lcccccc}
\hline \multicolumn{7}{c}{ Número de hogares } \\
\hline \multirow{2}{*}{ Grupo } & \multicolumn{2}{c}{ Total } & \multicolumn{2}{c}{ Pobres } & \multicolumn{2}{c}{ No pobres } \\
\cline { 2 - 8 } & T50 & T20 & T50 & T20 & T50 & T20 \\
\hline Controles & 5804 & 2372 & 1889 & 627 & 2104 & 901 \\
Tratados & 6165 & 1691 & 2842 & 635 & 1550 & 589 \\
Total & 11969 & 4063 & 4731 & 1262 & 3654 & 1490 \\
\hline \multicolumn{7}{c}{ \%rupo de hogares } \\
\cline { 2 - 8 } \multicolumn{1}{c}{ Gotal } & T50 & T20 & T50 & T20 & T50 & T20 \\
\hline Controles & 48 & 58 & 40 & 50 & 58 & 60 \\
Tratados & 52 & 42 & 60 & 50 & 42 & 40 \\
Total & 100 & 100 & 100 & 100 & 100 & 100 \\
\hline
\end{tabular}




\section{RESULTADOS}

Antes de presentar los resultados del ejercicio econométrico se presenta un análisis del ingreso neto principal y secundario promedio del hogar y su composición, pero diferenciando la muestra entre controles y tratados. Se encuentra que el nivel de ingresos de línea de base es, en promedio, similar, con excepción de la identificación del tratamiento T20 para distritos no pobres (ver el Gráfico 6, panel (d)). Asimismo, tanto controles como tratados, mejoraron, en promedio, sus ingresos netos entre el periodo de línea de base y de seguimiento. En el panel (c) y (d) del Gráfico 6 hay una clara correlación positiva entre la identificación del tratamiento y el incremento del ingreso neto de los hogares en distrito no pobres, mientras que los hogares en distritos pobres muestran una diferencia menos notoria. Los resultados del modelo econométrico permiten calcular la diferencia promedio de ese impacto del tratamiento, controlando por variables observables de los hogares y de los distritos.

Para la descripción de los efectos observados del gasto público en riego en los hogares de producción agrícola independiente de la sierra, se hace uso de instrumental gráfico donde se presenta los coeficientes estimados. Los coeficientes, su significancia estadística y las desviaciones estándar correspondientes se presentan en la Tabla 17. Los resultados de los seis bloques de regresiones se exponen en la sección de Anexos de la Tabla 21 a la Tabla 25.

Como se observa en el Gráfico 7, hay un incremento del ingreso neto principal y secundario del hogar para la totalidad de la muestra y en mayor medida para los hogares localizados en distritos no pobres, siendo estadísticamente significativo en el tratamiento T50 y T20 (ver la Tabla 17). Los hogares en distritos pobres tienen un efecto positivo en sus ingresos netos, pero estadísticamente igual a cero con un nivel de significancia menor al $10 \%$. Asimismo, se observa que el impacto en el ingreso neto agropecuario, que es la suma del ingreso no salarial y salarial agropecuario, tiene signo negativo aunque es estadísticamente igual a cero. Mientras que los hogares en distritos no pobres incrementaron sus ingresos netos agropecuarios entre S/. 981 y S/. 1611 de forma significativa. Esto implica que la primera hipótesis del modelo se cumple en los hogares localizados en distritos no pobres, pero no en los pobres, aunque el signo es el esperado en ambos casos. Es decir, mayor gasto en riego, tendría un efecto estadísticamente nulo en los hogares que residen en distritos con mayor concentración de la pobreza en el año 2007 $\mathrm{y}$ un positivo en distritos con no pobres. 
Gráfico 6. Composición promedio de ingresos neto principal y secundario del hogar del total de la muestra según identificación del tratamiento

(a)

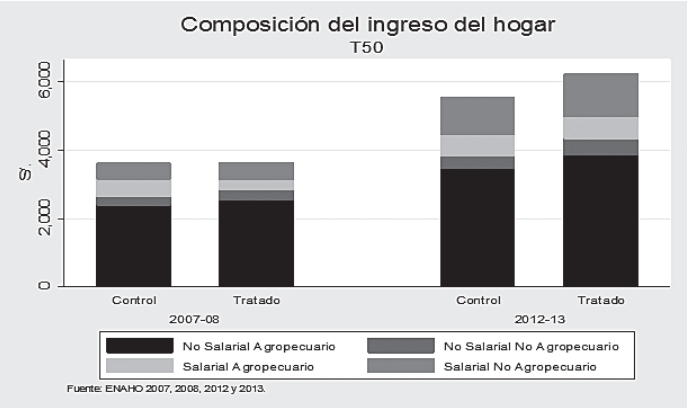

(c)

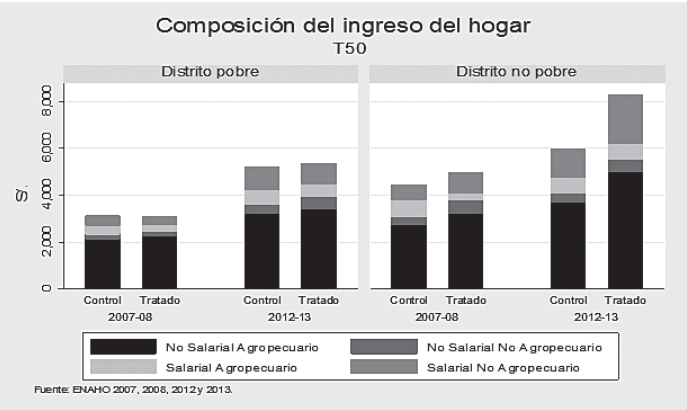

(b)

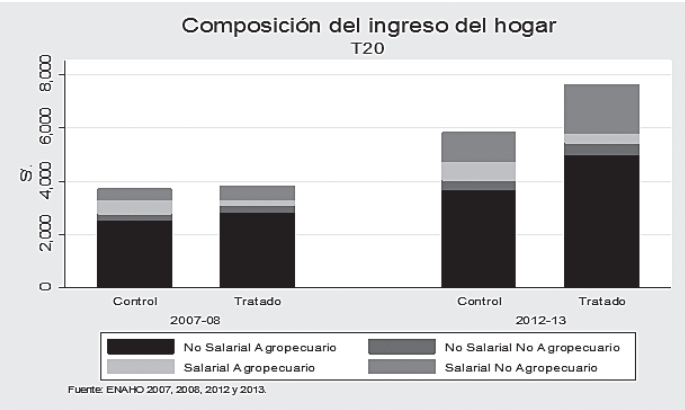

(d)

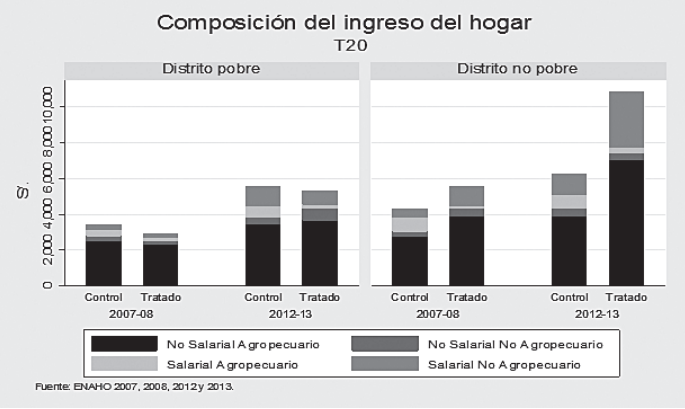

Gráfico 7. Resultados del gasto en riego en el ingreso neto principal y secundario y en el ingreso neto agropecuario, según identificación del tratamiento y muestra analizada $(S /$.

Ingreso neto principal+secundario $(\mathrm{S} /$.)

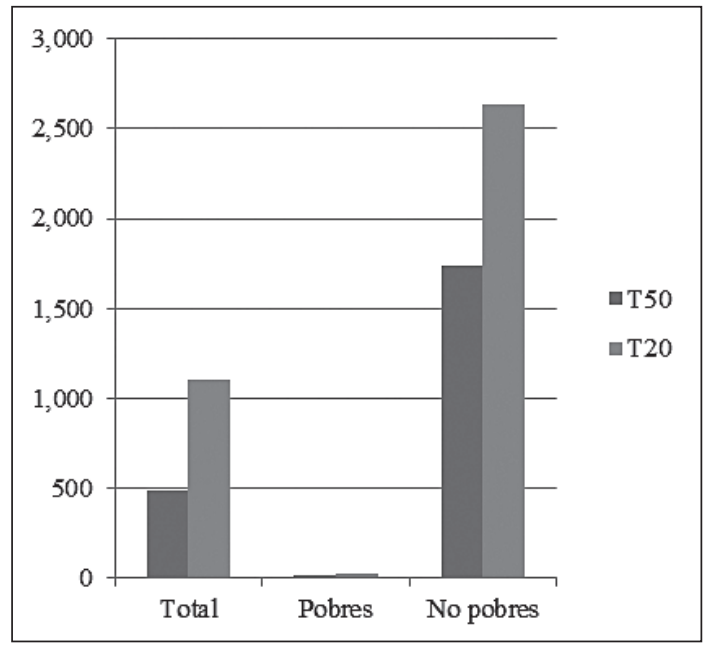

Ingreso neto agropecuario $(\mathrm{S} /$.)

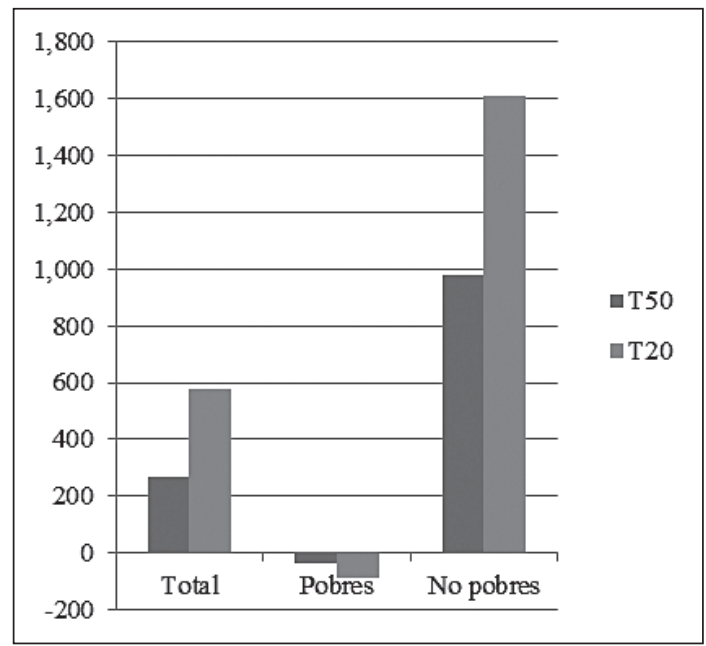


Al observar la composición del ingreso del hogar en el Gráfico 8, se observa que, en la muestra total, los hogares localizados en distritos con mayor gasto en riego (T20) experimentaron un incremento significativo del ingreso neto no salarial agropecuario y del ingreso neto salarial no agropecuario. Este resultado es similar al encontrado por Escobal y Ponce (2002) en la evaluación de impacto del Programa de Caminos Rurales en el que el mayor incremento del ingreso fue en el componente salarial no agropecuario.

Al segmentar la muestra entre hogares en distritos pobres y no pobres, se encuentra efectos diferenciados. Los hogares en distritos no pobres incrementaron, de forma estadísticamente significativa, el ingreso neto no salarial agropecuario entre $S / .547,9 \mathrm{y}$ S/. 1482, y el ingreso neto salarial no agropecuario entre S/. 691,4 y S/. 1207. Por otro lado, los hogares en distritos pobres solo experimentaron un incremento significativo del ingreso neto no salarial no agropecuario. Es decir, en los hogares pobres ocurrió un efecto similar al predicho por el escenario 4 de doble restricción en el autoconsumo de bienes agropecuarios, en el que el hogar dedica menos tiempo a las actividades agropecuarias, manteniendo una producción agropecuaria mínima, y asignando más tiempo a actividades más productivas y de otras ramas de actividad económica, en este caso, actividades independientes no agropecuarias. Sin embargo, vale hacer notar que este efecto solo es significativo en el escenario de mayor gasto riego (T20), lo cual implica que en un escenario de un gasto moderado no se tendría efectos en los hogares en distritos pobres.

Con respecto a los hogares en distritos no pobres, los efectos son los esperados según lo establecido en el escenario 1, sin restricciones en el autoconsumo. Estos hogares pueden asignar su dotación de tiempo libremente, buscando la mayor productividad marginal de las actividades que tienen a su alcance. De esta forma se incrementa el ingreso neto no salarial agropecuario y, en mayor medida, el ingreso salarial no agropecuario. En este sentido, aumenta la producción independiente de bienes agropecuarios, pero la mayor ganancia se genera por actividades dependientes de otras ramas de actividad económica. Entonces, se puede argumentar que, en los hogares en distritos no pobres, se cumple la segunda hipótesis del modelo.

En el estudio de Del Carpio et al. (2011) se encuentra un efecto positivo en el ingreso de los hogares pobres, debido a un efecto sustitución del ingreso independiente a favor del ingreso dependiente. En el caso de la sierra del Perú, se observa que los hogares localizados en distritos pobres, el impacto en el ingreso neto es positivo, explicado por un aumento del ingreso neto no salarial no agropecuario. No se encuentra un efecto positivo en el ingreso agropecuario

Sin embargo, a pesar de que el gasto en riego no tiene el efecto esperado en hogares localizados en distritos pobres, sí genera un cambio en algunas variables intermedias. El valor bruto de producción (VBP) agrícola aumenta en los tratados T20 en S/. 514,8 con una significancia de 10\%. Entonces, al menos en los distritos donde se asignó un mayor gasto en riego, se encuentra un efecto positivo en el VBP, posiblemente explicado 
por un incremento en el rendimiento (Lipton et al., 2003; Hussain y Hanjra, 2004). Asimismo, tanto para el efecto T50 como el T20 se incrementa el porcentaje del VBP cuyo destino es la venta, lo cual puede deberse a que, al contar con una oferta de agua más estable y segura, esto les permite elegir cultivos con una mayor demanda de mercado (Schoengold y Zilberman, 2007).

Gráfico 8. Resultados del gasto en riego en el ingreso neto independiente, dependiente, por autoconsumo y agrario del hogar, según identificación de la intervención y muestra analizada

Ingreso neto no salarial agropecuario $(\mathrm{S} /$.

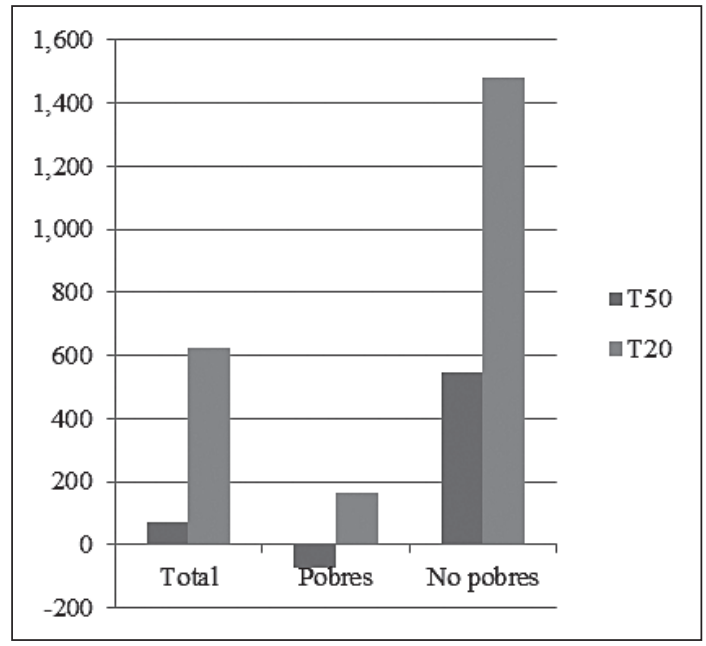

Ingreso neto no salarial no sgropecuario (S/.)

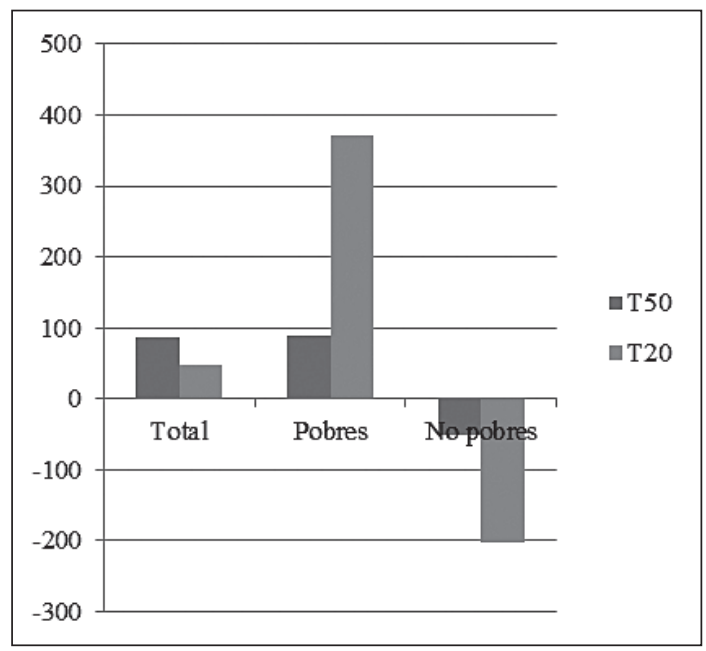

Ingreso neto salarial agropecuario $(\mathrm{S} /$.

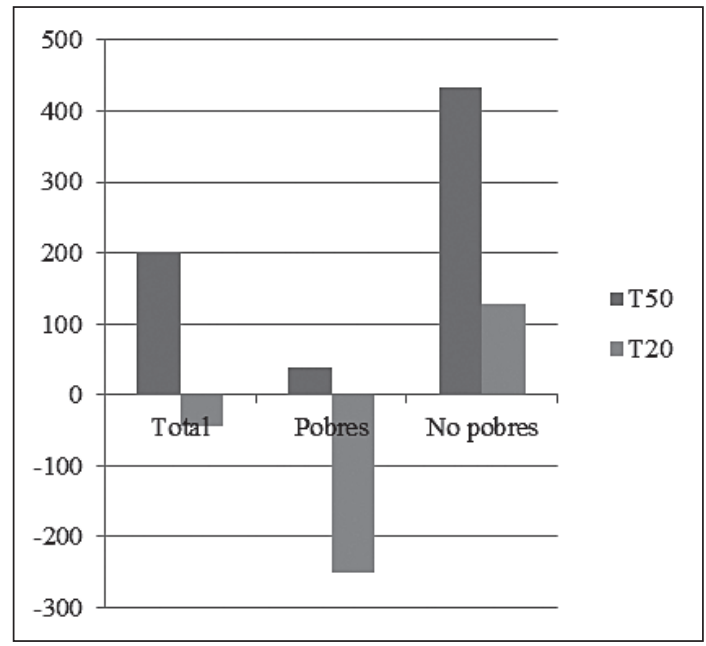

Ingreso neto salarial no agropecuario (S/.)

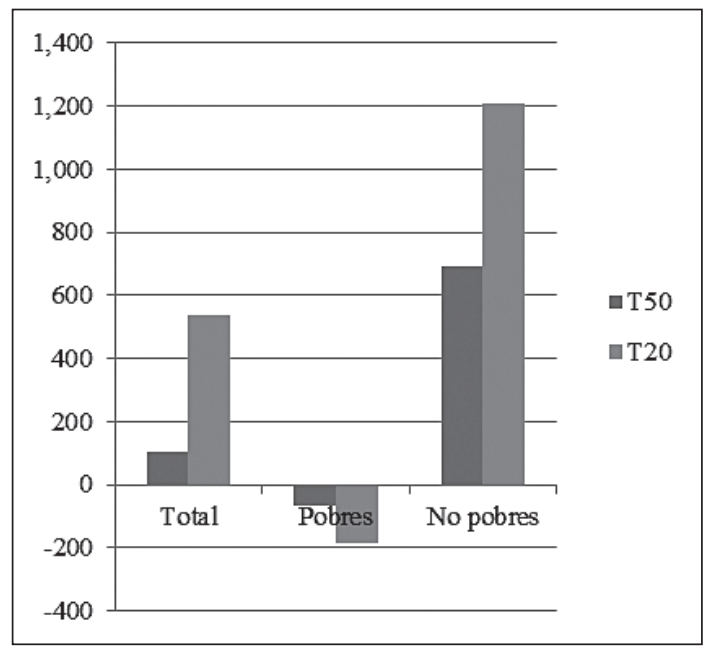


Es interesante notar que el VBP de autoconsumo decrece en ambos hogares, siendo estadísticamente significativo en los hogares en distritos no pobres. Esto refuerza la posibilidad de que los hogares no pobres se encuentren en un escenario 1 sin restricciones de autoconsumo de bienes agropecuarios, lo cual les permite una mayor flexibilidad para asignar tiempo a actividades de mayor productividad marginal. Por otro lado, los efectos de T50 y T20 en el VBP son similares en los hogares no pobres, mientras que en los pobres la diferencia es notable a favor de la identificación del tratamiento T20.

Gráfico 9. Resultados del gasto en riego en el valor bruto de producción agrícola del hogar, según identificación de la intervención y muestra analizada

VBP agrícola $(S /$.

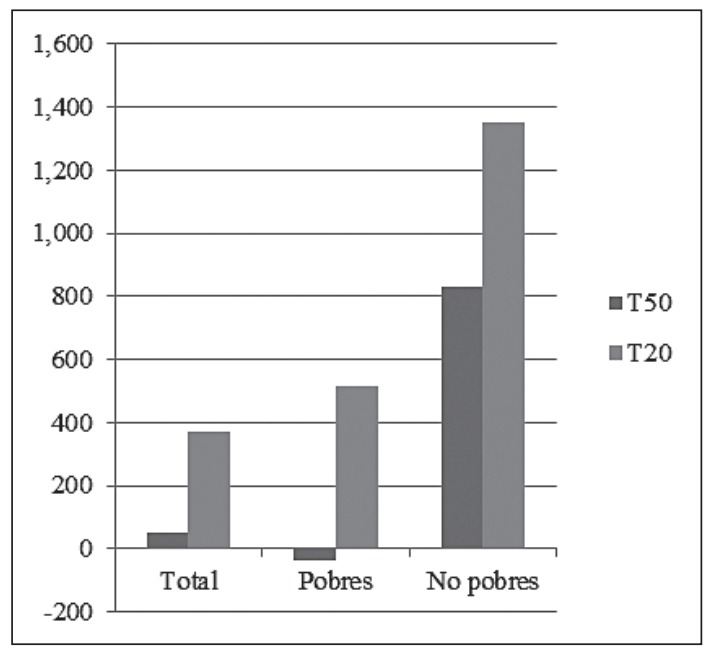

$\%$ VBP agrícola - venta (\%)

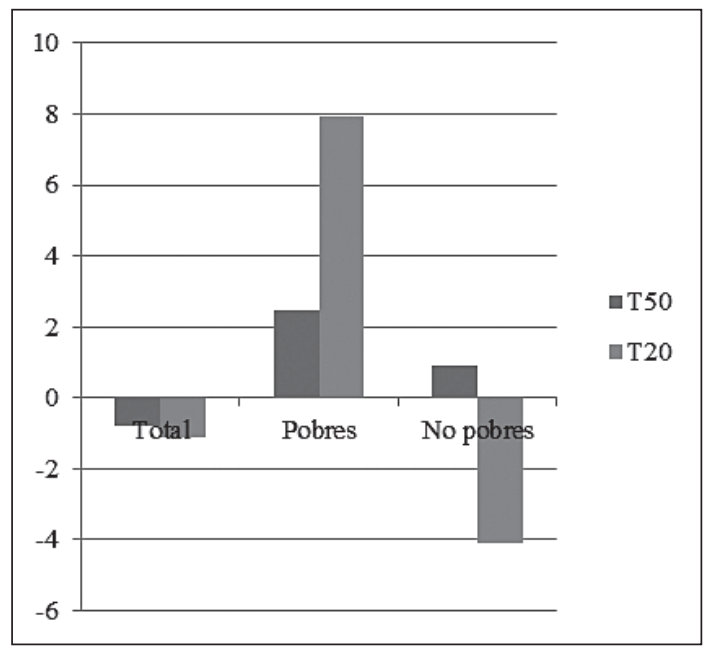

VBP agrícola - autoconsumo $(\mathrm{S} /$.)

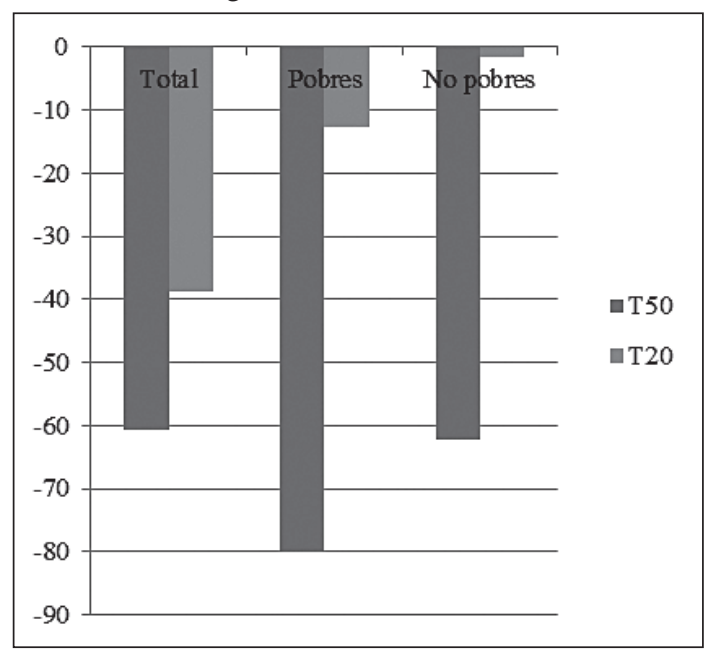

VBP agrícola - venta (S/.)

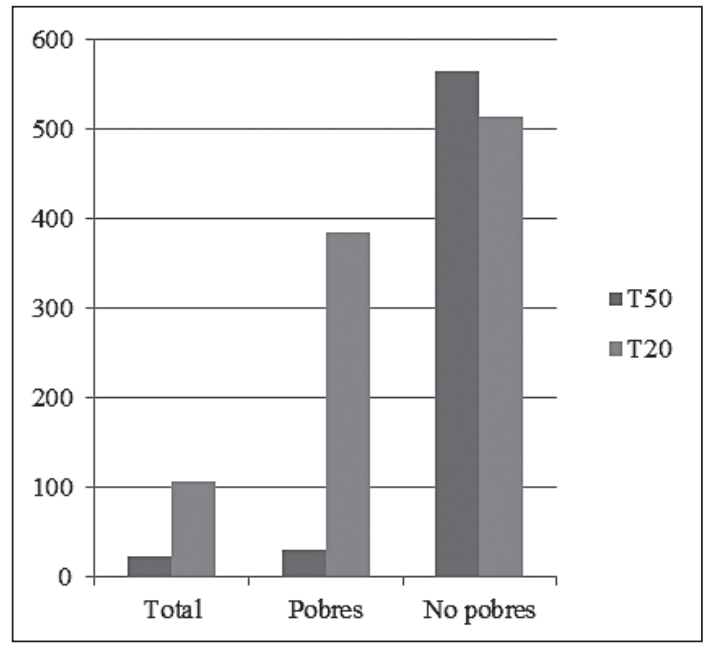


Los gastos agrícolas totales solo se incrementan significativamente en los hogares no pobres T50 y T20 (ver el Gráfico 10), explicado por un aumento del gasto en abonos y pesticidas. El gasto agrícola según componentes muestra un mayor aumento en el gasto de agua de riego en los pobres que en los no pobres (ver el Gráfico 11), aunque sin ser estadísticamente significativo. El costo en el que incurre un hogar para el pago de jornales tiene un efecto significativo en pobres y en no pobres, salvo en los no pobres T20. Esto puede deberse a una mayor demanda de mano de obra en el campo, la cual podría encarecer el pago por jornal. Por otro lado, el gasto en semillas tiene un efecto negativo pero estadísticamente igual a cero en los hogares pobres, y un efecto ambiguo en los no pobres.

Gráfico 10. Resultados del gasto en riego en el gasto agrícola total del hogar, según identificación de la intervención y muestra analizada (S/.)

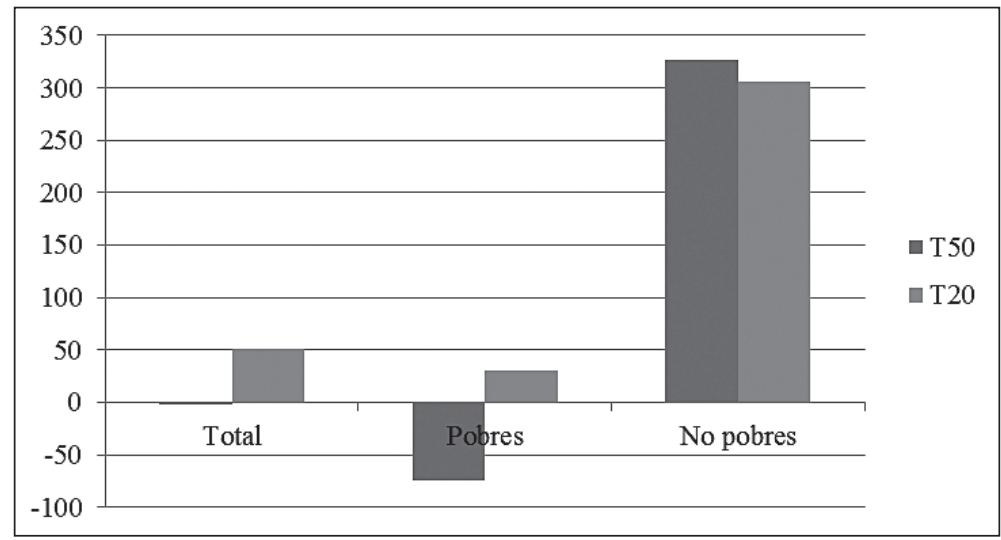

Sobre la base de los resultados expuestos, se puede concluir que el efecto del gasto público en riego tiene efectos diferenciados en los hogares pobres y no pobres, el cual es explicado por la existencia de una restricción de autoconsumo en los primeros, más no en los segundos. Esto genera una recomposición del ingreso a favor de actividades no agropecuarias e independientes, en el caso de los hogares pobres, y en el ingreso independiente agropecuario y salarial no agropecuario en los hogares no pobres. Sin embargo, en los hogares pobres ocurren efectos intermedios en la proporción del VBP cuyo destino es la venta, lo cual puede deberse a que, al contar con una oferta de riego más estable, pueden elegir cultivos con mayor demanda de mercado e incrementar su acceso a este, aunque esto no implique, necesariamente, un mayor VBP total o ingreso agropecuario. 
Gráfico 11. Resultados del gasto en riego en el gasto agrícola del hogar por componentes de gasto, según identificación de la intervención y muestra analizada

Gasto agrícola en agua de riego $(\mathrm{S} /$.

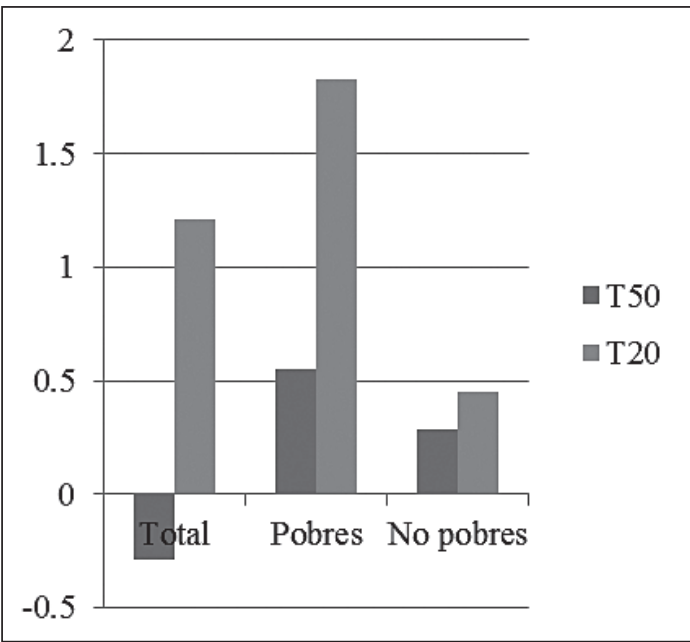

Gasto agrícola en jornales (S/.)

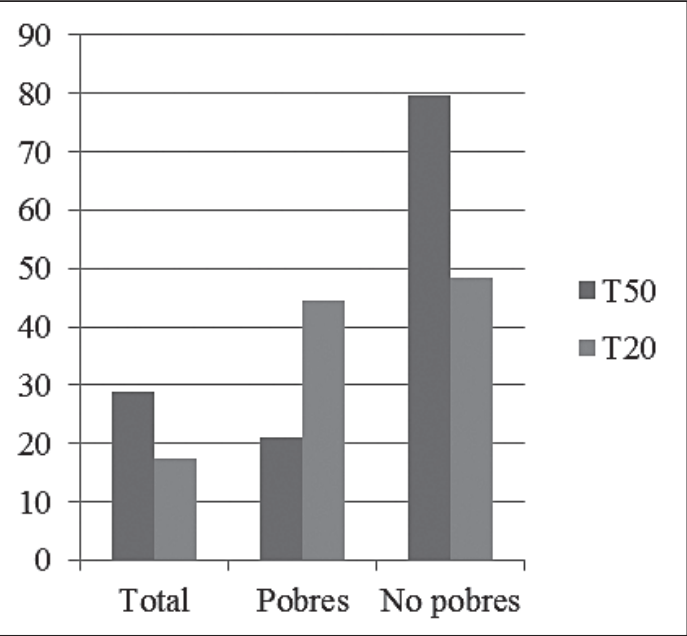

Gasto agrícola en semillas (S/.)

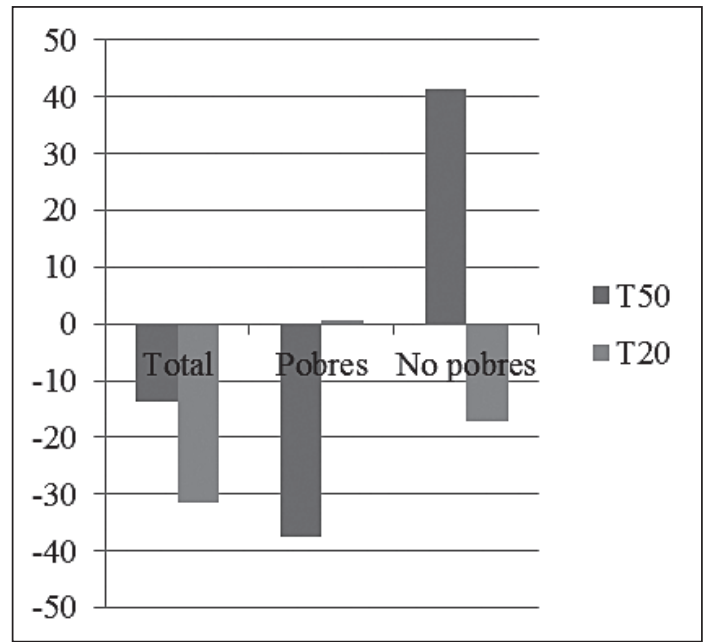

Gasto en abono y pesticidas (S/.)

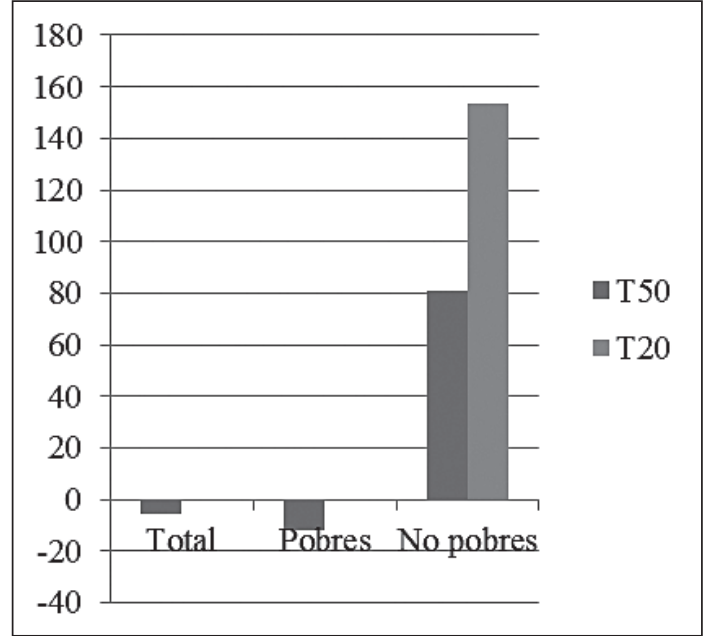




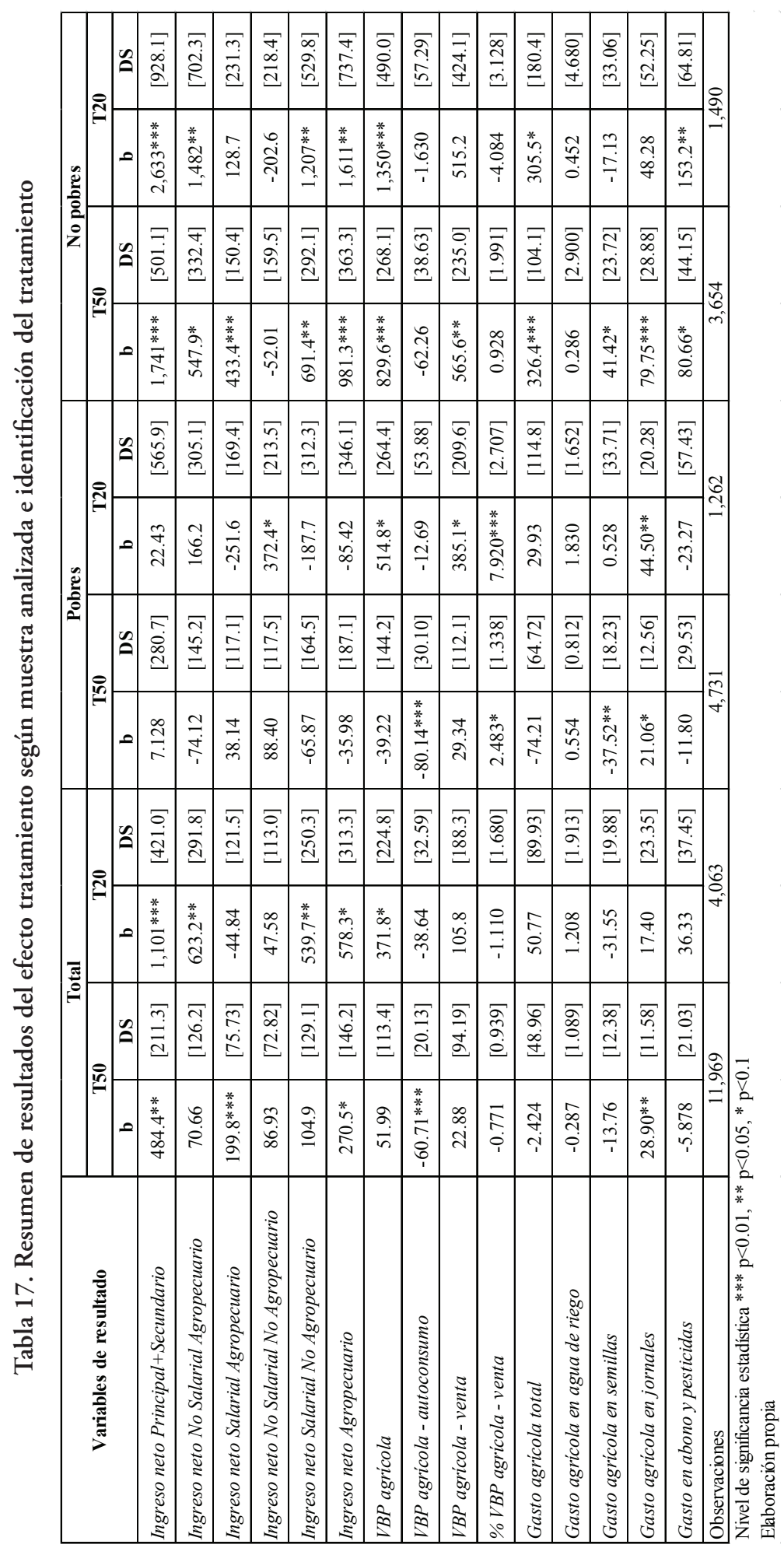




\section{CONCLUSIONES}

1. La primera hipótesis establece que un mayor gasto público en riego provoca un incremento del ingreso neto principal y secundario del hogar. Esta hipótesis se cumple para la muestra total y la muestra de hogares en distritos no pobres, con un nivel de confianza mayor al $1 \%$ para la identificación del tratamiento T50 y T20 (ver la Tabla 18). No obstante, esto no ocurre con los hogares en distritos pobres. Mayor gasto en riego tendría un efecto estadísticamente nulo en el ingreso neto principal y secundario de los hogares que residen en distritos con mayor porcentaje de pobres en el ańo 2007.

2. La segunda hipótesis plantea que el incremento de los ingresos se da por una recomposición del ingreso la cual depende de la restricción de autoconsumo del hogar. Según los resultados, los hogares en distritos no pobres se comportan como en el escenario sin restricciones de autoconsumo al incrementar el ingreso en actividades agropecuarias y no agropecuarias, mientras que los hogares en distritos pobres tienen un efecto similar al predicho por el escenario con restricción de autoconsumo, ya que el ingreso neto agropecuario no cambia, pero el ingreso neto no salarial no agropecuario aumenta significativamente para el tratamiento T20.

3. Los resultados distintos con respecto a la costa puede deberse a que la infraestructura de riego es necesaria, mas no suficiente para la adopción de tecnología que permita incrementar el rendimiento agrícola, aumentar el ingreso y, consecuentemente, reducir la pobreza. Esta infraestructura requiere de otros activos, públicos y privados, para potenciar la rentabilidad de esta inversión. Entonces, sin el acceso a esta infraestructura inicial, particularmente escasa en distritos con mayor incidencia de pobreza, el gasto en riego no tendría los efectos esperados en los ingresos del hogar. La diferencia en covariables presentada en la sección 5.1 sustenta este argumento.

4. Para el tratamiento T20 se encuentra efectos intermedios en los hogares en distritos pobres, tales como un incremento en el VBP agrícola del hogar y en la proporción que se destina a la venta. Este incremento puede estar explicado por una selección de cultivos más orientados al mercado y con un mayor valor.

5. Con respecto al cambio técnico y a la adopción de nuevas tecnologías, el gasto en riego no induce a un mayor gasto en semillas, pero en los hogares en distritos no pobres induce a un aumento en el gasto de abonos y pesticidas. Los hogares en distritos pobres solo experimentan un incremento del gasto del jornal, aunque sin que implique más gasto agrícola total (ver la Tabla 18). Si el gasto agrícola se mantiene fijo, esto se debe a que se redistribuye el presupuesto del hogar hacia el factor productivo cuyo costo se incrementa, de tal forma que se reduce 
la asignación a los otros componentes. De esta forma, en los hogares en distritos pobres se observa una ligera caída en el gasto en abonos y pesticidas y cambios ambiguos o nulos en el gasto en semillas. Claramente, para los hogares en distritos pobres el pago de jornales es un factor más relevante que el de semillas, abonos y pesticidas.

Tabla 18. Resumen de resultados según muestra analizada

\begin{tabular}{lccc}
\hline \multicolumn{1}{c}{ Variables de resultado } & Total & Pobres & No pobres \\
\hline Ingreso neto principal + secundario & ++ & + & ++ \\
Ingreso neto no salarial agropecuario & + & 0 & ++ \\
Ingreso neto salarial agropecuario & 0 & 0 & + \\
Ingreso neto no salarial no agropecuario & + & + & - \\
Ingreso neto salarial no agropecuario & + & - & ++ \\
Ingreso neto agropecuario & ++ & - & ++ \\
VBP agrícola & + & 0 & ++ \\
VBP agrícola - autoconsumo & - & - & - \\
VBP agrícola - venta & + & + & + \\
\% VBP agricola - venta & - & ++ & + \\
Gasto agrícola total & 0 & 0 & ++ \\
Gasto agricola en agua de riego & 0 & + & + \\
Gasto agricola en semillas & - & 0 & + \\
Gasto agricola en jornales & + & ++ & ++ \\
Gasto en abono y pesticidas & 0 & - & \\
\hline Notas: & & & - \\
\hline Coeficiente: & & Efecto positivo & Efecto negativo \\
\hline Dirección del efecto estadisticamente significativo & & ++ & -- \\
Dirección del efecto & & + & - \\
Sin impacto o efecto ambiguo & & & \\
\hline
\end{tabular}

\section{RECOMENDACIONES DE POLÍTICA}

1. Esta investigación ha significado un reto para evaluar los impactos de intervenciones que no fueron diseñadas para ser evaluadas, lo cual es usual en el sector público. Es necesario un mínimo de información para poder realizar evaluaciones retrospectivas: momento de la intervención y población beneficiada.

2. El primer paso consiste en definir la temporalidad de la intervención, teniendo claramente definido el punto de corte temporal desde el cual se puede esperar efectos observados en la población beneficiada. El segundo paso implica identificar los beneficiarios de la intervención. Al no contar con un padrón, la mejor opción es asociar los beneficiarios a un espacio determinado. El escenario ideal 
es contar con un área georreferenciada del ámbito de intervención. En caso no se cuente con esta información, es posible utilizar el registro de centros poblados que serían potencialmente beneficiados. Sin embargo, el SIAF no llega a este nivel de precisión, y la información de centros poblados beneficiados registrada en el SNIP no está sistematizada. Asimismo, existen proyectos genéricos que no pasan por el SNIP por lo que no cuentan con una ficha donde se liste los centros poblados que serán atendidos. En este sentido, la única información disponible para identificar potenciales beneficiarios es el distrito donde se interviene, registrado en el SIAF, con las limitaciones que esto implica.

3. Debido al tamaño de los distritos, es posible que el porcentaje de la población efectivamente beneficiada sea menor que si se identificara a nivel de centro poblado, o de un área de impacto acotada. Otra limitación se halla en el gasto multidistrital, el cual en el caso de esta investigación, representa el 18\% del gasto total, lo que, a pesar de estar vinculado a otro tipo de agricultura, de mayor escala y más comercial, podría afectar los resultados.

4. En este sentido, se recomienda plantear mejoras de corto y mediano plazo en los sistemas de información del sector público. Con respecto al SNIP, es necesaria la sistematización de los centros poblados que se registran como beneficiarios en cada ficha de proyecto. En una siguiente etapa, se debe exigir la georreferenciación de los proyectos de inversión pública nuevos que ingresen al SNIP. Por ejemplo, en el caso de los proyectos de riego, el trazo del canal, el polígono del reservorio y, de ser posible, el área potencial a ser irrigada. En esta etapa, se puede empezar por los proyectos financiados por fondos concursables como el Fondo para la Inclusión Económica en Zonas Rurales (Fonie) del Ministerio de Desarrollo e Inclusión Social; el Fondo de Promoción a la Inversión Pública Regional y Local (Foniprel) del MEF; y el Fondo de Promoción del Riego en la Sierra «Mi Riego» del Minagri. Esta información debería colocarse en un repositorio digital, de tal forma que la academia pueda acceder a ella y apoyar al sector público en la realización de estudios con recursos privados. La iniciativa del Consejo Nacional de Ciencia, Tecnología e Innovación Tecnológica (Concytec) de apoyar en el desarrollo de repositorios digitales de información generada con recursos públicos podría ser la plataforma para impulsar esta medida ${ }^{11}$.

5. Por otro lado, debido a la falta de información de capacidad de uso mayor del suelo para determinar las zonas con aptitud agrícola, es posible que se esté invirtiendo recursos públicos en proyectos de riego en áreas sin potencial agrícola.

${ }^{11}$ Concytec-Acceso Libre a Información Científica para la Innovación (ALICIA). Disponible en: http://alicia.concytec.gob.pe/vufind/ 
Se requiere de una actualización del mapa de capacidad de uso mayor, desarrollado por la Onern (1982) a inicios de la década de 1980, y mayor difusión de la información sobre aptitud de suelos agrarios generada por el Minagri a través de la Dirección General de Asuntos Ambientales Agrarios (DGAAA) ${ }^{12}$. La DGAAA, en coordinación con el Servicio Nacional de Meteorología e Hidrología del Perú (Senamhi), ha priorizado cerca de cuarenta distritos en la sierra del Perú para la realización de estudios de zonificación agroecológica en detalle (escala de 1:10 000) y otros estudios para apoyar en el diseño de intervenciones agropecuarias inteligentes, ya sea a través de los Gobiernos regionales y locales, así como las unidades ejecutoras del Minagri.

6. Los resultados observados del ejercicio econométrico muestran que el gasto en riego tiene un efecto positivo en los ingresos de los hogares localizados en distritos no pobres. Esto puede estar asociado a la desarticulación del gasto entre sectores. La inversión en infraestructura de riego es necesaria, pero requiere de infraestructura básica para que pueda rentabilizar los activos privados de la población. Por ejemplo, se requiere de infraestructura de servicios básicos de saneamiento y electrificación, así como infraestructura productiva, como caminos y terrazas, que complemente la inversión en riego.

7. Por otro lado, es preocupante el hecho de encontrar un impacto reducido en los hogares pobres en un indicador intermedio como el VBP agrícola, a pesar de un alto nivel de gasto en riego (T20). Asimismo, encontrar el mayor efecto en el ingreso de los hogares es en actividades salariales no agropecuarias, para el caso de los no pobres, y en actividades no salariales no agropecuarias, podría sugerir que la inversión en riego no es la inversión más idónea para este grupo poblacional. Por este motivo, se recomienda profundizar en los vínculos entre la estructura de ingresos de la población rural, en particular de los productores agropecuarios independientes de la sierra rural, junto con información sobre el potencial productivo de su entorno. De esta forma se podrá planificar y ejecutar intervenciones que tengan un mayor impacto marginal en sus ingresos totales y así reducir la incidencia de la pobreza rural.

12 Minagri-DGAAA. Disponible en: http://dgaaa.minag.gob.pe/. 


\section{ANEXO}

Tabla 19. Criterios de identificación del gasto en riego

\begin{tabular}{ccc}
\hline & \multicolumn{2}{c}{ Cadena funcional de gasto de PIP en riego } \\
\hline Función & Programa & Subprograma \\
\hline Agraria & Promoción de la producción agraria & Irrigación \\
Agropecuaria & Riego & $\begin{array}{c}\text { Infraestructura de riego } \\
\text { Riego tecnificado }\end{array}$ \\
Agropecuaria & Riego & Irrigación \\
& Palabras clave para la identificación de gasto en riego \\
\hline Ribereña & Presa & Hidráulica \\
Represa & Riego & Bocatoma \\
Reservorio & Pozo & Conducción \\
Captación & Aspersión & \\
\hline & Palabras clave de exclusión & Estudio \\
Potable & Carretera & Exploración \\
Gestión & Camino & Salud \\
Información & Alcantarillado &
\end{tabular}

Fuente: SNIP y SIAF. Elaboración propia. 


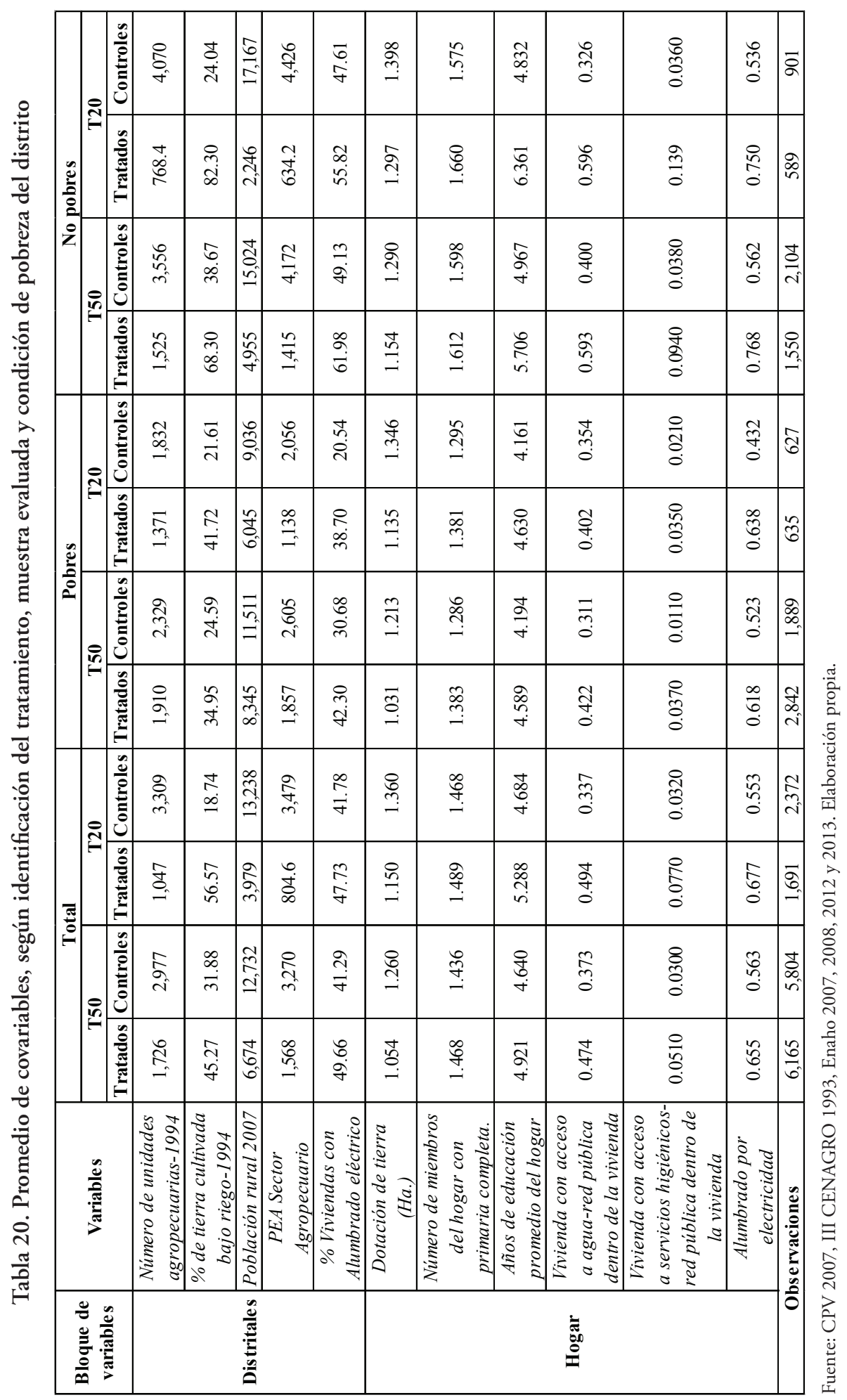




\begin{tabular}{|c|c|c|c|c|c|c|c|c|c|c|c|c|c|c|c|c|c|}
\hline 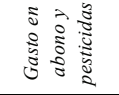 & 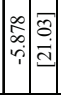 & 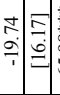 & 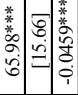 & 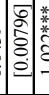 & 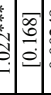 & 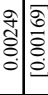 & 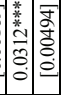 & 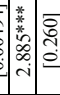 & 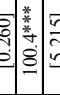 & â. & 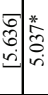 & i & 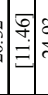 & & . & & \\
\hline 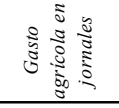 & 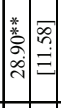 & 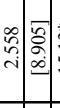 & 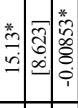 & $\left(\begin{array}{lll}0 \\
0 \\
0 \\
0 \\
0\end{array}\right.$ & $\begin{array}{l}0 \\
0 \\
0 \\
0 \\
0 \\
0 \\
0\end{array}$ & : & 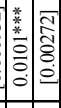 & {$\left[\begin{array}{ll}0 \\
0 \\
0 \\
0 \\
0 \\
0\end{array}\right.$} & 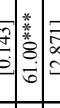 & is & 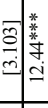 & 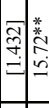 & & & 象 & & \\
\hline 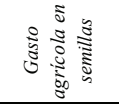 & 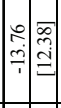 & 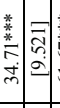 & 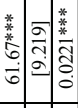 & $\left(\begin{array}{ll}0 \\
0 \\
0 \\
0 \\
0 \\
0\end{array}\right.$ & 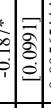 & 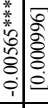 & $\left(\begin{array}{ll}* \\
0 \\
0 \\
0 \\
0 \\
0 \\
0 \\
0\end{array}\right.$ & 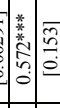 & : & 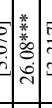 & 를 & $\stackrel{n}{=}$ & & & 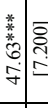 & & \\
\hline 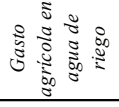 & 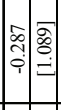 & & 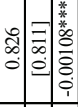 & $\left(\begin{array}{lll}3 \\
0 \\
0\end{array}\right.$ & 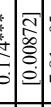 & 党 & & 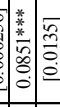 & 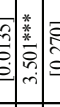 & $=0$ & 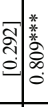 & 司旅 & & & 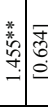 & & \\
\hline 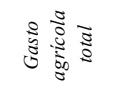 & 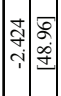 & & 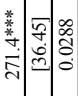 & 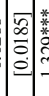 & c. & 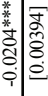 & 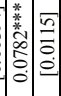 & : & 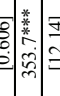 & 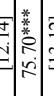 & تָ & "ृ: & 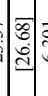 & & $\overbrace{}^{\infty}$ & 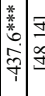 & \\
\hline 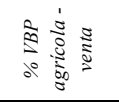 & \begin{tabular}{|c|c|c|} 
& 0 \\
0 & 0 \\
0 & 0 \\
0 & 0 \\
0
\end{tabular} & . & 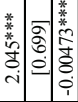 & 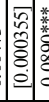 & 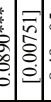 & 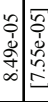 & 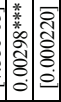 & 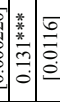 & $\dot{b}:=0$ & $=$ & 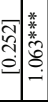 & 월 & : & & & 5 & \\
\hline 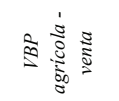 & 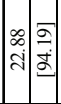 & & 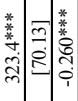 & {$\left[\begin{array}{lll}* \\
0 \\
0 \\
0\end{array}\right.$} & $\stackrel{0}{:}$ & 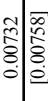 & $\left(\begin{array}{lll}* \\
0 \\
0 \\
0\end{array}\right.$ & $\stackrel{4}{*}$ & $\overbrace{}^{\infty}$ & 3 & 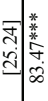 & 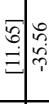 & & & & 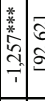 & \\
\hline 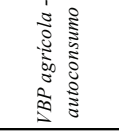 & 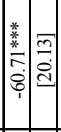 & 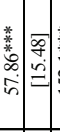 & 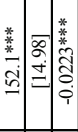 & $\begin{array}{l}0 \\
0 \\
0 \\
0 \\
0\end{array}$ & $:=$ & 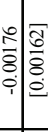 & & & & 国絭 & 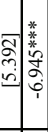 & $\mid$ & 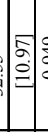 & & & & \\
\hline 产 & के & 守 & 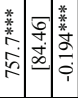 & 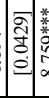 & 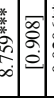 & 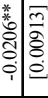 & 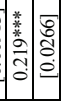 & 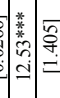 & 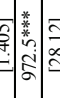 & 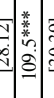 & ç & 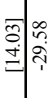 & & & 它 & $\frac{5}{3}$ & \\
\hline 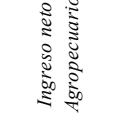 & 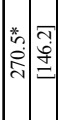 & & 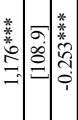 & $\left(\begin{array}{lll}n \\
\vdots \\
\vdots \\
\vdots \\
\vdots \\
\vdots\end{array}\right.$ & : & & & & & : & 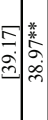 & {$\left[\begin{array}{c}0 \\
0 \\
0\end{array}\right]$} & & & & & \\
\hline 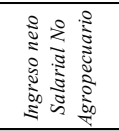 & : & & î & 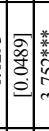 & 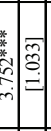 & 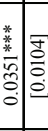 & & $\begin{array}{l}* \\
* \\
*\end{array}$ & & : & ר్ & 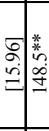 & 急 & & & & \\
\hline 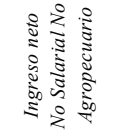 & 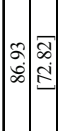 & ง. & 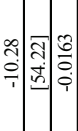 & 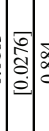 & 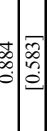 & & & : & 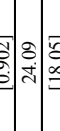 & 军: & 昰粪 & 毫 & 类 & & 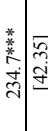 & & \\
\hline 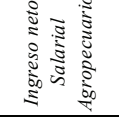 & 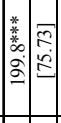 & $\infty$ & 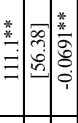 & 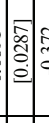 & 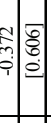 & : & $\left(\begin{array}{l}0 \\
0 \\
0 \\
0 \\
0\end{array}\right.$ & 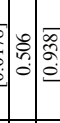 & 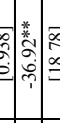 & 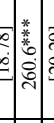 & 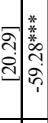 & 㕝 & 馬 & & & 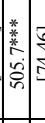 & \\
\hline 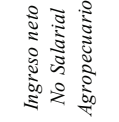 & 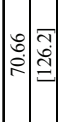 & 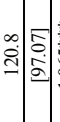 & 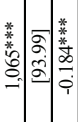 & $\left(\begin{array}{lll}\infty \\
0 \\
0 \\
0 \\
0\end{array}\right.$ & $\stackrel{*}{*}:=$ & 絭萦 & $\mid \begin{array}{lll}0 & 0 \\
0 & 0 \\
0 & 0 \\
0\end{array}$ & 絭絭 & : & 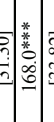 & 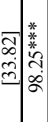 & 可 & 象 & & 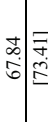 & & \\
\hline 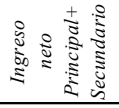 & 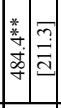 & 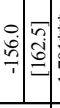 & 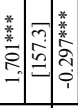 & 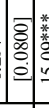 & : & * & 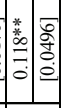 & 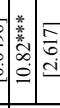 & 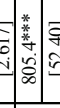 & 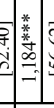 & 类 & 国䊁 & 赵 & 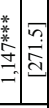 & 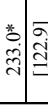 & 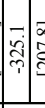 & \\
\hline 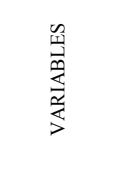 & 产 & 80 & 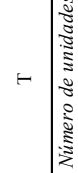 & ปู่ & 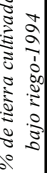 & है & 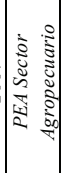 & 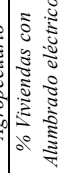 & 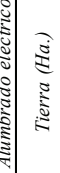 & 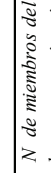 & 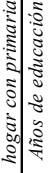 & 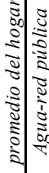 & 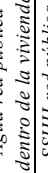 & |ै। & 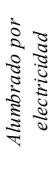 & 气ू & \\
\hline
\end{tabular}




\begin{tabular}{|c|c|c|c|c|c|c|c|c|c|c|c|c|c|c|c|c|c|c|c|}
\hline 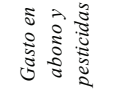 & 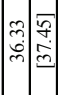 & & 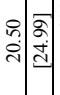 & 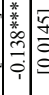 & 要 & 闹 & 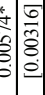 & 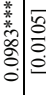 & & 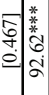 & & & 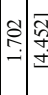 & 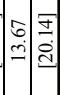 & 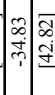 & 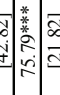 & & & \\
\hline 竎 & & 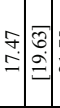 & 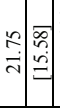 & 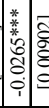 & aี & : & : & & & 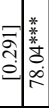 & 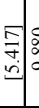 & : & 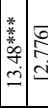 & 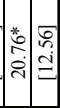 & 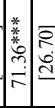 & 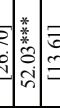 & 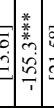 & & \\
\hline 竎 & 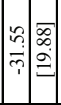 & & 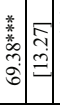 & 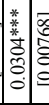 & : & 可 & : & \begin{tabular}{c}
0 \\
\hdashline \\
0
\end{tabular} & & 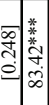 & 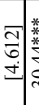 & 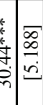 & 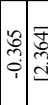 & $=$ & $=\mathbb{d}$ & 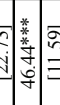 & 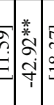 & 旤 & \\
\hline 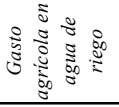 & 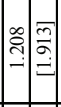 & & : & 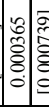 & 类 & 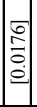 & 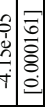 & & 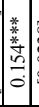 & 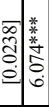 & 索 & 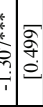 & $\mid \begin{array}{c}0 \\
0 \\
0 \\
0 \\
0\end{array}$ & & i & $\stackrel{0}{0.0}$ & & & \\
\hline 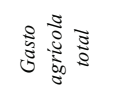 & 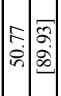 & 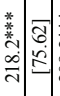 & 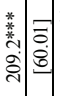 & 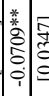 & : & 旅 & 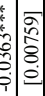 & & 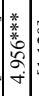 & 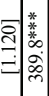 & 矛 & : & $\begin{array}{ll}* \\
0 \\
0 \\
0\end{array}$ & & & 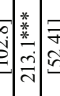 & & $\exists$ & \\
\hline 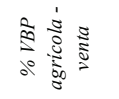 & 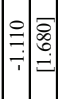 & 絭 & त्ञ & & & 氖 & 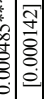 & & & 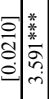 & & 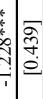 & 絭 & 1 & $1=$ & 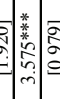 & & : & \\
\hline 彦 & 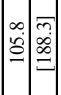 & 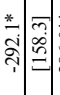 & 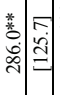 & 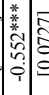 & & 吕 & & & 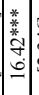 & 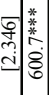 & 字 & : & 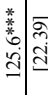 & & 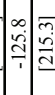 & 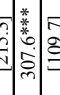 & & 辛 & \\
\hline 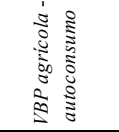 & 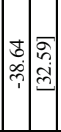 & & $\stackrel{\Delta}{\vec{\Delta}}$ & : & & 恿 & & & 9 & 类 & 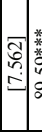 & 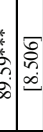 & $\mid$ & & 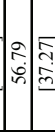 & 或烍 & & 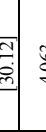 & \\
\hline 气. & 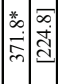 & 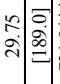 & 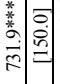 & & 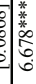 & 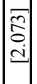 & : & & $\mid$ & 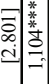 & & 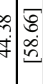 & 絭 & & 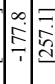 & $\hat{a}$ & & . & \\
\hline 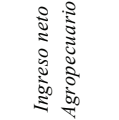 & 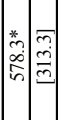 & 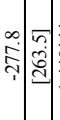 & 密 & & & 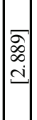 & & & 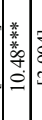 & 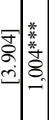 & : & & 葩 & f̀ & $\Rightarrow \begin{array}{l}m \\
\infty \\
0 \\
0\end{array}$ & $\hat{0}$ & & 赵 & \\
\hline 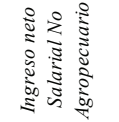 & 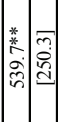 & & 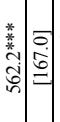 & & & : & & & & \begin{tabular}{lll}
0 \\
\hdashline \\
\hdashline \\
\hdashline
\end{tabular} & $\mid \begin{array}{c}0 \\
0 \\
0 \\
0 \\
0 \\
0 \\
0\end{array}$ & & & & 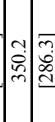 & : & & ב্ב & \\
\hline 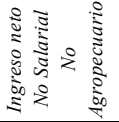 & 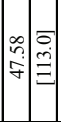 & 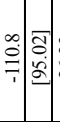 & 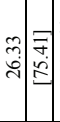 & & & 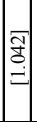 & & & 差 & 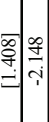 & $=$ & 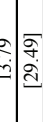 & 曾 & & 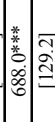 & 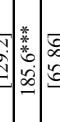 & & 吾 & \\
\hline 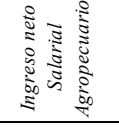 & 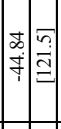 & $\begin{array}{lll}* & 7 \\
0 \\
0\end{array}$ & 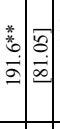 & & : & : & డ్రి & & | & $=$ & 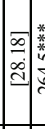 & : & 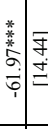 & 0 & 帘 & 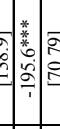 & & בֶ: & \\
\hline 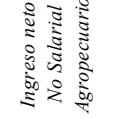 & 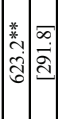 & $m$ & 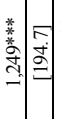 & & 8 & is & & & तु & 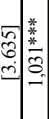 & 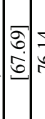 & $\therefore$ & 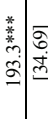 & 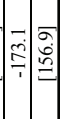 & 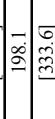 & $\begin{array}{l}0 \\
0 \\
0 \\
0\end{array}$ & & 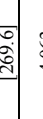 & 8 \\
\hline 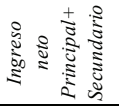 & 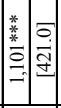 & 䊒: & 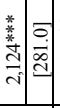 & 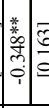 & 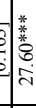 & $\left|\begin{array}{l}\overrightarrow{0} \\
0 \\
0 \\
0\end{array}\right|$ & 8 & $\approx$ & 絭 & 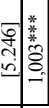 & 图 & : & 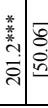 & 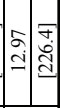 & 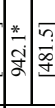 & ầ & $\begin{array}{c}* \\
\vdots \\
0\end{array}$ & $\overrightarrow{:}$ & 8 \\
\hline 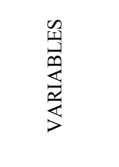 & 产 & ఫ్రి & $r$ & 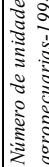 & : & 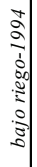 & 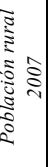 & "ूँ & 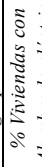 & 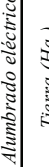 & 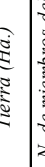 & 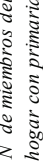 & 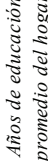 & 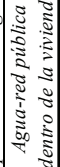 & 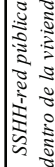 & 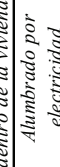 & 气ึ & & \\
\hline
\end{tabular}




\begin{tabular}{|c|c|c|c|c|c|c|c|c|c|c|c|c|c|c|c|c|c|c|}
\hline 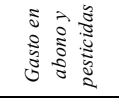 & 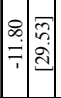 & 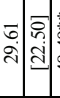 & 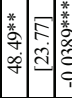 & 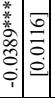 & 絭 & 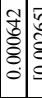 & & 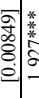 & 의 & & & & & : & & $\infty$ & 桲 & $\vec{f}$ \\
\hline 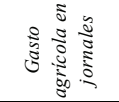 & 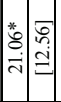 & 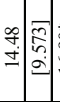 & $=0$ & 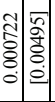 & 事 & & & 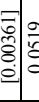 & 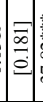 & & & & & 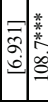 & & & 䊁: & \\
\hline 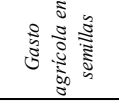 & 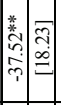 & 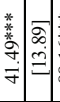 & 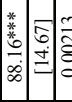 & 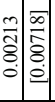 & 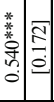 & & & : & 旅 & 苛 & & : & ป̂. & $\left.\begin{array}{ll}0 \\
0 \\
0\end{array}\right)$ & & 象是 & 类 & f \\
\hline 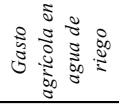 & 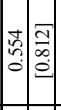 & 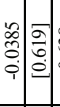 & 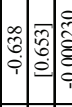 & 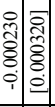 & 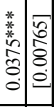 & $\left.\begin{array}{ccc}0 & 0 \\
0 & 0\end{array}\right]$ & & : & . & & & & : & 象 & & త్ & 絭: & $\vec{c}$ \\
\hline 宽 & 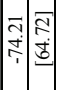 & 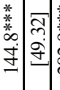 & 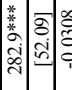 & 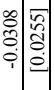 & 絭: & 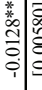 & 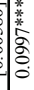 & \begin{tabular}{c}
$:$ \\
\hdashline
\end{tabular} & $\dot{\theta}$ & 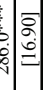 & & & 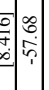 & : & & 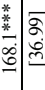 & 氕 & $\begin{array}{l}\overrightarrow{\mathrm{m}} \\
\mathrm{f}\end{array}$ \\
\hline 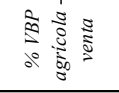 & 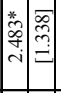 & 絭: & 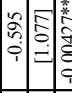 & 密 & 表: & 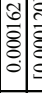 & & ஜః" & 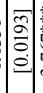 & 0 & & & : & 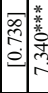 & & مُ & : & $\mid \begin{array}{l}a \\
a \\
f\end{array}$ \\
\hline 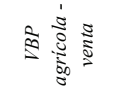 & 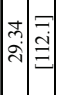 & 美: & 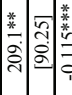 & 絭: & & 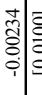 & & $\bar{\partial}$ & 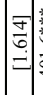 & 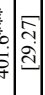 & & & & 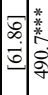 & & ते & : & $\begin{array}{l}\vec{m} \\
\stackrel{f}{f}\end{array}$ \\
\hline 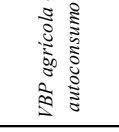 & 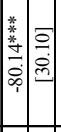 & 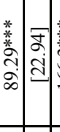 & 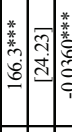 & 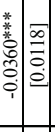 & & & & & ?̂. & & & & & 可 & & $m$ & 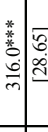 & $\vec{m}$ \\
\hline ) & 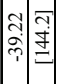 & 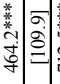 & 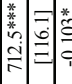 & 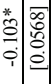 & & 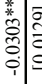 & & & 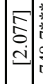 & 年 & & & $\frac{0}{0}$ & 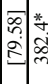 & & D. & 絭 & $\overrightarrow{\substack{f \\
f}}$ \\
\hline 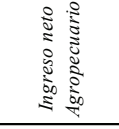 & 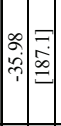 & $\begin{array}{l}\exists \\
\dot{J}\end{array}$ & 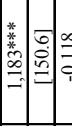 & 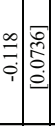 & & & & & $\sqrt{3}$ & 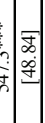 & & 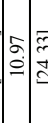 & 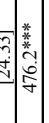 & $\begin{array}{l}\pi \\
\infty \\
2\end{array}$ & & 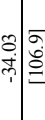 & a & $\vec{c}$ \\
\hline 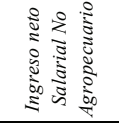 & $\begin{array}{lll}0 & \\
0 & 0 \\
0 & 0 \\
0 & 0 \\
0 & 0\end{array}$ & 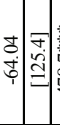 & 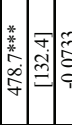 & : & 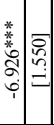 & 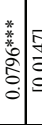 & & & & 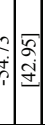 & & & 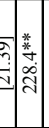 & $\begin{array}{ll}1 \\
\vdots \\
\vdots\end{array}$ & & & 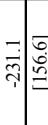 & $\begin{array}{l}\overrightarrow{\vec{f}} \\
\vec{f}\end{array}$ \\
\hline 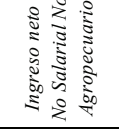 & 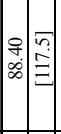 & 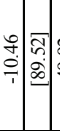 & $\dot{\vec{g}}$ & : & & & & & & & & & 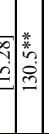 & 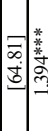 & & فे & & $\overrightarrow{\tilde{f}}$ \\
\hline 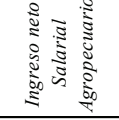 & $\stackrel{\square}{\Rightarrow}=$ & 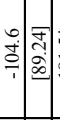 & 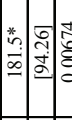 & 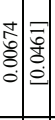 & 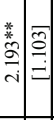 & : & & & : & & & 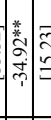 & 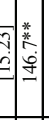 & 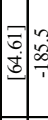 & & 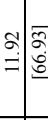 & 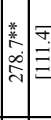 & $\begin{array}{l}\overrightarrow{\tilde{f}} \\
\dot{f}\end{array}$ \\
\hline 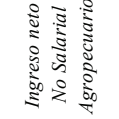 & 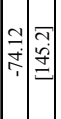 & 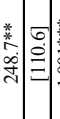 & 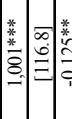 & 资: & 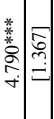 & 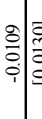 & & & & & & 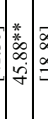 & 0 & 包 & & & 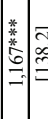 & \begin{tabular}{|l}
$\overrightarrow{\tilde{f}}$ \\
$\vec{f}$
\end{tabular} \\
\hline 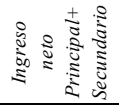 & 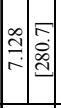 & 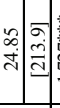 & $=\sqrt{9}$ & : & $\stackrel{\vec{f}}{\overrightarrow{8}}$ & $\frac{4}{\frac{*}{3}}$ & & 3 & 永 & D & : & {$\left[\begin{array}{lll}a \\
g \\
g\end{array}\right.$} & 实 & 粪 & & 1 & : & $\begin{array}{l}\overrightarrow{\mathrm{r}} \\
\stackrel{f}{f}\end{array}$ \\
\hline 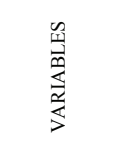 & 空 & 5 & • & 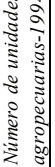 & 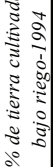 & : & 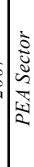 & 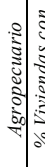 & $\mid$ & 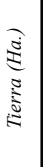 & 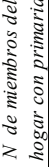 & 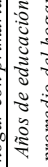 & 竎 & 资 & & ปัँّ & $\approx$ & 总总 \\
\hline
\end{tabular}




\begin{tabular}{|c|c|c|c|c|c|c|c|c|c|c|c|c|c|c|c|c|c|c|}
\hline 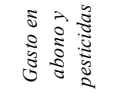 & 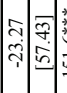 & & ț. & 恶: & 絭 & & 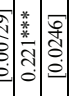 & 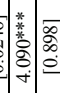 & 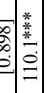 & & & 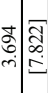 & & de & & 茪 & 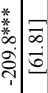 & \\
\hline 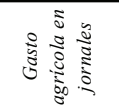 & 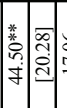 & & 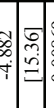 & 资: & 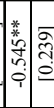 & 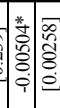 & 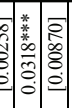 & : & & & & & & & & $\exists$ & 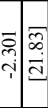 & \\
\hline 范 & 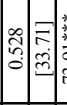 & & : & \begin{tabular}{ll}
0 \\
0 \\
0 \\
\hdashline
\end{tabular} & : & 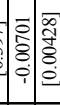 & 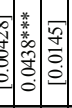 & : & 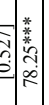 & & 2 & & ? & & ؛ํ. & ले & 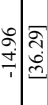 & త్ర \\
\hline 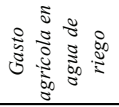 & 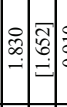 & & ד. & 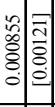 & 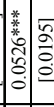 & 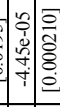 & : & 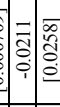 & & & & & 0 & & c) & \pm & 宓 & ్ㅡㅁ \\
\hline 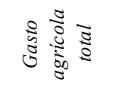 & 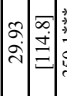 & ำ & $=$ & 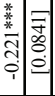 & 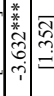 & 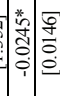 & 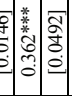 & 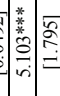 & 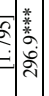 & & $\hat{0}$ & & 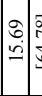 & & & ปึ) & * & ণ్ర \\
\hline 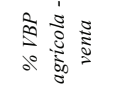 & 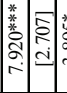 & 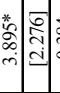 & 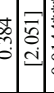 & 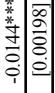 & 表方 & 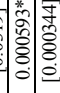 & : & 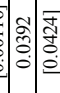 & 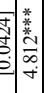 & : & 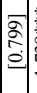 & 桲 & 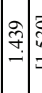 & $-i$ & 4 & శ్ & 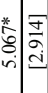 & : \\
\hline 悉 & 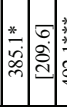 & 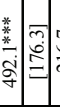 & 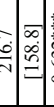 & 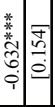 & 粒 & 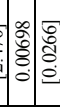 & $\therefore$ & $\hat{n}$ & 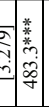 & 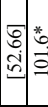 & : & & iे & $\stackrel{\infty}{\Phi}$ & & : & 类 & ב్ \\
\hline 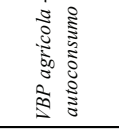 & & $\exists$ & 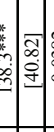 & 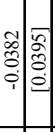 & & : & & & & & & : & & & & & 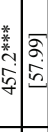 & $\underset{\Im}{\widetilde{I}}$ \\
\hline 产 & 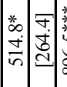 & & 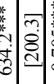 & 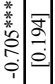 & & & 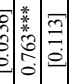 & & 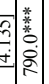 & & 矛 & & $\Leftrightarrow$ & & & & 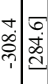 & త్ \\
\hline 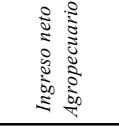 & 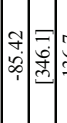 & $\cong$ & 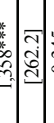 & 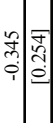 & & & & & 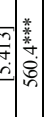 & & $\mid$ & & & & 告 & & 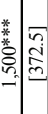 & త్త \\
\hline 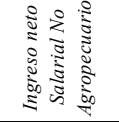 & 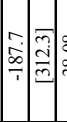 & $\infty$ & : & : & & & & & 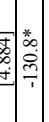 & & 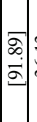 & 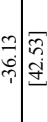 & & 象题 & & & ఫิ่ & త్త \\
\hline 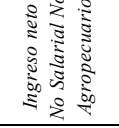 & 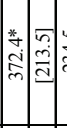 & ำ & $f$ & 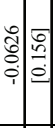 & & & & 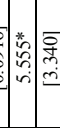 & 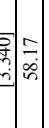 & & 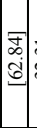 & & & 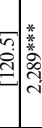 & & & *. & త్త్త \\
\hline 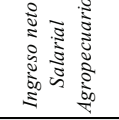 & 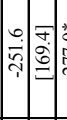 & 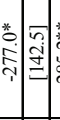 & (c) & 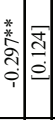 & & 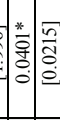 & & 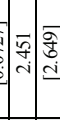 & $\stackrel{d}{a}$ & 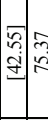 & $\mid \begin{array}{l}\overline{0} \\
0 \\
\dot{q} \\
\end{array}$ & $\stackrel{5}{\approx}$ & & & & & 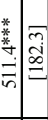 & 엄 \\
\hline 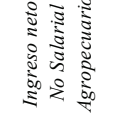 & $\begin{array}{ll}a \\
0 \\
0 \\
0\end{array}$ & 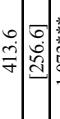 & 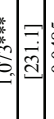 & 究 & $\left(\begin{array}{c}2 \\
\hdashline \\
\hdashline\end{array}\right.$ & 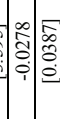 & & 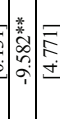 & 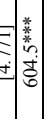 & & $\begin{array}{l}1 \\
\vdots \\
0 \\
0\end{array}$ & & & 킹ำ & $\frac{\sqrt[a]{q}}{\mathfrak{d}}$ & & 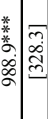 & త్ర \\
\hline 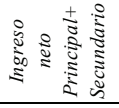 & 学 & 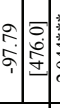 & 全 & 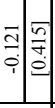 & 00 & 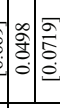 & 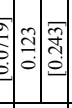 & 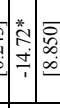 & 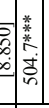 & 窇 & . & $=$ & 1 & 表: & & & 它宫 & ్ㅗㅁ \\
\hline 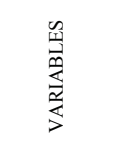 & 矛 & ఫ్తి & $r$ & | & 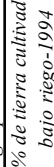 & 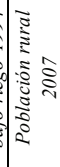 & 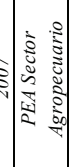 & 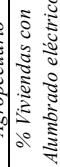 & | & 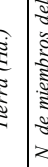 & . & 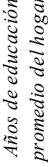 & $\mid$ & $\begin{array}{l}3 \\
3 \\
8 \\
8 \\
0\end{array}$ & & 8 & 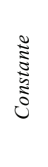 & \begin{tabular}{|l}
0 \\
0 \\
0 \\
0
\end{tabular} \\
\hline
\end{tabular}




\begin{tabular}{|c|c|c|c|c|c|c|c|c|c|c|c|c|c|c|c|c|c|c|}
\hline 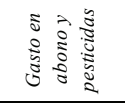 & : & 究 & & 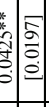 & 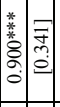 & & : & 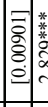 & 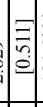 & & & : & $\left(\begin{array}{l}0 \\
\vdots \\
\dot{a}\end{array}\right.$ & 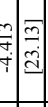 & 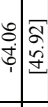 & 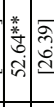 & 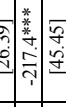 & 芯 \\
\hline 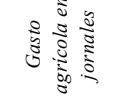 & 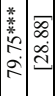 & & & : & 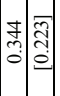 & & 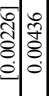 & 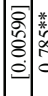 & ? & 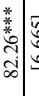 & & 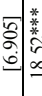 & : & 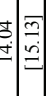 & $=$ & 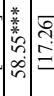 & 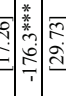 & 芯 \\
\hline 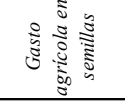 & 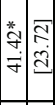 & 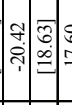 & $=0$ & $\begin{array}{ll}0 \\
0 \\
0 \\
0 \\
0 \\
0 \\
0 \\
0 \\
0\end{array}$ & 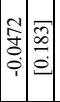 & & 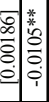 & 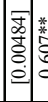 & : & 这 & 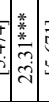 & 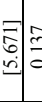 & : & $=\sqrt{a}$ & 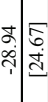 & $\left(\frac{*}{*}\right.$ & 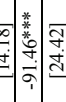 & 芯 \\
\hline 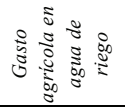 & 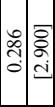 & 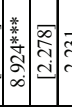 & : & 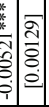 & 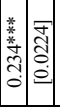 & & 宓 & & : & 粪 & $\left(\begin{array}{lll}0 \\
\vdots \\
i\end{array}\right.$ & 类 & : & : & نُ & 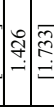 & 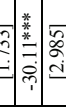 & 范 \\
\hline 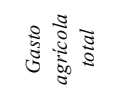 & 美 & 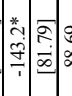 & & 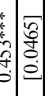 & 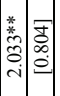 & 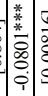 & |con & & : & 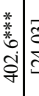 & : & 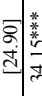 & : & 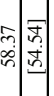 & ন & 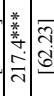 & & 密 \\
\hline 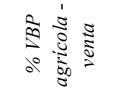 & : & 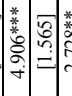 & iv & 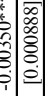 & & & : & & 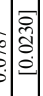 & & & 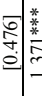 & 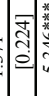 & 悉 & & 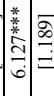 & & f \\
\hline 产 & 类: & $=0$ & ì & 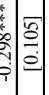 & 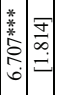 & 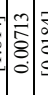 & 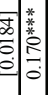 & 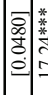 & 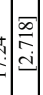 & & 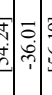 & 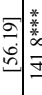 & : & $=$ & 粶 & 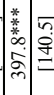 & 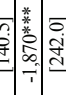 & 苦 \\
\hline 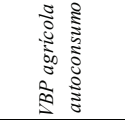 & |c: & 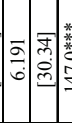 & 可过: & ? & & & 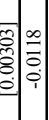 & & 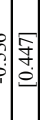 & & & 命 & 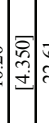 & 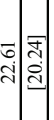 & $\rightarrow$ i & 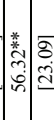 & 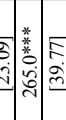 & 范 \\
\hline 产 & 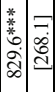 & 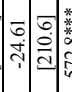 & & : & 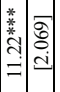 & & : & & & : & & 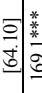 & $\frac{2}{0}$ & : & 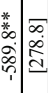 & 䊎 & 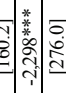 & 范 \\
\hline 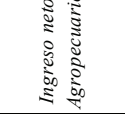 & 曾: & ज्ञ & & 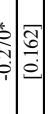 & $\dot{\mathrm{u}}$ & & $\stackrel{\circ}{0}$ & & & $=$ & : & 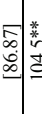 & 字 & 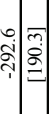 & ㄱำ & $6 \mid \frac{6}{2}$ & & 范 \\
\hline 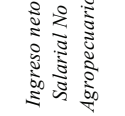 & 絭 & & & : & 齐 & & & & & & & & $\begin{array}{ll}\vec{\alpha} \\
0 \\
0\end{array}$ & & 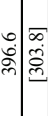 & $\stackrel{ \pm}{=}$ & 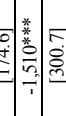 & 落 \\
\hline 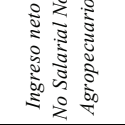 & 至 & 童 & : & 资: & 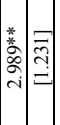 & & $\therefore$ & & & & & 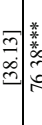 & 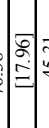 & $\vec{f}$ & 絭絭 & 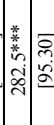 & & 范 \\
\hline 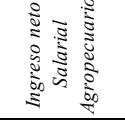 & 絭索 & 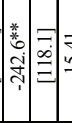 & 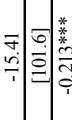 & \begin{tabular}{c} 
: \\
\hdashline
\end{tabular} & 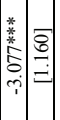 & & 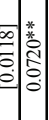 & 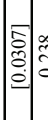 & & 莡 & 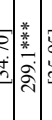 & 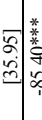 & : & 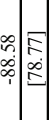 & 党 & 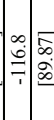 & & 菏 \\
\hline 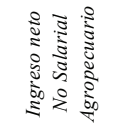 & 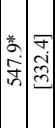 & : & $=$ & :i: & 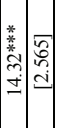 & & 4 & 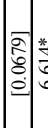 & $\begin{array}{l}0 \\
0 \\
0\end{array}$ & & & 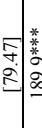 & ?ân & 帘: & \begin{tabular}{l|l} 
ते \\
ते̀
\end{tabular} & & & 荡 \\
\hline 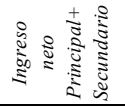 & $=$ & त्ञ & 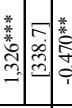 & 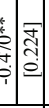 & 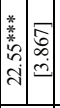 & 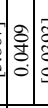 & 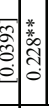 & 粗 & 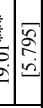 & 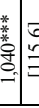 & : & 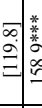 & 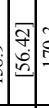 & \begin{tabular}{c}
1 \\
\hdashline \\
\hdashline
\end{tabular} & : & 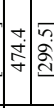 & 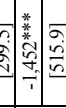 & $\exists$ \\
\hline 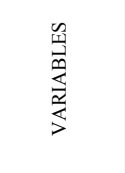 & 言 & हิ & 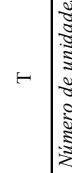 & 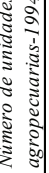 & 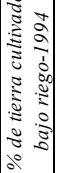 & 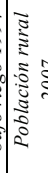 & 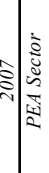 & : & 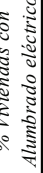 & 胥 & 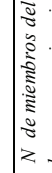 & 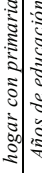 & 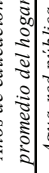 & 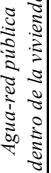 & 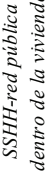 & 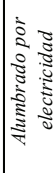 & 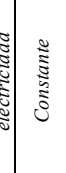 & 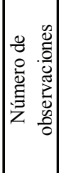 \\
\hline
\end{tabular}




\begin{tabular}{|c|c|c|c|c|c|c|c|c|c|c|c|c|c|c|c|c|c|c|}
\hline 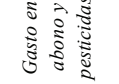 & 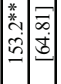 & & $\sqrt{2}$ & 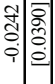 & 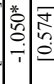 & & 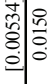 & : & 2 & & 草 & 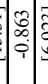 & : & స్ & | & & 垈 & $\underset{\&}{\stackrel{g}{G}}$ \\
\hline 竎 & 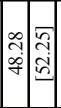 & & 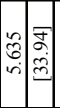 & : & 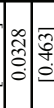 & 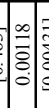 & 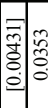 & : & : & & & & 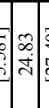 & 矛旅 & $\mid$ & & 勿 & $\underset{f}{\stackrel{8}{q}}$ \\
\hline 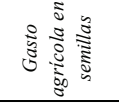 & \begin{tabular}{cc}
0 \\
\hdashline \\
\end{tabular} & & 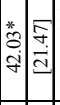 & 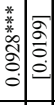 & 善 & 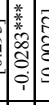 & 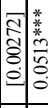 & a & : & 絭: & $\mid \begin{array}{lll}0 \\
0\end{array}$ & & $\hat{a}$ & 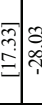 & : & & : & $\underset{g}{\stackrel{g}{G}}$ \\
\hline 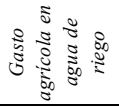 & 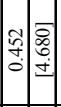 & & {$\left[\begin{array}{ccc}0 \\
0 \\
0\end{array}\right]$} & 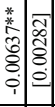 & 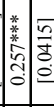 & 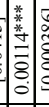 & 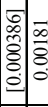 & : & : & $\stackrel{\text { o. }}{=}$ & & & $0^{\infty}$ & : & 等 & & $\begin{array}{l}\text { : } \\
\bar{f} \\
\dot{ \pm} \\
\end{array}$ & $\underset{g}{\stackrel{g}{-}}$ \\
\hline 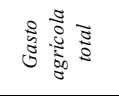 & 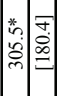 & & 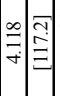 & 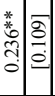 & $\underset{\substack{\infty \\
\hdashline}}{\substack{\infty \\
\hdashline}}$ & 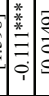 & 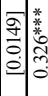 & $=$ & : & 絭类 & & & 因絭 & : & $=$ & & 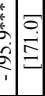 & $\underset{d}{\stackrel{g}{g}}$ \\
\hline 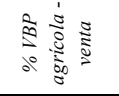 & 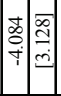 & & 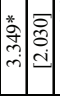 & 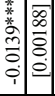 & 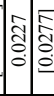 & 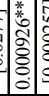 & & 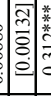 & 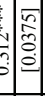 & 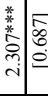 & & & : & 勇: & $\left|\begin{array}{l}a \\
\vec{d} \\
\vec{i}\end{array}\right|$ & & 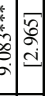 & $\stackrel{\infty}{\stackrel{\leftrightarrow}{-}}$ \\
\hline 离 & 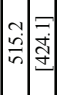 & 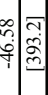 & $\stackrel{\infty}{\infty}\left[\begin{array}{c}a \\
0\end{array}\right]$ & 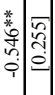 & 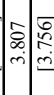 & $\int_{0}^{\infty}$ & 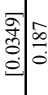 & 气 & 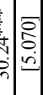 & & & & 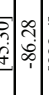 & 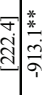 & aิ่ & & 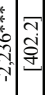 & $\underset{\sim}{\stackrel{g}{g}}$ \\
\hline 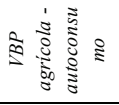 & : & \begin{tabular}{c}
0 \\
\hdashline \\
\hdashline
\end{tabular} & \begin{tabular}{l|l}
$*$ \\
0 \\
0 \\
0 \\
0 \\
0 \\
0
\end{tabular} & 畧 & 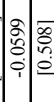 & 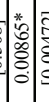 & 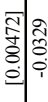 & 䧽: & 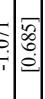 & : & & & $\vec{m}$ & 守 & 㿣 & & $\begin{array}{c}c \\
\vdots \\
\vdots\end{array}$ & $\underset{d}{\stackrel{g}{a}}$ \\
\hline 产 & 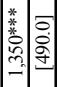 & & 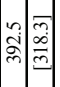 & : & & $\left(\begin{array}{c}* \\
0 \\
0 \\
0 \\
\hdashline \\
\hdashline\end{array}\right.$ & & : & 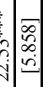 & 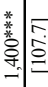 & & & : & . & $\left(\begin{array}{c}0 \\
0 \\
0 \\
0\end{array}\right.$ & & 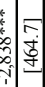 & $\underset{g}{\stackrel{g}{g}}$ \\
\hline 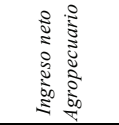 & 粷 & 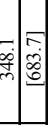 & 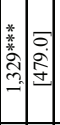 & 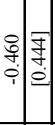 & $\frac{7}{2}$ & & & $=2$ & 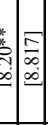 & & & & & कृ & | & & : & of \\
\hline 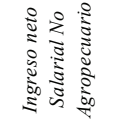 & 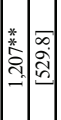 & & 点 & 党 & & & & : & & & 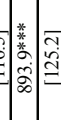 & & & 氞要学 & & & 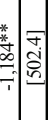 & $\stackrel{8}{\stackrel{g}{a}}$ \\
\hline 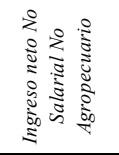 & 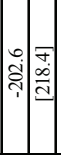 & & 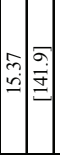 & 㐫 & & & & & & 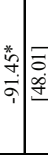 & & & 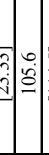 & 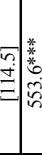 & & & 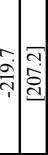 & $\stackrel{8}{\stackrel{8}{9}}$ \\
\hline 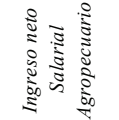 & : & & مُ & 类 & 絭 & & & & & & & & & & & & 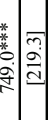 & $\stackrel{8}{g}$ \\
\hline 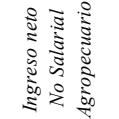 & 絭 & & 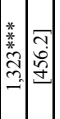 & 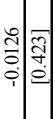 & 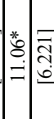 & & & 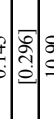 & 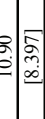 & & fे & 粪 & 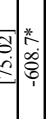 & 䍒: & $\sqrt{6}$ & & | & $\underset{g}{\stackrel{g}{g}}$ \\
\hline 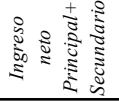 & 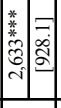 & - & : & : & 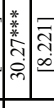 & $\left(\begin{array}{ccc}0 \\
0 \\
0 \\
0\end{array}\right.$ & $\left.\mid \begin{array}{c}1 \\
0 \\
0 \\
0 \\
0\end{array}\right]$ & 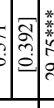 & : & 类事 & 事 & 絭 & $\theta$ & \& & 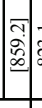 & & $\begin{array}{lll}* & \\
0 \\
0\end{array}$ & $\underset{g}{\stackrel{g}{g}}$ \\
\hline 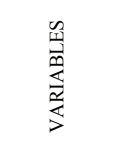 & 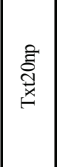 & ज्ञे & $r$ & 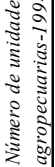 & 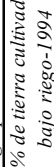 & 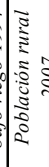 & จิ & : & 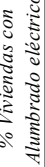 & 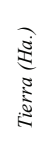 & 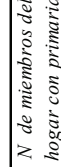 & 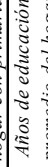 & 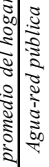 & 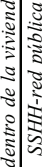 & 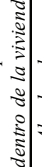 & : & है & 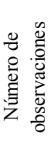 \\
\hline
\end{tabular}




\section{REFERENCIAS BIBLIOGRÁFICAS}

Alfaro, Julio César (1997). Viabilidad de la pequeña agricultura y la política agraria 1990-1996. En Pequeña agricultura en el Perú: Presente y futuro. Proyecto de Apoyo a ONGs-PACTPerú. 11-77.

Baca, E. (1998). La experiencia del Plan MERISS/INKA. Debate Agrario, 28, 55-83. Lima, Perú: Cepes.

BID y CIES (2011). Perú: Atlas de la pobreza. Lima, Perú.

Billor, N., A. Hadi y P. Velleman (2000). BACON: Blocked adaptive computationally efficient outlier nominators. Computational Statistics \& Data Analysis, 34, 279-298. https://doi. org/10.1016/S0167-9473(99)00101-2

Blundell, R. y M. Costa Dias (2000). Evaluation methods for non-experimental data. Fiscal Studies, 21(4), 427-468. https://doi.org/10.1111/j.1475-5890.2000.tb00031.x

Del Carpio, X., N. Loayza y G. Datar (2011). Is Irrigation Rehabilitation Good for Poor Farmers? An Impact Evaluation of a Non-Experimental Irrigation Project in Peru. Journal of Agricultural Economics, 62( 2), 449-473. https://doi.org/10.1111/j.1477-9552.2011.00295.x

Duflo, E. y R. Pande (2007). Dams. The Quarterly Journal of Economics, 122(2), 601-646.

Escobal, J. (2005). The role of public infraestructure in market development in rural Peru. PhD Thesis. Wageningen: Wageningen Universiteit.

Escobal, J. (2008). Estrategias de generación de ingresos en las áreas rurales: la evidencia de las ENAHO 2002-2007. En Una mirada a la evolución de la pobreza en el Perú: avances y desafíos (pp. 87-121). Washington DC: Banco Mundial.

Escobal, J. y Ponce, C. (2002). El beneficio de los caminos rurales: ampliando oportunidades de ingreso para los pobres. Documento de Trabajo 40. Lima, Perú: Grade.

Escobal, J. y M. Torero (2000). ¿Cómo enfrentar una geografía adversa? El rol de los activos públicos y privados. Documento de Trabajo 29. Lima, Perú: Grade.

Escobal, J., J. Saavedra y M. Torero (1998). Los activos de los pobres en el Perú. Documento de trabajo 26. Lima, Perú: Grade.

FAO (2012). Marco estratégico de mediano plazo de cooperación de la FAO en: Agricultura familiar en América Latina y el Caribe: 2012-2015. V.14.0. Disponible en: http://www.rlc.fao.org/ fileadmin/content/publicaciones/mecfaf.pdf. Fecha de consulta: 1 de Marzo del 2013. 45p.

Figueroa, Adolfo (1989[1981]). La economía campesina de la sierra del Perú. 4a ed. Lima: PUCP. Fondo Editorial.

Figueroa, Adolfo (1997). Viabilidad económica de la pequeña agricultura. En Pequeña agricultura en el Perú: Presente y futuro (pp. 79-113). Proyecto de Apoyo a ONGs-PACT-Perú.

Gebregziabher G. y R. Namara (2008). Investment in irrigation as a poverty reduction strategy: Analysis of small-scale irrigation impact on poverty in Tigray, Ethiopia. En Awulachew, SeleshiBekele; Loulseged, Makonnen; Yilma, Aster Denekew (comps.). Impact of irrigation on poverty and environment in Ethiopia: draft proceedings of the symposium and exhibition (pp. 156-178). Addis Ababa, Ethiopia, 27-29 Noviembre 2007. Colombo, Sri Lanka: International Water Management Institute (IWMI).

Gonzales de Olarte, E. y B. Kervyn (1987). La lenta modernización: cambio técnico en comunidades campesinas. En La lenta modernización de la economía campesina (pp. 75-175). Lima, Perú: Instituto de Estudios Peruanos.

Hayami, Y. y V. W. Ruttan (1970). Factor Prices and Technical Change in Agricultural Development: The United States and Japan, 1880-1960. Journal of Political Economy, 78(5). 1115-1141. https://doi.org/10.1086/259694 
Hayami, Y. y V. W. Ruttan (1971). Agricultural Development: An International Perspective. Maryland, Estados Unidos: The Johns Hopkins Press.

Hayami, Y. y V. Ruttan (1989[1971]). Desarrollo agrícola: una perspectiva internacional. México, D.F.: Fondo de Cultura Económica.

Hopkins, A. (2016). Efectos del gasto público en riego en los hogares de la sierra del Perú. Tesis de Maestría en Economía, Pontificia Universidad Católica del Perú.

Hopkins, R. y R. Barrantes (1987). El desafío de la diversidad: hacia una tipología de la agricultura campesina. En La lenta modernización de la economía campesina (pp. 15-74). Lima, Perú: Instituto de Estudios Peruanos.

Hopkins, A. y M. Figallo (2014). La sierra tiene sed: efecto de las inversiones públicas en riego sobre los hogares de agricultura familiar de la sierra. SEPIA XV, 567-597.

Hussain I. y M. Hanjra (2004). Irrigation and poverty alleviation: review of the empirical evidence. Irrigation and Drainage, 53, 1-15. Colombo, Sri Lanka: International Water Management Institute (IWMI). https://doi.org/10.1002/ird.114

INEI (2013). Ficha Técnica de la Encuesta Nacional de Hogares. Lima, Perú: INEI.

Inurritegui, M. (2006). El rol del capital social en la pequeña agricultura comercial. En C. Trivelli, J. Escobal y B. Revesz (eds.), Pequeña agricultura comercial (pp. 185-269). IEP-CIES-Grade-Cipca.

Khandker, S., G. Koolwal y H. Samad (2010). Handbook on Impact Evaluation. Quantitative Methods and Practices. Washington, DC.: Banco Mundial.

Lipton, M., J. Litchfield y J. M. Faurès (2003). The effects of irrigation on poverty: A framework for analysis. Journal of WaterPolicy, 5, 413-427.

Minag (2012). Plan estratégico sectorial multianual 2012-2016. Lima-Perú: Oficina General de Planificación Agraria.

Oficina de Evaluación de Recursos Naturales-ONERN (1982). Clasificación de las tierras del Perú. Lima, Perú.

Perú (2012 y 2013). Discurso Presidencial de 28 de julio.

Ray, S., H. Rao y K. Subbarao (1988). Unstable Agriculture and Droughts: Implications for Policy. Studies in Economic Development and Planning, 47. Editor T.N. Madan. Nueva Delhi: Institute of Economic Growth.

Rosenstein-Rodan, P. N. (1957). Notes on the theory of the "big push". Cambridge, Massachusetts: Center for International Studies, Massachusetts Institute of Technology.

Schoengold, K. y D. Zilberman (2007). The economics of water, irrigation and development. Handbook of Agricultural Economics, volumen 3, capítulo 58, 2933-2977. https://doi. org/10.1016/S1574-0072(06)03058-1

SNIP (2011). Análisis Funcional: Inversión pública en agricultura - Riego. Boletín Política de Inversiones. Lima, diciembre de 2011.

Solow, R. (1957). Technical change and the aggregate Production function. The Review of Economics and Statistics, 39(3), 312-320. https://doi.org/10.2307/1926047

Zegarra, E. (2002). La investigación social sobre el manejo del agua de riego en el Perú: una mirada a conceptos y estudios empíricos. En M. Pulgar-Vidal, E. Zegarra, J. Urrutia, J. (eds.), Perú, el problema agrario en debate: Seminario Permanente de Investigación Agraria (pp. 319-348), (9o: Noviembre 2002. Oct. 22-24: Puno, Perú). Lima: Sepia.

Zegarra, E. y V. Minaya (2007). Gasto público, productividad e ingresos agrarios en el Perú. En Grade (ed.), Investigación, politicas y desarrollo en el Perú (pp. 27-66). Lima: Grupo de Análisis para el Desarrollo-Grade. 


\section{Sitios web}

Concytec - Acceso Libre a Información Científica para la Innovación (ALICIA). Fecha de consulta: 23/07/2015. Disponible en: <http://alicia.concytec.gob.pe/vufind/>

INEI - Estadísticas Sociales. Población en situación de pobreza, según ámbitos geográficos. Fecha de consulta: 18/10/2015. Disponible en: <http://www.inei.gob.pe/estadisticas/ indice-tematico/sociales/>

Minagri-DGAAA. Fecha de consulta: 23/07/2015. Disponible en: <http://dgaaa.minag.gob. pel>.

Plan MERISS Inka-Gobiernos Regional de Cusco. Fecha de consulta: 10/07/2013. Disponible en: <http://www.meriss.gob.pe/gestion.html>.

\section{Bases de datos}

Ministerio de Economía y Finanzas

Base de datos del Sistema Integrado de Administración Financiera de gasto a nivel de actividad y proyecto

Banco de Proyectos del Sistema Nacional de Inversión Pública

Instituto Nacional de Estadística e Informática

Censo Nacional de Población y Vivienda 1993

Censo Nacional de Población y Vivienda 2007

Censo Nacional Agropecuario 1994

Censo Nacional Agropecuario 2012

Encuesta Nacional de Hogares 2007, 2008, 2012 y 2013.

Documento recibido el 29 de noviembre de 2017 y aprobado el 11 de diciembre de 2017 